Die

\title{
Vögel Neu-Caledoniens und der Loyalty-Inseln
}

\author{
Dr. Frity Sarasin
}

F. Sarasin \& J. Roux, Nova Caledonia, Zoologie, Band I, Heft I

Wiesbaden

C. W. Kreidels Verlag

1913 


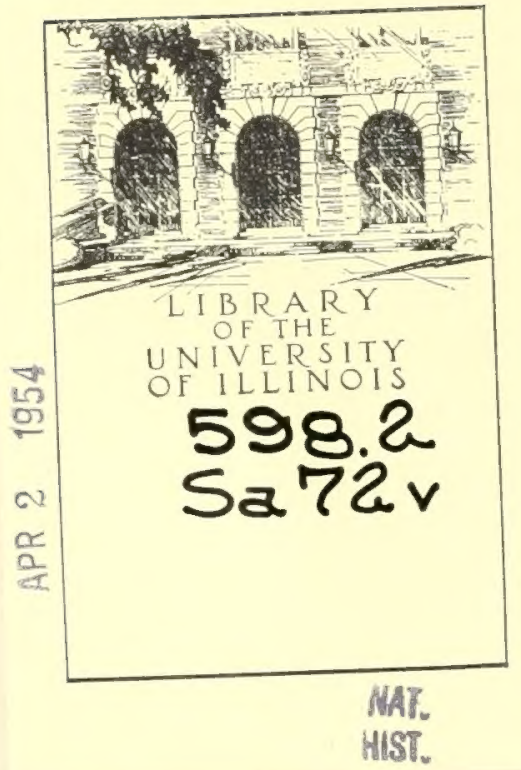


Die

\title{
Vögel Neu-Caledoniens und der Loyalty-Inseln
}

\author{
Dr. Frity Sarasin
}

F. Sarasin \& J. Roux, Nova Caledonia, Zoologie, Band I, Heft I

Mit 3 Tafeln in Lithographie und 6 Abbildungen im Text

Wiesbaden

C. W. Kreidels Verlag 


\section{Digitized by the Internet Archive in 2011 with funding from}

University of Illinois Urbana-Champaign

http://www.archive.org/details/dievgelneucale00sara 



\section{Fritz Sarasin \& Jean RouX}

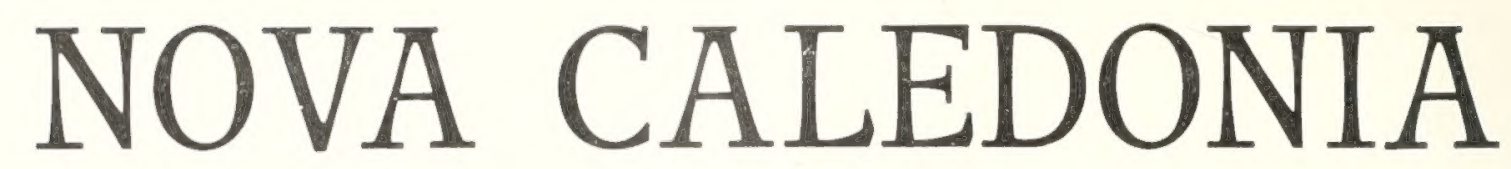

Forschungen

in Neu-Caledonien und auf den Loyalty-Inseln
Recherches scientifiques en Nouvelle Calédonie et aux Iles Loyalty

\section{A. ZOOLOGIE \\ Vol. I · L. I}

1. Dr. Fritz Sarasin, Die Vögel Neu-Caledoniens und der Loyalty-Inseln

Wiesbaden

C. W. Kreidels Verlag 
Die

\title{
Vögel Neu-Caledoniens \\ und der Loyalty-Inseln
}

von

\author{
Dr. Frity Sarasin
}

Nova Caledonia, Zoologie, Band I, Heft I

Mit 3 Tafeln in Lithographie und 6 Abbildungen im Text

Wiesbaden

C. W. Kreidels Verlag

1913 
Alle Rechte vorbehalten

Tous les droits réservés 


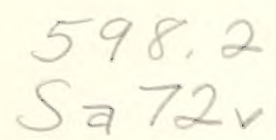

\section{Inhalts-Übersicht.}

Einleitung .......... Seite

Falconidae. ......... 5

Pandionidae ....... 10

Strigidae . . . . . . 10

Loriidae . . . . . . . . 11

Psittacidae . . . . . 13

Cuculidae . . . . . . 14

Alcedinidae . . . . . 16

Podargidae . . . . . . . 17

Macropterygidae . . . . . 17

Hirundinidae . . . . . . . 19

Muscicapidae . . . . . . . 19

Campophagidae . . . . . 26

Artamidae . . . . . . . . 29

Laniidae . . . . . . . . 29

Prionopidae . . . . . . . . . 32

Zosteropidae . . . . . . . 33

Meliphagidae . . . . . . . 36

Timeliidae ........ 40

Turdidae . . . . . . . . 41
Seite

Ploceidae . . . . . . . . 43

Über die Reflexionsperlen der Nestiungen von Erythrura psittacea (Gm.) . . . 44

Sturnidae . . . . . . . . . 48

Corvidae . . . . . . . . . 50

Treronidae . . . . . 50

Columbidae ....... . . . . 52

Peristeridae . . . . . . . . 53

Turnicidae. . . . . . . . . . 54

Rhinochetidae . . . . . . . 55

Rallidae . . . . . . . . . . 60

Charadriidae . . . . . . . . 64

Oedicnemidae . . . . . . . 65

Ardeidae . . . . . . . . 65

Anatidae . . . . . . . 67

Podicipedidae . . . . . . . . . 68

Marine Vögel . . . . . . . . . 68

Importierte Vögel _. . . . . . . . 69

Verzeichnis der Vögel Neu-Caledoniens und der Loyalty-Inseln mit Register . . . 71

\section{Anhang.}

Über einige Vögel der Neuen Hebriden . . . . . . . . . . . . . . . . . . . 74

Literaturverzeichnis . . . . . . . . . . . . . . . . . . . . . . . . . . 


\title{
Die Vïgel Neu-Caledoniens und (ter Loyalty-Inseln
}

\author{
Dr. Iirit\% Sirasin
}

Mit Tafel I-III 


\section{Die Vögel Neu-Caledoniens und der Loyalty-Inseln. \\ Von \\ Fritz Sarasin.}

Die Bearbeitung der von Neu-Caledonien und ron den Loyalty-Inseln mitgebrachten Vogelsammlung hat es notwendig gemacht, die ganze aus diesem Gebiete bis jetzt bekannte Avifauna einer Revision zu unterziehen. Immerhin habe ich mich dabei auf die Landvögel beschränkt und die marinen Arten nicht berücksichtigt, da diese für zoo. geographische Fragen, deren Klarstellung vor allem unsere Sammlungen dienen sollen, unvesentlich sind.

Schon die beiden Forster, welche als Naturforscher die denkwürdige Fahrt mitmachten, auf welcher James Cook im Jahre 1774 Neu-Caledonien entdeckte, brachten von dort eine Anzahl Vögel nach Hause, die teils von Forster selbst, teils von Gmelin beschrieben worden sind. Die methodische Forschung begann aber erst mit der Besitznahme des Landes durch Frankreich (1853), und die Grundlagen unserer Kenntnisse bilden G. R. Grays List of New Caledonian Birds, 22, I859 und namentlich die Arbeit von J. Verreaux und O. Des Murs, Description d'Oiseaux nouveaux de la Nouvelle Calédonie et indication des Espèces déjà comnues de ce pays, 79, I860. Auch E. Maries Liste, 47, I870, mag hier erwähnt sein. In der Folge sind es dann namentlich die beiden Layard, Vater und Sohn, gewesen, welche einen $51 / 2$ jährigen Aufenthalt auf Neu-Caledonien in eifrigster Weise zur Vermehrung der ornithologischen Kenntnisse ausgenutzt und eine grosse Anzahl von Schriften hieruber in der lbis, 1877-1882, zum Teil unter Mitwirkung von H. B. Tristram, veröffentlicht haben. Die schönsten Entdeckungen lieferten ihnen die Loyalty-Inseln, von denen sie Lifou selber besuchten. Die Loyalty-Inseln waren in ornithologischer Hinsicht vor den Layards so gut wie unbekannt gewesen. Für diese sowohl, 37, I880, als für Neu-Caledonien, 41, I882, stellten sie ein Verzeichnis der ihnen bekannten Vogelarten zusammen, begleitet von. zahlreichen biologischen Beobachtungen. Ich erwähne noch die allerdings hauptsächlich auf Literaturstudium beruhende Vogelliste von $L$. W. Wiglesworth in seinen, Aves Polynesiae", 82, i892. Kleinere Beitrige verschiedener Autoren sollen bei der Besprechung der Arten, von denen sie handeln, zur Enwähnung kommen.

Über die caledonische Ornis sagen abschliessend die beiden Lay a r d, 41, p. 494 : "We may therefore, we think, safely conclude that there is very little, if anything, 
new to be discovered". Das scheint nach unseren Erfahrungen für Neu-Caledonien richtig zu sein, obschon ein längerer Aufenthalt in der Gipfelregion der hohen Berge doch noch einiges Neue ergeben könnte. Sicher aber hat dieser Satz auch heute noch keine Giltigkeit für die Loyalty-Inseln. Auf diesen Inselchen ist, wie wir sehen werden, die Neigung, Lokalformen auszubilden, ungemein gross. Es gibt Arten, die auf jeder derselben eine eigene Umprågung zeigen, so dass sich hier auch nach unserer Ausbeute noch vieles erwarten lässt, namentlich auf der nördlichsten Insel, Ouvéa, auf der wir ungünstiger Windverhältnisse wegen nur 6 Tage bleiben konnten. Auf Maré haben wir einen Monat zugebracht, auf Lifou drei Wochen; aber es konnte anderer, mir näherliegender Arbeiten halber nur ein kleiner Bruchteil dieser Zeit auf ornithologische Studien verwandt werden, wonach auch hier noch vieles zu tun übrig bleibt.

Es ist eine höchst sonderbare Erscheinung, dass eine ganze Reihe von Arten auf den Loyalty-Inseln melan otische Tendenzen zeigen. Diese drücken sich vielfach in einer Reduktion der weissen Schwanzflecke, gegenüber der caledonischen Form aus. Dieses gilt für Pscudogerygone flacilateralis lifucnsis nov., gegenüber der caledonischen farilatcralis typica (Gray), gilt für Myingra calcdonica riridinitens Gray von Lifou, marensis nov. von Maré und uveacnsis nov. von Ouvéa, gegenüber M. caledonica typica Bp. von Neu-Caledonien, gilt für Diaphoropterus nacvizs simillimus nov. von Lifou, und Maré, gegenüber nacuius typicus (Forst.). Andere Arten zeigen in toto ein dunkleres Gefieder als die verwandten caledonischen. So ist Grancalus lifucnsis Tristr. schwärzer als Gr. colcdonicus (Gm.), Mrycomcla lifucnsis Lay. als 1 . calcdonica Forbes. Zostcrops lateralis grisconota Gray von Neu-Caledonien erscheint auf Maré und Ouvéa in einer dunkleren Form, nigrescens nov., welche zum schwarzköpfigen $Z$. latcralis mclanops Gray von Lifou überleitet. Eine irgendwie plausible Erklärung für das Auftreten dieser melanotischen Tendenzen auf den Loyalty-Inseln zu finden, ist mir bis jetzt nicht gelungen.

Weiter ist bemerkenswert, dass das kleine Lifou eine viel stattlichere Pachycephala-Art, P. littayci Lay., als irgend eine caledonische besitzt, desgleichen einen viel grösseren Zosterops, Z. inornata Lay., einen wahren Riesen der Familie. Aber eine allgemein giltige Regel ist das keineswegs, denn Lifou beherbergt daneben auch die winzigste \%osterops-Form des Gebietes, Z. mimuta Lay. Aplonis atronitus typica Gray der Loyalty's ist zwar grösser als calcdonica Bp., aber daneben kommt auf den Loyalty's noch eine kleine Form vor, 1. atronitens minor nov. Graucalus lifucnsis Tristr. ist kleiner als caledonicus (Gm.), die Ouvéa-Form von Columba hypocnochrou (Gld.), uveacnsis nov., kleiner als die caledonische, Halcyon sancta Vig. und Horsf. auf den Loyalty's kleiner als auf der Hauptinsel. Endlich ist es sonderbar, dass das winzige Lifou drei Zostcrofs-Arten beherbergt, während Neu-Caledonien deren nur zwei hat.

Die Vogelwelt der Insel Neu-Caledonien ist insofern eine ausserordentlich homogene, als sich kein Gegensatz zwischen dem Norden und dem Süden nachweisen lässt, ¿rotz der erheblichen Länge der Insel, die sich durch fast drei Breitegrade $\left(20-23^{0} \mathrm{~S}\right.$. 
erstreckt und trotz den verschiedenen geologischen Verhältnissen im Norden und Süden. Es gibt sehr wenige Arten, die nicht jetzt schon über die ganze Insel hin nachgewiesen wären, und bei denen, die dies nicht sind, wie z. B. dem Kagu (Rhinochotus) und der grossen Ralle (Tricholimmas) ist es nicht ausgeschlossen, dass sekundäre Eingriffe des Menschen daran beteiligt sind. Es ist ferner auffallend, dass Neu-Caledonien, welches auf ungeheure Strecken mit Grassavannen bedeckt ist, namentlich längs der Westküste, aber auch in grossen Teilen des Inneren, nur eine einzige, Grassamen fressende Vogelart, Erythrura psittacer (Gm.), besitzt und nur eine auf Grasland als Wohnort angewiesene Tumix-Art, Tumix iaria notaccaldomiac Ogilv. Grant. Es scheint mir das darauf hinzudeuten, dass die Grassavanne Caledoniens liein hohes geologisches Alter beanspruchen kann, sondern eine sekundäre, durch den Menschen hervorgerufene Erscheinung bedeutet. Auch kann man tatsächlich beobachten, wie Jahr für Jahr infolge von Bränden das Grasland auf Kosten des Waldes an Ausdehnung gewinnt. In der trockenen Jahreszeit nehmen grosse Teile Caledoniens einen fast wüstenartigen Charakter an; die Grasstrecken und die mit niederem Gestrüpp und Farnen bestandenen offenen Berghänge unterhalb der Urwaldzone trocknen aufs äusserste aus, ebenso die lichten, Hunderte von Quadratkilometern bedeckenden Niauli (Melaleuca) Wälder mit ihrem Unterwuchs von Buschwerk, Farn und Gras. Fast täglich werden dann solche trockene Strecken in Brand gesteckt, meist von den Eingeborenen aus reiner Freude am Brennen, seltener zu Anlage ihrer Ptlanzungen, oder auch von Europäern, um das Weideland ihrer Viehherden mit Asche zu düngen und dessen Ausdehnung zu vergrössern. Durch diese Brände wird sehr oft der Urwaldrand angesengt und zum Absterben gebracht, worauf dann das Gras an seine Stelle zu rücken vermag. Es ist sicher, dass die Häufigkeit dieser Brände gegenüber von früher, als die Eingeborenen noch keine Streichhölzer kannten, sondern auf Reiben von Hölzern zur Feuererzeugung angewiesen waren, bedeutend zugenommen hat, und es ist ferner klar, dass, abgesehen von der Ausbreitung des Graslandes auf Kosten des Waldes, hierdurch die Vogelwelt auch ganz direkt geschädigt wird, indem eine Unzahl von Nestern in den Flammen zugrunde geht. Ein älterer Kolonist glaubte, eine Abnahme der Zosterops-Arten konstatieren zu können, welche früher in viel grösseren Schwärmen vorgekommen seien und führte dies auf die vielen Buschbrände zurück. Ausser ZostcropsNestern werden jedenfalls auch in Menge solche der Glwophila- und Khifidum-Arten und anderer im Buschwerk und im Niauliwald brütender Spezies zerstört.

Das Vogelleben in Neu-Caledonien ist überhaupt kein reiches. Die Wälder der Berge fallen durch ihre Stille auf. Höchst charakteristisch ist hier der unheimliche, wie ein dumpfes Feuerhorn tönende Ruf der grossen Goliathtaube, I\%morhm goliath Gray, in den südlichen Gebieten vor Sonnenaufgang auch das an Bellen junger Hunde erinnernde Geschrei des Kagu, Rmmochetus jubatus Verr. u. Des Murs. An Hundegebell gemahnt auch der Ruf des Raben, Jhysocorax moneduloides (L_ess.), eines Bewohners des Hochwaldes sowohl, als der Niaulizone. Gleichfalls in beiden Gebieten 
häufig ist Cimanalus caledonicus (Gm.); sein Ruf ist ein hässliches Krächzen. Von den vier caledonischen Papageiarten macht sich im Landschaftsbild eigentlich nur Trichoglossus hacmatodus diplanchit Verr. u. Des Murs bemerklich; überaus häufig und in grossen Flïgen auftretend, belebt er sowohl die Kronen der Urwaldbäume, als auch zur Zeit der Blüte den lichten Niauliwald. Von kleinen Formen machen sich im Walde namentlich zwei Würger, die glänzend gelbbäuchige Pachycephala morariensis Verr. u. Des Murs und Eopsaltria Auizcntris Verr. u. Des Murs, sowie die beiden Rhifidura-Arten, acrrauxi Marie und bulgeri Lay, diese beiden auch Bewohner offener Strecken, und die winzige Pscudoserygone Aarilateralis (Gray) durch ihre Häufigkeit bemerklich. Alle diese lassen sich ganz aus der Nähe beobachten. Philcmon lessomi (Gray) fült mit seinem abwechslungsreichen Geschrei Hochwald und Busch.

Der Niauliwald zieht zur Zeit seiner Blüte eine Reihe von Vögeln an. Die beiden Glycuphilu, incana (Lath.) und undulata (Sparrm.), die Zostcrops-Arten, sowie die glänzend rot gefärbte M/y:omcla calcdonica Forbes sind dann an den gelblichen Blütenbürsten ständige Gäste. Auch Pachycephala xantherythraca (Forst.) und Artamus melanoloucus (Forst.), dieser in kleinen Gesellschaften dicht nebeneinander auf dürren Ästen sitzend, sind hier überaus gemein. Gegen die Küste zu, wo Sumpfland auftritt und in der Mangrovenzone wird man nie den Königsfischer, Halcyon sancta Vig. u. Horsf., vermissen.

Auffallend kümmerlich im Verhältnis zu Ländern ähnlicher Klimate sind die Flüsse von Vögeln belebt. Hin und wider ein einsamer Reiher, meist Demigretta sacra (Gm.) und einige Enten, vorwiegend Anas sufercitiosa Gm., sind fast das einzige, was man zu Gesicht bekommt. Auch die Meeresküsten sind nur spärlich von Möven und anderem Seegeflügel bevölkert.

Mit Weglassung der rein marinen Formen sind bis jetzt in Neu-Caledonien 68 Gattungen nachgewiesen worden, auf den Loyalty-Inseln 35, von denen alle auch Caledonien angehören. Die Loyalty's besitzen somit keine einzige, nicht auch caledonische Gattung. Endemisch sind auf Neu-Caledonien 6 Genera: Megaturulus, Physocorax, Phacnorhina, Drepanoptila, Rhinochetus und Tricholimnas. Hierzu die ausschliesslich mit Ouvéa, der nördlichsten Loyalty-Insel, gemeinsame Gattung $\Lambda^{\top} y^{\prime}$ mhicus.

Auf ein enges Gebiet beschränkt sind ferner Clytorhynchus (Neu-Caledonien und Neu-Hebriden) und Leptomỹr (Neu-Caledonien, Fidji, Samoa). Von den übrigen 59 nicht endemischen Gattungen sind 34 auch auf den Loyalty-Inseln nachgewiesen: Astur, Strix, Trichoglossus, Cacomantis, Chalcococcyx, Halcyon, Collocalia, Rhipidura, Pscudo. scrysone, Mjiagra, Grancalus, Diaphoropterus, Artamus, Pachycephala, Zosterops, Myso. mela, Glycyphila, Philemon, Memla, Erythrura, Aplonis, Ptilopus, Globicera, Columba, Chatiophaps, Hypotacnidia, Poliolimnas, Porthyrio, Charadrius, Limosa, Hetcractitis (die letzteren drei Wanderer), Demiegretta, Notophoyx und Lnas.

Bleiben 25 nicht endemische Genera übrig, die nach unserer jetzigen Kenntnis den Loyalty.Inseln fehlen: Circus, Faliastur, Falco, Pandion, Glossopsittacus, Cyanorhamphus, Urodynamis, Aegotheles, Firnudo (in Caled. noch zweifelhaft), Edoliisoma, 
Eopsaltria, Tumix, Porana, Armaria, Numenns, Hetcropygia (diese drei sicher Wandervögel), Orthorhamphus, Nycticorax, Butorides, Botaums, Dendrocysna, Nettion, Spatula, Aythya und Podicipes.

Die 68 oder mit Weglassung der noch unsicheren Gattung Hirundo, 67 Genera sind auf Neu-Caledonien und den Loyalty-Inseln bloss durch 87 Arten, mit den Unterarten durch 97 Formen vertreten. Nur 7 Gattungen sind durch 3 oder mehr Spezies und Subspezies repräsentiert: Collocalia, Myiagra, Pseudogorygone, Pachycchhala, Zostcrops, Mimla und Aflonis.

Von den 97 Arten und Unterarten sind 32 auf Neu-Caledonien beschränkt, I9 auf die Loyalty-Inseln; 7 kommen ausschliesslich Neu-Caledonien und den Loyalty's zu; 4 weitere dehnen ihr Verbreitungsgebiet bis zu den Neuen-Hebriden aus; 2 sind wahrscheinlich bloss den Loyalty's und den Hebriden eigen.

Endlich kommen 18 Arten weiterer Verbreitung Neu-Caledonien zu, ohne bisher auf den Loyalty's nachgewiesen zu sein; I5 Arten weiterer Verbreitung endlich sind sowohl von Caledonien, als von den Loyalty's bekannt. Die 33 Arten der beiden letzten Rubriken sind fast ausschliesslich Raubvögel, Enten, Reiher und Charadriiden.

Bei jeder Gattung und bei jeder Art ist die geographische Verbreitung angegeben worden; indessen sollen die daraus sich ergebenden Schlüsse erst später, wenn auch andere Tiergruppen bearbeitet sein werden, im Zusammenhang diskutiert werden. Die Synonymie habe ich nur in strittigen Fällen in extenso wiedergegeben; bei allgemein anerkannten Arten schien es mir überflüssig zu sein, die Liste der Syno* nymen abzudrucken; man konsultiere hierfür die Kataloge des Britischen Museums und die sorgfältige Zusammenstellung von Wiglesworth, 82, in seinen Aves Polynesiae. Die Messungen sind stets in Millimetern angegeben; die Zollmaasse der englischen Literatur sind nach den von der Deutschen Zoologischen Gesellschaft herausgegebenen Umrechnungstabellen in Millimeter umgesetzt worden.

Wir gehen nun zur Besprechung der einzelnen Arten über. Die endemischen Gattungen und Arten sind mit einem * bezeichnet. Als endemisch sind auch solche gerechnet, welche ausschliesslich Neu-Caledonien und den Loyalty-Inseln zukommen.

\section{Falconidae. \\ Gen. Circus Lacép.}

Verbreitung: Fast kosmopolitisch.

I. Circus gouidi wolfi (Gurney).

Circus roolfi, Gurney, 24, p. 823, Taf. 44, 1865.

Verbreitung von Circus gouldi ty. Bp.: Süd- und Ost-1ustralien, Neu-Sec. land, Fidji, Sharpe, 66, p. 73, Verbreitung von Corns gumli arolfi Gurn.: NeuCaledonien, Neu-Hebriden, Lord Howe's Island, Wiglesworth, 82, p. 3. 
Ich kann mich nicht entschliessen, der Gurney'schen Art mehr als SubspeziesWert zuzuerkennen.

Verbreitung in Neu-Caledonien: Ganze, Insel, schon von Verrea ux und Des Murs I860 aufgeführt, 79, p. $3^{87}$ (C. assimilis); bewohnt sumpfige Wiesen, wo er sich gerne auf dem Boden aufhält, nach den Layards, 4I, p. 500, auch offene Bergspitzen, aber nicht den Wald.

ơ juv., Oubatche, I7. März I9II.

Das Jugendkleid steht dem von $C$. gouldi nahe, wie es Sharpe, 66, p. 72, beschreibt, aber die Schenkel sind hellrostrot mit dunkelbraunen Schaftstreifen, nicht tief kastanienbraun, der Schwanz ungebändert. Nach Sharpe zeigen die Mittelfedern Reste dunkler Bänder. Nach Finsch und Hartlaub, I7, p. 9, hat ein junger Vogel von Australien auf der Innenfahne der äusseren Schwanzfedern vier Querbinden, ein solcher von Fidji quer über die Schwanzfedern fünf Binden.

Da noch nie ein Jugendkleid des Vogels von Neu-Caledonien bekannt geworden ist, möge die Beschreibung folgen:

Oberseite schokoladebraun, jederseits an der Schnabelwurzel ein Fleck gelblichweisser Federn, deren Enden dunkelbraun sind; Federn des Hinterkopfes und Nackens weiss mit braunem Endfleck, eingerahmt von Hellrostrot gegen die weisse Basis zu; obere Schwanzdecken an der Basis weiss, dann rötlichweiss, dann braun mit roströtlichem Saum; Schwanzfedern braun mit helleren Enden, die äusseren auf der Innenfahne mit rostroten Flecken; Primärschwingen schwarzbraun mit hellerem Endsaum, Sekundärschwingen heller braun mit weisslichem Endsaum, Flügeldecken noch heller braun.

Unterseite: Kinn, Kehle und Brust braun, die Federn mit weisser Basis, Brustfedern rostbräunlich gesäumt, Bauch und untere Schwanzdecken tief rostbraun, Beinfedern hellrostrot mit hellen Enden und dunkeln Schaftlinien; Schwanzfedern silbergrau, gegen die Spitze hellbraun, mit noch hellerem Endsaum, auf den Innenfahnen mit rötlichen Zeichnungen; Flügel braun, die Innenfahnen etwa auf $2 / 3$ der Federlänge hellrötlich mit dunklen Flecken; untere Flügeldecken braun und rostrot.

Iris dunkelbraun, Wachshaut und Beine hellgelb.

Maasse: Long. tot. ca. 555, ala 4ro, cauda 250, tarsus 94, culmen 32,5. Die Layards, 4I, p. 50I, geben für zwei caledonische Vögel: ô Long. tot. 559, ala 400, cauda 248, tarsus 95; q Long. tot. 584, ala 420, cauda 267, tarsus 102.

Die Maasse des ô stimmen sehr gut mit unserem jungen $\hat{f}$ Exemplar von Oubatche.

\section{Gen. Astur Lacép.}

Verbreitung: Fast kosmopolitisch, in Ozeanien ostwärts bis zu den Fidji-Inseln.

$$
\begin{aligned}
& \text { 2. Astur haplochrous (Sclater). } \\
& \text { Sclater, 63, p. 275, Taf. 8, т859. }
\end{aligned}
$$

Verbreitung: Neu-Caledonien. Der Vogel bewohnt die ganze Insel und zwar sowohl den Bergwald, als offene Flächen. Die Layards, 4I, p. 498, nennen ihn 
besonders scheu, was ich nicht bestätigen kann; er lässt sich im Gegenteil oft ganz aus der Nähe beobachten.

o ad., Bergwald des Ignambi oberhalb Oubatche, c. $800 \mathrm{~m}$, Iris goldrot, Füsse und Wachshaut hell goldgelb, Schnabel schwarz, gegen die Wurzel zu bläulich, Oberbrust reinweiss, I5. April igi I.

o ad., ebenda bei ca. Iooo m, 6. Okt. 19II. Oberbrust noch mit schwarzen Bändern, wie bei dem von Sclater abgebildeten Exemplar.

t und $q$ juv., Yaté, 2I. März I9I2, in dem so sehr abweichenden Jugendkleid.

Ich habe den Vogel auch bei Coné an der Westküste beobachtet (Aug. IgII).

Maasse, o und $q$ ad.: Long. tot. ca. 355 und 37o, ala 203 und 227, cauda 172 und 185 , culmen $2 \mathrm{I}$ und 23,5 .

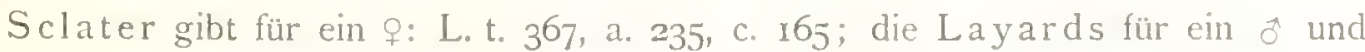
ein : L. t. 432 und 330, ala 229 und 242, cauda 165 und I9r. Die Gesamtlänge des q Vogels 330 (I $\left.3^{\prime \prime}\right)$ ist jedenfalls ein Versehen, da die $q$ grösser sind als die $\hat{\sigma}$ und nicht umgekehrt.

\section{Astur approximans Vigors und Horsfield.}

Verbreitung: Ost-Australien, Tasmanien, Norfolk-Ins., Neu-Caledonien, Lifou, Neu.Hebriden (?).

Verbreitung in unserem Gebiete: Die Layards, 4I, p. 499, nennen ihn mit Recht den gemeinsten Raubvogel der Insel; sie erhielten, wie auch ich, weit mehr Individuen im Jugendkleid, als im fertigen Gefieder. Für Caledonien wurde die Art schon von Verreaux und Des Murs, 79, p. 387, aufgeführt, für die Loyalty-Inseln (Lifou) zuerst von den Layards, 37, p. 222. Exemplare von Lifou sollen etwas abweichend gefärbt sein. Als Mageninhalt fand ich bei einem jungen Exemplar Heuschrecken.

q, q ad., Coné, 6. und 8. Aug. IgrI.

$\hat{\jmath}, \hat{o}$ juv., Hienghiène, Anfang Juni IgII.

q, $q, q$ juv., Oubatche, von der Küste bis 800 m., I8. April, 20. Mai, 6. Juli IgII. juv., Canala. I. Nov. Igr I.

Die adulten, gebänderten Exemplare stimmen mit einem verglichenen australischen Exemplar von N.-O.-Queensland und mit der Beschreibung bei Sharpe, 66, p. I26, überein; höchstens ist der caledonische Vogel auf der Unterseite etwas dunkler; die rostbraunen Bänder sind dunkler und die schwarzen Begleitbänder deutlicher, auch der Oberkopf dunkler aschbraun.

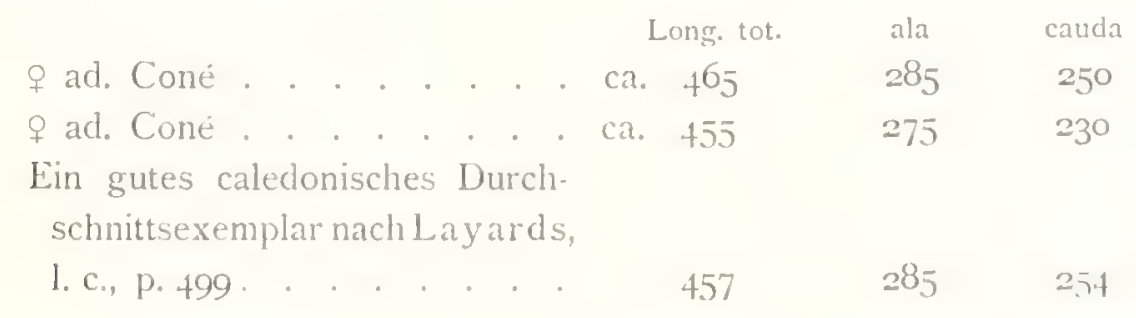


$\widehat{o}$ ad. Queensland . . . . .

AustralischeAdulte nach Sharpe,

$\begin{array}{ccc}\text { Long. tot. } & \text { ala } & \text { cauda } \\ 44^{6} & 285 & 2 \mathrm{I} 5 \\ & & \\ 38 \mathrm{I} & 25^{8} & 2 \mathrm{I} 4 \\ 508 & 3^{\text {IO }} & 254\end{array}$

Das australische Weibchen erscheint somit wesentlich grösser als die caledonischen. Auch Tristram, 77, p. 18r, sagt von drei Weibchen von Caledonien: Wenn das Ge. schlecht richtig bezeichnet ist, sind diese Stücke merklich kleiner als solche von Tas. manien in 'Tarsus, Schwanz- und Flügellänge. Layards, 37, p. 222, bemerken dagegen, sie besässen ein „solitary old female", reichlich so gross als die australischen.

Das Jugendkleid der caledonischen Vögel zeigt gewisse konstante Abweichungen von dem des australischen Exemplares, wie es Sharpe, I. c., beschreibt, und wie es auch von mir verglichene australische Stücke aufweisen, insofern, als die Unterseite des Körpers nicht weiss ist, sondern isabellfarben, die Oberbrust nicht gestreift ist mit breiten, ovalen Tropfen "of pale rufous“, sondern von schwarzbraunen, Brust, Flanken, Schenkel und Unterschwanzdecken breit mit dunkelbraun gebändert sind und nicht mit „pale rufous", endlich die unteren Flügeldecken rötlich isabellfarben sind mit schwarzbraunen Bändern. Iris goldgelb, ebenso ein nackter Ring um das Auge, Wachshaut hellgelb, Schnabel hornblau mit schwärzlicher Spitze, Beine goldgelb. Wie die Maasse ergeben, haben die australischen Jugendexemplare auch längere Flügel und Schwänze als die caledonischen.

\begin{tabular}{|c|c|c|c|c|c|}
\hline \multirow{2}{*}{\multicolumn{2}{|c|}{$\hat{o}$ juv. Hienghiène }} & & Long, tot. & \multirow{2}{*}{$\begin{array}{l}\text { ala } \\
235\end{array}$} & \multirow{2}{*}{$\begin{array}{c}\text { cauda } \\
200\end{array}$} \\
\hline & & & ca. $43^{2}$ & & \\
\hline 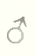 & $"$ & & ca. $4 \mathrm{I}_{5}$ & 236 & 200 \\
\hline & " Oubatche. & & ca. 407 & 230 & 185 \\
\hline & " & & ca. 430 & 235 & 195 \\
\hline & $"$ & & ca. 4 Io & 230 & 185 \\
\hline & "Canala & & ca. $4 \mathrm{I} 2$ & 230 & 180 \\
\hline & & Mittel & ca. 418 & 233 & I9I \\
\hline \multicolumn{2}{|r|}{ juv. Australien } & & ca. 405 & 245 & 200 \\
\hline & $"$ & . . . & ca. 355 & 255 & 195 \\
\hline & & Mittel & ca. 380 & 250 & 197,5 \\
\hline
\end{tabular}

Es scheint sich somit in den Jugendformen die Bildung einer neuen Art auf NeuCaledonien anzubahnen, welche vielleicht jetzt schon als Astur approximans insularis noi'. zu bezeichnen wäre.

Irrtümlich für Neu-Caledonien aufgeführt ist Astur torquatus (Temm.) von Verreaux und Des Murs, 79, p. 385. Ich habe das betreffende Exemplar, ein adultes $\$$, in Paris vergleichen können; es gehört zu Astur approximans und zeigt, wie das öfters vorkommt, 
ein ununterbrochenes, rostrotes Nackenband. Dasselbe gilt für ein in derselben "Collection de l'exposition coloniale" im Muséum d'Histoire Naturelle befindliches, als Astur cmentus Gould bezeichnetes $q$ Exemplar von Neu-Caledonien.

\section{Gen. Haliastur Selby.}

Verbreitung: Vorderindien, Ceylon, Hinterindien, Indoaustralischer Archipel, Australien, Neu-Caledonien.

\section{Haliastur sphenurus (Vieill.).}

Verbreitung: Australien, Neu-Guinea. Yule-Ins., Neu-Caledonien, IViglesworth, 82, p. I.

Verbreitung in Neu-Caledonien: Alle in der Literatur aufgeführten Fundstellen (Verreaux und Des Murs, 79, p. 385, Layards, 4I, p. 498) und auch die unserer Exemplare, liegen an oder in der Nähe der Westküste, wo der Vogel nicht selten ist. Im August IgI I beobachteten wir ihn häufig auf den Grasflächen bei Coné.

o ad. u. ô juv., Coné, 3. und 6. August Igr I.

Wachshaut grau-bläulich, Schnabel dunkelhornfarben, Beine weisslich mit leicht bläulichem Ton, Iris braun.

Ma asse (Mittel von 5 Exemplaren, der beiden von Coné, eines guten Durchschnittsexemplares nach Layards, 4I, p. 498 und zweier Exemplare im Museum von Paris): Long. tot. : 525 (490-550), ala 388 (37o-tro), cauda 278 (270-285).

5 australische Exemplare ergeben als Mittelzahlen: Long. tot.: $560 \quad(528-585)$, ala $416(405-425)$, cauda $279(260-290)$.

Die caledonische Form ist also etwas kleiner und kurzflügeliger als die australische. Das junge Exemplar von Coné hat an den Rückenfedern, an den Schwanzund Flügeldecken bedeutend grössere und auffallendere helle, gelblichweisse Endspitzen, als ich sie bei australischen beobachten konnte; vor diesen erscheint häufig ein rostrotes Bändchen; an der Haube, namentlich am Nacken, zeigen die braunen Federn eine helle, tropfenfömig sich verbreiternde Spitze. Indessen ist die Färbung der Art sehr variabel.

\section{Gen. Falco L.}

Verbreitung: Fast kosmopolitisch.

\section{Falco melanogenys Gould.}

Verbreitung: Australien, Tasmanien, Neu-Caledonien, Neu-Hebriden, Fidji, Indoaustralischer Archipel und Philippinen, Meyer und Wiglesworth, 48, p. 86 (Filio peregrims milumogeny's Gld.). In Sharpe's Handist, 75, I, p. 274, ist als Verbreitung nur Australien angegeben. 
Verbreitung in Neu.Caledonien: Der Vogel wurde zuerst von den Layards, 35, p. 25I, nachgewiesen; sie geben Fundstellen an der West- und an der Ostküste an, 4 I, p. 496.

Wir haben die Art nicht erhalten.

\section{Pandionidae.}

\section{Gen. Pandion Savign.}

Verbreitung: Fast kosmopolitisch.

\section{Pandion haliae̊tus leucocephalus (Gld.)}

Verbreitung: Von Celebes über Neu-Guinea bis Australien, Palaus, Neu-Caledonien, Wiglesworth, 82, p. I.

Verbreitung in Neu-Caledonien: Von Gray, 22, p. 160, von der lle des Pins namhaft gemacht. Nach Layards, 4I, p. 497, brütet er auf den kleinen Inseln beider Küsten oder an der felsigen Küste selbst. Ich habe ihn an der Ostküste beobachtet.

\section{Strigidae.}

\section{Gen. Strix L.}

Verbreitung: kosmopolitisch.

\section{Strix flammea lulu Peale.}

Verbreitung: Die Spezies kosmopolitisch, die Subspezies: Gesellschaftsinseln, Fidji, Samoa, Tonga, Niuafu, Neu-Hebriden, Lifou, Neu-Caledonien, Wiglesworth, 82 , p. 4 .

Verbreitung im neucaledonischen Gebiet: Schon lange von Caledonien bekannt, siehe Verreaux u. Des Murs, 79, p. 387 (delicatula Gould) und auf der Insel allgemein verbreitet; für Lifou nachgewiesen von den Layards, 37, p. 222, wahrscheinlich auch Maré.

\section{o Oubatche, i6. Mai I9Ir. \\ o Coné, 9. August IgII. \\ o Quépénéé, Lifou, 3. Mai igiz.}

Die Subspezies lum steht der australischen delicatula Gould sehr nahe; sie hat etwas kürzere Flügel als diese; das Mittel unserer 3 Stücke beträgt 257 mm, von 3 australischen 278. Der Federkranz um die beiden Gesichtsschleier ist bei lulu deutlicher markiert, namentlich die untere Hälfte, an welcher die dunkelbraunen Federenden sehr stark hervortreten, wie angebrannt; die obere Hälfte rostrot mit schwarzen Fleckchen. Bei delicatula ist der ganze Kranz heller, fast weiss, oben mit schwarzen Fleckchen, 
unten mit sehr schmalen dunklen Såumen. Die weisse Körperunterseite ist bei unserem Exemplar von Lifou ganz ungefleckt, bei dem von Coné mit sehr spärlichen und sehr kleinen dunklen Fleckchen von der Kehle bis zum Bauch besäet; bei dem von Oubatche sind sie auf dem Bauch zahlreicher und grösser.

Das Vorkommen der folgenden Art auf Caledonien ist mehr als zweifelhaft: Strix norachollandiac Steph.

Die Layards, 35, p. 252, führen Strix castanops Gould (eine Subspezies) für Caledonien auf, sich gründend auf ein Exemplar mit solchem Vermerk in der Kolonial. sammlung von Nouméa. Es ist dies wohl dasselbe Stück, welches Marie, 47, p. 327, in seine Liste aufgenommen hat. Später wird von den Layards, 37, p. 223, wiederum dasselbe Exemplar, als von Lifou stammend, der Fauna der Loyalty's zugerechnet, als Strix novachollandiue. Weder die Layards, noch sonst Jemand, haben die Art jemals in unserem Gebiete angetroffen. Es dürfte daher eine Etikettenverwechslung vorliegen. Diese australische Art ist daher vorderhand aus der caledonischen Fauna zu streichen, wenn auch die Sharpe'sche Handlist, 75, I, p. 3oI und Wiglesworth, 82, p. 4, sie dieser zurechnen. Auch Oustalet, 53, p. 218, zweifelt am Vorkommen dieser Eule, da weder im Britischen Museum, noch in Paris oder Leyden, sich ein caledonisches Exemplar befinde.

\section{Loriidae.}

\section{Gen. Trichoglossus Vig. u. Horsf.}

Verbreitung: Australien, Tasmanien, Neu-Guinea, Papuasische Inseln, Molukken, Celebes, Kleine Sunda-Inseln, Salomonen, Neu-Hebriden, Lifou, Neu-Caledonien. (Sa l. vadori, 58, Sharpe, 75).

8. ${ }^{*}$ Trichoglossus haematodus deplanchei Verreaux u. Des Murs.

Trichoglossus deflanchei Verr. u. Des Murs, 79, p. 388.

Verbreitung der Spezies: Rothschild und Hartert, 57, p. 68, vereinigen eine ganze Reihe von Arten, welche sämtlich gewisse gemeinsame Merkmale aufweisen, zu einer Speziesgruppe, der sie den ältesten, Linnéschen Namen hacmatodus beilegen. Als Subspezies dieser Art führen sie Formen auf von Lombok, Sumbawa, Sumba, Timor, Djampea, Ambon, Ceram, Buru, Südost-Inseln, Neu-Guinea und den umgebenden Papuasischen Inseln, den Salomonen, Neu-Hebriden und Neu-Caledonien. Auch drei australische Arten mögen nach Rothschild und Hartert in diese Gruppe zu rechnen sein.

Eine dieser hacmatodus-Formen ist Trichoglossus massend Bp. Mit dieser wurde seit Finsch, I5, II, p. 834, allgemein die von Verreaux und Des Murs als Trichoglossus deplanchei beschriebene caledonische Art vereinigt. Als Verbreitungsgebiet von Trichoglossus massend Bp. oder, wie ihn Rothschild und Hartert, 1. c., p. 7o, be. zeichnen, Trichoglossus hacmalodus masscna Bp., gelten das südöstliche Neu-Guinea mit 
den Louisiaden, die Salomonsinseln, die Neu-Hebriden und Neu-Caledonien. Ich glaube aber, dass die caledonische Form aus unten folgenden Gründen doch als Lokalform zu unterscheiden sei, und in diesem Falle muss ihr der älteste Name, d. h. deplanchci V. und D. M., als Subspezies-Bezeichnung belassen werden.

Verbreitung der Subspezies im neucaledonischen Gebiete: Es ist der gemeinste Papagei der Insel, wie schon die Layards, 4I, p. 525, angeben und? bewohnt in Schwärmen die Wälder bis zu grossen Höhen, Iooo $m$ und mehr. Im Mai kam er in Oubatche täglich in starken Flügen aus dem Bergwald herunter auf die in Blüte stehenden Niaulibäume und auf Bäume des Seestrandes, des Abends bergwärts zurückkehrend. Der Flug ist sehr rasch, mit rapiden Flügelschlägen, wobei die Vögel laut kreischen. Das Tier hat einen Duft, ähnlich gebranntem Zucker.

Auf Lifou, Loyalty, wurde er von den Layards, 37, p. 230, nachgewiesen; ob es dieselbe Subspezies ist, wird noch zu erforschen sein (vgl. Tristram, 77, p. I85), auf Maré und Ouvéa scheint er zu fehlen.

$$
\begin{aligned}
& \hat{\jmath}, \hat{\jmath}, \hat{\jmath}, \hat{o} \text { Gegend von Oubatche, Ende April und Mai I9I } \\
& \text { 우, 오, 우 } \\
& \text { q Coné, 9. Äugust IgII. }
\end{aligned}
$$

Die caledonische Form ist durchschnittlich grösser als masscna. Unsere 8 Exemplare geben folgende Mittelzahlen: Long. tot. 27I (260-290), ala I38 (135-142), cauda II3 (IO8-I2I), culmen 20 (I9-2I). Die Layards, 4I, p. 526, geben: Long. tot. 279, ala I52, cauda I33; J ou an, 28, p. 226, für ein đ̊ 280, also noch grössere Zahlen. Dagegen ergeben mir 8 Exemplare von Neu-Guinea, Salomonen und Hebriden als Mittelzahlen bloss: Long. tot. 244 (234-260), ala 134 (128-146). cauda 106 (100-123), culmen 20,7 (17,5-23). Salvadori, 58, p. 54, gibt als Längenmaass 254 an. Ferner sind die Farben des caledonischen Vogels lebhafter, namentlich das Grün der Oberseite heller und leuchtender, besonders auffallend an den Oberschwanzdecken, Nackenband schmaler und wie die Halsseiten fast ohne gelben Ton, freudig hellgrün, während bei den anderen der gelbe Ton häufig so überwiegt, dass das Band zuweilen gelb erscheint. Die Exemplare von den Salomonen und Hebriden nähern sich hierin der caledonischen Form; der Schnabel ist im Verhältnis zur Körpergrösse beim Caledonier etwas schwächer.

\section{Gen. Glossopsittacus (?) Bp.}

Verbreitung: Australien, Tasmanien, S. O. Neu-Guinea, Neu-Caledonien, Sharpe, $75, I$, p. 6 .

9. *Glossopsittacus (?) diadematus (Verreaux u. Des Murs). Psitteutcles diadema Verreaux u. Des Murs, 79, p. 390.

Verbreitung: Neu.Caledonien. Das einzige bekannte Exemplar ist das Weibchen, welches den genannten Autoren zu ihrer Beschreibung gedient hat. Ein 
arg zerschossener und schon angefaulter Papagei, der uns von den Bergen bei Oubatche zugetragen wurde, aber nicht mehr zu konservieren war, dürfte dieser Art angehört haben.

Verreaux und Des Murs beschrieben die Art als der Gattung Pitleutiles zugehörig; die Layards, 4i, p. 526, Finsch, I5, II, p. 867 und Andere stellen sie zu Trichoglossus; Reichenow, 55, p. I47, teilte sie dem Subgenus Glossopsittacus der Gattung Trichoglossus zu. Salvadori, 58, p. 69, der sie unter der Gattung Glossopsittncus aufführt. sagt, sie gehöre möglicherweise zu IJfochumospm. Oustalet, 54, welcher das Verreaux'sche Exemplar untersuchte, fuhrt aus, die Art habe mehr Analogie zur papuasischen Gattung Chrmosynd als zu irgend einer anderen. Psittoteles diadcmatus zeige gemischte Charalitere, er füge sich genau in keine Gattung der Trichoglossiden ein, und man müsse ihn vielleicht betrachten als Typus einer neuen Gattung, welche zwischen Glossopsittacus von Australien und Chammosmm ron Neu. Guinea zu stehen käme. Für eine Entscheidung dieser Frage sind weitere Exemplare abzuwarten.

\section{Psittacidae.}

\section{Gen. Cyanorhamphus Bp.}

Verbreitung: Neu-Seeland, Auckland-Ins, Antipoden Ins., Chatham-Ins, Nacquarie-Ins., Kermadec-Ins., Norfolk-Ins., Lord Howe's-Ins., Gesellschafts-Inseln (Tahiti), Neu-Caledonien, Salvadori, 58, p. 577 ff.; die Angabe "Loyalty-Ins." ist unrichtig.

Io. ${ }^{*}$ Cyanorhamphus saisseti Verreaux u. Des Murs.

Verreaux u. Des Murs, 79, p. 387.

Verbreitung: Neu-Caledonien. Nicht erhalten.

Die Layards, 4I, p. 524, kannten ihn als Bewohner der Bergwälder der Westküste, Moindou usw. Finsch, I5, II, p. 273, vereinigt die Art mit C: normcanhndun (Sparrm.), mit der sie sicherlich sehr nahe verwandt ist; R e ichenow, 55. p. +3, lässt sie als Subspezies dieser Art gelten.

\section{*Gen. Nymphicus Wagl.}

(Nach Reichenow, 55, p. 44, bloss Untergatung von Cyanomamphus).

Verbreitung: Neu.Caledonien und Ouvéa (Loyalty).

\section{II. *Nymphicus cornutus (Gm.).}

Verbreitung: Neu-Caledonien; er bewohnt nach den Latyards, 4I, p. 524. alle Waldgegenden der Insel. 
12. "Nymphicus uveaensis E. L. u. E. L. C. Layard.

E. L. u. E. L. C. Layard, 42, p. 408. (Tafel mit schönen Bildern der beiden Nymphicus-Arten.)

Verbreitung: Ouvéa, die nördlichste der drei Loyalty-Inseln. Auf Lifou und Maré fehlt er sicherlich; er wird sogar als Käfigvogel, wie wir gesehen haben, von Ouvéa nach Lifou gebracht.

$\hat{o}, q$ u. juv., lebend gekauft in Fayaoué, Ouvéa.

Der Ouvéa-Papagei geht dem Untergang rasch entgegen. Da er leicht sprechen lernt, ist er in Nouméa sehr begehrt. Jedes Schiff bringt einige Pärchen nach Nouméa. An Ort und Stelle bezahlt man jetzt schon Io-15 Frs. für das Paar, während sie früher für eine Stange Tabak erhältlich waren. Die Eingeborenen fangen die Tiere mit Schlingen, die sie auf Bäumen vor reifen Papajafrüchten anbringen. Wenn das Tier frisst, tritt es leicht in die Schlinge, welche dann von unten angezogen wird.

Wenn die französische Kolonialregierung nicht sofortenergische Schutzmassregeln ergreift, wird die seltene Art in Bälde vernichtet sein. Überhaupt werden auf den Loyalty's, namentlich auf Ouvéa, eine Menge Vögel vernichtet und zwar durch die Jugend, welche mit Schlingen, Steinen und Pfeil. bogen auf alles Erreichbare Jagd macht. Überdies werden zahlreiche Nester leichtsinnig zerstört.

Aus der caledonischen Fauna zu streichende Papageiarten:

Platyccrous calcdonizus (Gm.). Finsch, I5, II, p. 204, vereinigt diese Art mit Platyccrus fartientris (Temm.) von Tasmanien und Australien, so auch Reichenow, 55. p. I22 und Salvadori, 58, p. 545. Die Layards, 35, p. 253, wie früher schon Latham (Finsch, 1. c., p. 206), vermuten darunter das Weibchen, Tristram, 77, p. r8I, das Junge von Jymphicus cormutus. Es ist höchst wahrscheinlich, dass die Zuteilung zu dieser letzteren Art richtig ist, wie es auch O ustalet, 53, p. 218, annimmt.

Eclectus fectoralis (P. L. S. Müller), von Marie, 47, p. 327, aufgeführt (Polyckloros magnus), von Wiglesworth, 82, p. 4, noch mit einem Fragezeichen von Caledonien erwähnt, ist, falls wirklich auf Caledonien erbeutet, ein entwichener Käfigvogel.

\section{Cuculidae.}

\section{Gen. Cacomantis S. Müll.}

Verbreitung: Vorderindien mit Ceylon, ostwärts bis China, Hinterindien, Indo. australischer Archipel und Philippinen bis Neu-Guinea, Australien, Tasmanien, BismarckArchipel, Salomonen, Neu-Hebriden, Fidji, Loyalty-Ins., Neu-Caledonien.

\section{3. ${ }^{*}$ Cacomantis bronzinus (Gray).}

$$
\text { Gray, 22, p. } 164 .
$$

Verbreitung: Neu-Caledonien und Loyalty's; über ganz Caledonien verbreitet nach La y ards, 4I, p.522. Für Lifou von ebendenselben nachgewiesen, siehe Tristram, 
77, p. 185 und La yards, 37, p. 230. Ich habe ihn auch auf Ouvéa gefunden; von Maré ist er noch nicht bekannt. Die Angabe "Neu-Hebriden" bei Wiglesworth, 82, p. II, ist wohl irrtümlich, da dort C. schistaceigularis Sharpe zu Hause ist.

$$
\begin{aligned}
& \text { đ, ô Quépénéé, Lifou, I8. und 25. April r9iz } \\
& \text { o Fayaoué, Ouvéa, 15. Mai 1912. }
\end{aligned}
$$

Er ist nahe verwandt mit C. simus (Peale) von Fidji und steht auch dem australischen flabelliformis (Lath.) nicht fern. Farbige Abbildung bei Brench le y, 7, Taf. XVII.

\section{Gen. Chalcococcyx Cab.}

Verbreitung: Vorderindien mit Ceylon, Hinterindien, Indoaustralischer Archipel und Philippinen, Neu-Guinea, Australien, Tasmanien, Neu-Seeland, Bismarck-Archipel, Salomonen, Loyalty's, Neu-Caledonien.

\section{Chalcococcyx plagosus (Lath.).}

Verbreitung: Australien, Tasmanien, Neu-Guinea, Bismarck-Archipel, Salomonen, Lifou, Neu-Caledonien.

Verbreitung im neucaledonischen Gebiet: Nach den Layards, 4I, p. 523, ziemlich allgemein über die Insel verbreitet, aber selten (Chalcites lucidus); für Lifou durch die Layards, 37, p. 230, von Maré und Ouvéa noch nicht bekannt.

o Coné, If. August IgII.

ơ Quépénéé, Lifou, 7. Mai ıgı.

Beim Lifou-Vogel greift die kupferbraune Farbe von Kopf und Nacken bedeutend tiefer auf den Rücken hinunter als bei meinem caledonischen Exemplar, aber die Tiere scheinen stark zu variieren, vgl. La yards, 35, p. 253.

\section{Gen. Urodynamis Salvad.}

Verbreitung: Pazifische Inseln: Gesellschaftsinseln, Marquesas, Cook's, Samoa, Tonga, Palaus, Carolinen, Marshall, Gilbert, Salomonen, Neu-Britannien, Neu-Hebriden, Fidji, Neu-Caledonien, Neu-Seeland, Wiglesworth, 82, p. I2.

15. Urodynamis taitiensis (Sparm.).

Einzige Spezies der Gattung.

Verbreitung in Neu-Caledonien: Nach den Layards, 4I, p. 523, sehr selten und wahrscheinlich Wandervogel, aber in Caledonien brütend; ich habe die Art nicht erhalten. 


\section{Alcedinidae. \\ Gen. Halcyon Swains.}

Verbreitung: Afrika, Arabien, Südost-Europa, Kleinasien, Persien, Beludschistan, Vorderindien mit Ceylon, Hinterindien, China, Korea, Japan, Formosa, Philippinen, Indoaustralischer Archipel bis Australien, Bismarck-Archipel, Carolinen, Palaus, Mariannen, Salomonen, Neu-Hebriden, Fidji, Loyalty's, Neu-Caledonien, Neu-Seeland, Norfolk, Lord Howe, Samoa, Freundschaftsinseln, Marquesas, Sharpe, 75, II, p. $56 \mathrm{ff}$.

16. Halcyon sancta Vig. u. Horsf.

Verbreitung: Sumatra, S. Borneo, Java, Celebes, Kleine Sunda-Inseln, Molukken, Papuasische Inseln, Australien, Tasmanien, Palaus, Salomonen, Neu-Hebriden, Loyalty's, Neu-Caledonien, Meyer und Wiglesworth, 48, p. 288, Sharpe, 7I, p. 269.

Verbreitung im neucaledonischen Gebiet: Über ganz Caledonien verbreitet; man sieht ihn sehr håufig auf Bäumen und Telegraphendrähten in der Nähe sumpfiger Wiesen oder auch in der Flutzone des Meeres. Im Magen Insektenreste. In seinem Gefieder versteckt, lebt regelmässig eine nach der Bestimmung von Surcouf der Gattung Stilbomctopu angehörige, kommensale Fliege, welche nur schlecht fliegt. Für die Loyalty-Inseln wurde H. sancta schon von Gray, 22, p. I6o, aufgeführt, später von den Layards, 37, p. 223, für Lifou und Maré. Ich fand die Art auch auf Ouvéa.

\section{Conć, II. August rgir.}

$\hat{o}, \hat{o}, \hat{o}, \hat{o}, \hat{o}, \hat{q}$ Oubatche, I9. März bis 15 . Mai I9II.

* Quépénéé, Lifou, ro. Mai igiz.

¿ Fayaoué, Ouvéa, I2. Mai I9ı.

, ㅇ Netché, Maré, I7. und 27. November I9I I.

In Netché erhielten wir am 27. November Eier; sie sind kurzoval und weiss, $25 \mathrm{~mm}$ lang, 2I - 2I,5 $\mathrm{mm}$ breit.

Die Messungen ergaben folgende Mittelzahlen:

$$
\text { Long: tot. }
$$

7 Exemplare von Neu-Caledonien

$$
209 \quad(197-218)
$$

ala cauda culmen rostrum

4 Exemplare der Loyalty's

$$
\text { I90,5 (I85-200) }
$$

$87 \quad 65$

39

50

Die Loyalty-Form ist also, was die Gesamtlänge angeht, etwas kleiner als die caledonische; namentlich hat sie einen merklich kürzeren Schnabel.

Aus der Liste der caledonischen Vögel endgiltig zu streichen ist:

Ilakgon jula (Heine), von Tristram, 77, p. I8I, infolge einer Fundortsverwechslung (Anse, d. h. Bucht Vata bei Nouméa, statt Vaté in den Hebriden) für Caledonien aufgeführt. Vergleiche hierzu Layards, 33, p. 459 und 41, p. 503. Sharpe, 71, p. 264, sagt, Layard behaupte, diese Art von Ansevata in Caledonien erhalten zu haben. Das haben die La yards nie gesagt, sondern das Gegenteil. In der Handlist, 75, II, p. 59, ist 11 . juline immer noch für Caledonien mit einem ? aufgeführt; er gehört sicherlich nicht zur caledonischen Fauna. 


\section{Podargidae.}

\section{Gen. Aegotheles Vig. u. Horsf.}

Verbreitung: Molukken, Neu-Guinea, Aru, Australien, Neu-Caledonien, Hartert, 25 . p. 9 .

17. *Aegotheles savesi Layard u. Tristram.

Layard und Tristram, 39, p. I32, Taf. V.

Verbreitung: Auf Neu-Caledonien beschränkt; nur ein Exemplar aus der Năhe von Nouméa bekannt.

\section{Macropterygidae. \\ Gen. Collocalia G. R. Gray.}

Verbreitung: Vorderindien und Ceylon, südwärts zu den Seyschellen, Malayische Halbinsel, Indoaustralischer Archipel und Philippinen, Mariannen, Salomonen, NeuHebriden, Loyalty-Ins., Neu-Caledonien, Nord-Australien, Tonga, Gesellschaftsinseln, Marquesas, Hartert, 25, p. 66, Oberholser, 49, p. I $79 \mathrm{ff}$.

18. Collocalia leucopygia Wallace.

$$
\text { Wallace, } 8 \mathbf{I}, \text { p. } 384 \text {. }
$$

Verbreitung: Neu-Caledonien, Loyalty's, Neu-Hebriden.

Verbreitung im neucaledonischen Gebiet: Die Layards, 35, p. 252, nennen die Art in Caledonien gemein und wenigstens partiell wandernd, indem sie bei Nouméa gelegentlich für längere Zeit verschwinde. In unserem Garten bei Canala war sie überaus häufig und nistete überall in verlassenen Häusern, Ställen und selbst in den unbewohnten Parterreräumen unseres Hauses. Wir fanden vier Nester und ein angebrütetes Ei Ende Oktober IgI . Die Nester (Fig. I) sind halbkreisförmige Schüsseln, ganz aus Moos gebaut, mit sehr wenig verfestigendem Speichel; sie waren mit ihrer flachen Rückwand mittelst Speichel an Mauern und Balken festgeklebt, in einem Falle an einer Tapete. Länge ca. $8 \mathrm{~cm}$, Breite ca. $5 \mathrm{~cm}$, Tiefe $2-2^{1} / 2 \mathrm{~cm}$. La y ard, 1. c., fand Nester in Kalksteinhöhlen bei Houaîlou (9. November), an die Felsen fest. gelalebt. Er besclureibt sie als zusammengesetzt aus Würzelchen, Casuarina-Nadeln, trockenem Gras und Federn, mittelst Speichel zu einer kompakten, harten Masse verkittet, was bei meinen Exemplaren nicht der Fall ist. Lin Ei in jedem Nest. Für Lifou wurde die Art von den Layards, 37, p. 223, nachgewiesen; ich fand sie auch auf Maré. 
ô Canala, If. Oktober IgIт.

7, ㅇ Canala, I5. Oktober I9II.

4 Exemplare in Sprit, La Roche, Maré, 2. Dezember IgII.

I Exemplar in Sprit, Quépénéé, Lifou, 22. April I9I2.

19. Collocalia agnota Oberholser.

Oberholser, 49, p. 183.

Verbreitung: Neu-Caledonien, ohne Fundstelle.

Diese nach einem einzigen Exemplare im American Museum of Natural History beschriebene Art steht lowcopygin nahe, von der sie sich bloss durch leichte Färbungsunterschiede abtrennt, namentlich brauneren Rücken und weissere Unterseite. Die

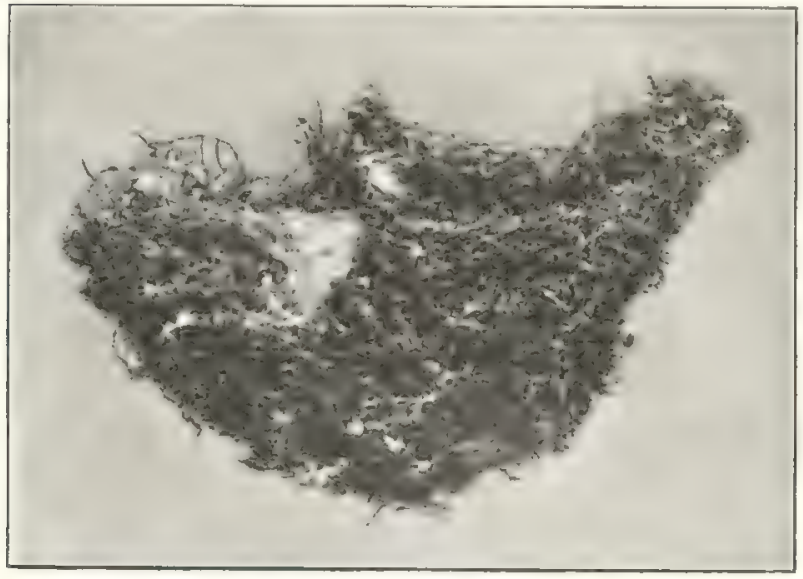

Fig. I.

Nest von Collocalia leucopyeia Wall. ca. $3 / 4$ nat. Gr. Färbung varilert aber auch bei lcucopygia beträchtlich. Es bleibt somit abzuwarten, ob weitere Exemplare die Berechtigung dieser neu aufgestellten Art bestätigen.

\section{Collocalia uropygialis}

G. R. Gray.

Verbreitung: Neu-Caledonien, Loyalty's und Neu-Hebriden.

Verbreitung im neucale. donischen Gebiet: Nach den L a y a d s, 4I, P. 502, über die ganze Insel Neu-Caledonien verbreitet, brütend in kleinen Felshöhlen und hohlen

Bäumen. Das von ihnen geschilderte, fast ganz aus grünem Moos gebaute Nest (3I, p. 337 U. 4I, p. 502) entspricht weit besser dem Nest von $C$. lcucofygia, als dasjenige, welches die Layards (siehe oben) leucopygia zuschreiben. Die genannten Autoren haben die Art nicht nur in Caledonien gefunden, sondern auch auf Lifou (37, p. 223). Ich konnte sie auch auf Ouvéa nachweisen. In Oubatche an der Ostküste von Nord-Caledonien ist sie überaus häufig. Farbige Abbildung bei Brench le y, 7, Taf. II.

ð, 우 Oubatche, I9. -22. April I9II.

I Exemplar in Sprit, Fayaoué, Ouvéa, I5. Mai 19ı.

Der Beschreibung ist beizufügen, dass die längsten Federn des weissen Bürzelbandes an ihren Enden schwarze Flecke haben, und dass die schwarzen Rückenfedern vor diesem weissen Band einen weissen Endsaum besitzen. 
21. Collocalia fuciphaga typica (Thunberg).

Verbreitung: Indoaustralischer Archipel und Philippinen, Mariannen, Carolinen, Salomonen, Neu-Hebriden, Fidji, Loyalty's, Neu-Caledonien, Tonga?

Verbreitung im neucaledonischen Gebiet: Wallace, 8I, p. 385, führte die Art zuerst für Neu-Caledonien auf. Die Lay ards, 35, p. 253 u. 4x, p. 503, beobachteten die ihnen von den Neu-Hebriden wohlbekannte Art (cincrę Gm.) bei Nouméa und auf Lifou, 37, p. 223, ohne ein Exemplar zu erbeuten. Da von tiergeographischem Standpunkte aus nichts gegen ihr Vorkommen einzuwenden ist, so mag sie der caledonischen Fauna auf das Wallace-Layard'sche Zeugnis hin zugerechnet werden. Ich habe sie nicht erhalten.

\section{Hirundinidae.}

Zweifelhaft scheint mir das Vorkommen der folgenden Art:

\section{Hirundo tahitica Gm.}

Die Layards, 4I, p.503, sahen einen einzigen jungen Vogel dieser Art in Nouméa in der Nähe des Bureau's des Postdampfers herumfliegen. Wenn die Beobachtung auch richtig sein mag, so könnte es sich doch hier leicht um ein auf einem Schiff hergebrachtes Exemplar handeln, obschon die geographische Verbreitung nicht gegen ein Vorkommen in Neu-Caledonien sprechen würde.

\section{Muscieapidae.}

\section{Gen. Rhipidura Vig. u. Horsf.}

Verbreitung: Vorderindien und Ceylon, Hinterindien, Indoaustralischer Archipel und Philippinen, Carolinen, Mariannen, Palaus, Bismarck-Archipel, Salomonen, NeuHebriden, Fidji, Samoa, Loyalty's, Neu-Caledonien, Lord Howe, Australien, Tasmanien, Neu-Seeland, Norfolk (nach den Arten in Sharpe's Handlist, 75, III, p. 252 ff.).

\section{2. "Rhipidura verreauxi Marie.}

$$
\text { Marie, } 47, \text { p. } 326 .
$$

Verbreitung: Neu-Caledonien; hier einer der gemeinsten und zahmsten Vögel, Layards, 4I, p. 512. Von ihnen auch auf Lifou beobachtet, 37, p. 227. Ich besitze die Art nicht von den Loyalty-Inseln, kann daher nicht beurteilen, ob sie mit der cale. donischen identisch ist.

\section{o Coné, 6. August Igrr.}

juv. Tal v. 'Tchalabel, Nord-Caledonien, 5. Juni igri.

Häufig beobachtet bei Yaté, März I9I2, im Süden der Insel. 
23. ${ }^{*}$ Rhipidura bulgeri E. L. u. E. L. C. Layard.

Die beiden Layard trennten zuerst, 34, p. 36r, diese Art von albiscapa Gould ab, mit welcher Verreaux und Des Murs, 79, p. 392, sie vereinigt hatten.

Verbreitung: Neu-Caledonien, ganze Insel, von den Layards, 37, p. 227 , auch auf Lifou gesehen.

o juv. Oubatche, II. Mai IgII.

Auch im Süden bei Yaté häufig angetroffen, März Igrz.

Nest (Fig. 2), von Eingeborenen in Canala gebracht, am 30. Oktober I9II. Es ist eine äusserst zierliche, vollkommen kreisrunde Tasse, rittlings auf einem Ästchen befestigt, aus feinen, kreisförmig angeordneten Pflanzenfasern gebaut und aussen mit Spinnwebfäden dicht umkleidet; mit solchen ist es auch auf dem durchgehenden Zweige festgemacht. Der untere, schwanzförmige Nestteil besteht aus Blattstückchen, mit Spinnweb umgeben. Höhe des Nestes

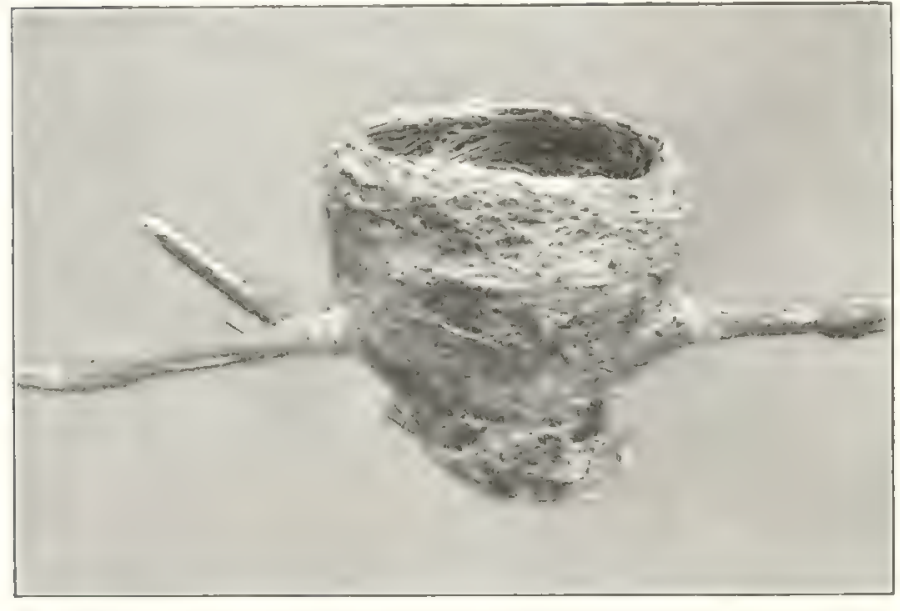

Fig. 2.

Nest von Rhipidure bulgeri Lay ard. ca. $1 / 3$ nat. Gr.
$4,5 \mathrm{~cm}$, Durchmesser der Iasse $5 \mathrm{~cm}$, Tiefe derselben ca. $2 \mathrm{~cm}$.

\section{Gen. Pseudogerygone}

Sharpe.

Verbreitung: Australien, Neu-Guinea und benachbarte Inseln, Neu-Seeland, Norfolk, Chatham, Lord Howe, NeuCaledonien, Loyalty's, Sh a r pe, 75. III, p. $227 \mathrm{ff}$.

\section{4. "Pseudogerygone flavi. lateralis (Gray).}

Verbreitung: Neu-Caledonien und Loyalty-Inseln.

24a. Pseudogerygone flavilateralis typica (Gray).

$$
\text { G. R. Gray, 22, 1). I6I. }
$$

Verbreitung: Neu-Caledonien und Maré. Die Art ist über ganz Caledonien verbreitet. Die Layards, 37, p. 225, geben auch Lifou als Fundort an, indessen scheint mir der Lifou-Vogel einen eigenen Varietätsnamen zu verdienen (siehe unten); dagegen fand ich die Art auch auf Maré und hier nur wenig abweichend von der caledonischen Form. 
2 ad. (sex.?) Oubatche bis $800 \mathrm{~m}, 7$. und I9. Juli I9I.

ad. (sex. ?) Coné, 6. August ig I .

q, , Netché, Maré, 20. November und 4. Dezember I9II.

Die Maré-Vügel haben die Flügelfedern und Flügeldecken weniger stark mit. Olivenfarbe gesäumt und den Schnabel etwas stärker, 9,25 mm im Mittel, gegen 8,5; sonst stimmen sie mit der caledonischen Form überein.

Nester (Fig. 3), Canala, 26. Oktober I9I I ; Mont Canala bei $650 \mathrm{~m}, 4$. November I9II, an einem Farnblatt hängend; Netché, Maré, 20. No. vember I9I I mit einem Nestjungen. Es sind Beutel, aufgehängt an dünnen Zweigen, vom Aufhängeort an gerechnet ca. I5 cm lang und am unteren, breiteren Ende ca. 6 cm breit, geflochten aus allerlei Grasfasern, Wurzeln, Federn, Wollflocken, Moos und dünnen Zweigchen. Oben seit. lich befindet sich unter einem kleinen Vordach ein Flugloch von kaum $2 \mathrm{~cm}$ Durchmesser; innen ist der Grund mit Federn und Baumwolle ausgefüttert. Der Beutel hat unten zuweilen einen aus Fasern gebildeten, kleinen Anhang. Nach den Layards, 4I, p. 509, besteht in Gegenden, wo der Niauli-Baum, eine Melaleuca-Art, wächst, das Nest oft ganz aus Streifchen seiner hautartigen Rinde.

24b. Pseudogerygone flavilateralis lifuensis nov. subsp.

Verbreitung: Lifou, Loyalty. ad (sex.?) Quépénéé, Lifou, 24. April I9I2.

Diese Subspezies unterscheidet sich wesent. lich durch die Färbung des Schwanzes, an welchem die sonst so auffallenden weissen Flecke seh"

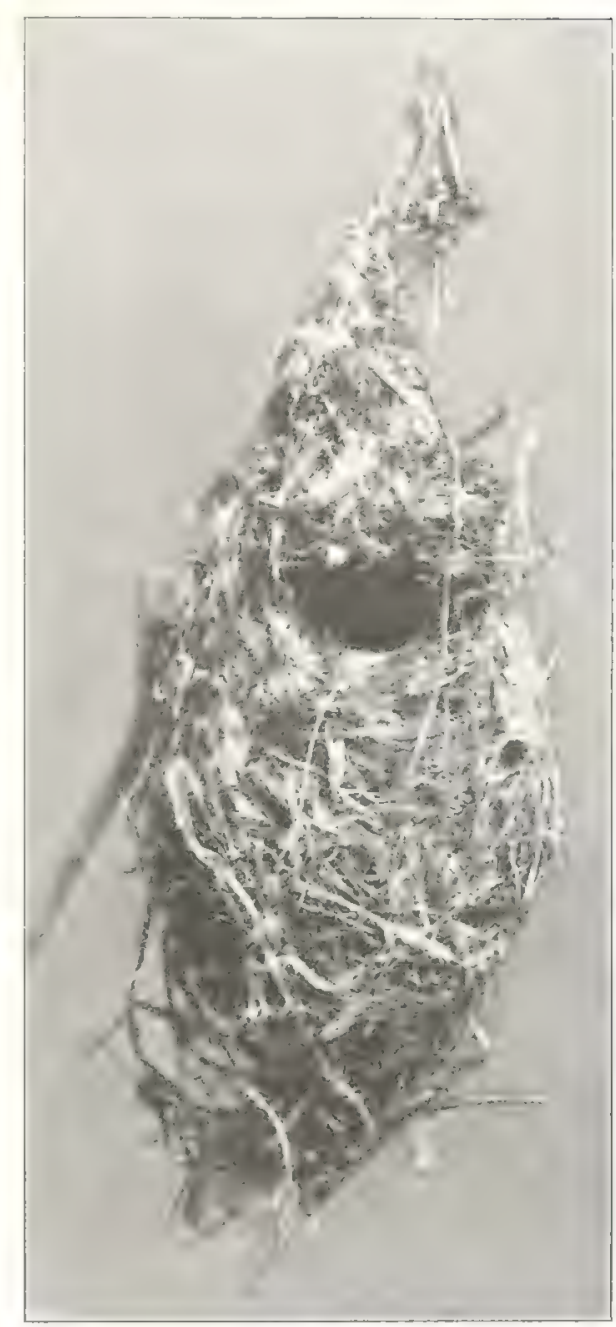

Iig. 3.

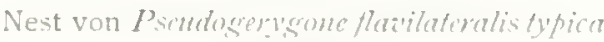
(Gray).

ca. $2 / 3$ nat. Gr. zurücktreten. Auf Tafel II, Figur I5 und I6, ist

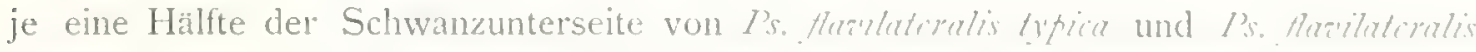
lifucnsis abgebildet. Die weissen Flecke nahe der Spitze der Innenfahnen sind bei der typischen Form (Fig. I5) leuchtend weiss und nehmen von der ersten nach der fünften Feder an Grösse ab, das mittlere Par ist ohne solche. Bei der var. lifumsis (Fig. 16) sind die Flecke auf der Unterseite der liedern trüber weiss, so auch auf der Aussen. 
fahne der ersten Feder, dabei wesentlich kleiner, auf der vierten nur noch schattenhaft angedeutet, auf den beiden innern fehlend. Sonst ist die Färbung ohne deutliche Unterschiede. Wurzel des Unterschnabels hell, bei der typischen Form schwarz.

Long. tot. c. 95 , ala 53,5, cauda 43 , culm. 9,5.

Drei caledonische Vögel ergeben:

Long. tot. C. 96, ala 50, cauda 42 , culm. 8,5.

Der Lifou-Vogel hat also einen etwas längeren Flügel und einen etwas stärkeren Schnabel.

25. ${ }^{*}$ Pseudogerygone rouxi nov. Spec. Taf, I, Fig. 4.

Verbreitung: Ouvéa, nördlichste Insel der Loyalty's.

Gerne gebe ich dieser neuen, durch ihre Färbung sich auf den ersten Blick unterscheidenden Art den Namen meines Freundes und Reisegefährten Dr. J. Roux, da er am Zustandekommen der Vogelsammlung, welche dieser Arbeit zugrunde liegt, den grössten Anteil hat, indem er unermüdlich, auch unter schwierigen Umständen, Bälge präparierte, dabei nur mangelhaft unterstützt durch einen tonkinesischen Diener.

q Fayaoué, Ouvéa, I5. Mai I9I2.

Oberseite dunkel olivengrün, Kopf hellbraun, obere Schwanzdecken heller olivengrün als der Rücken, obere Flügeldecken braun mit olivigen Säumen, Primär- und Sekundärschwingen braun mit schmalen Olivensäumen, die 2 mittleren Schwanzfedern jeder Seite braun ohne weissen Fleck; die folgenden mit kleinem weissem Fleck auf der Innenfahne, nach aussen zu grösser werdend, aber stets viel kleiner als bei flavilateralis und auf der äussersten Feder nur schattenhaft auf die Aussenfahne übergreifend; basalwärts vom weissen Fleck ein viel grösserer schwarzer; Zügel und schmale Linie über dem Auge hellgelb, um das Auge ein Kranz hellgelber Federchen, Ohrdecken und Halsseiten olivengrün, abweichend von der Kopffarbe, Kinn und Kehle weiss, mit gelblichem Anflug, ganze übrige Unterseite hell zitronengelb, ebenso die Federn der Beine; Unter. schwanzdecken weiss, leicht gelblich; untere Flügeldecken und Flügelbug hell gelblichweiss; Flügelfedern unten braun, leicht weisslich gerändert, Schnabel und Beine schwarz.

Long. tot. ca. 97,5 , ala 49 , cauda 38 , culmen 9 .

\section{Gen. Myiagra Vig. u. Horsf.}

Verbreitung: Australien, Tasmanien, Neu-Guinea und umgebende Inseln, Kleine Sunda-Inseln, Molukken, Carolinen, Mariannen, Palaus, Salomonen, Neu-Hebriden, Fidji, Samoa, Loyalty's, Neu-Caledonien (nach den Arten in Sharpe's Handlist, 75, III, p. 268).

In dieser Gattung herrscht, was die Arten unseres Gebietes angeht, eine nicht geringe Verwirrung, welche wesentlich durch die Frage hervorgerufen wird, ob die schwarzkehligen Vögel die Männchen, die kastanienbraunkehligen die Weibchen einer 
und derselben Art sind oder ob sie zwei verschiedene Arten repräsentieren. Diesen letzteren, meiner Meinung nach irrtümlichen Standpunkt vertreten die Lay ards, 37, p. 227, indem sie sagen, sie hätten zahlreiche Exemplare auf ihr Geschlecht untersucht und sowohl Männchen, als Weibchen der schwarz- und der rotkehligen Art in vollem Hochzeitskleid angetroffen. Mein Material ist nicht sehr gross, aber alle untersuchten rotbraunkehligen Exemplare waren Weibchen oder junge Männchen, die schwarzen adulte Männchen. Die roten Exemplare überwiegen bedeutend, und es ist sehr wahrscheinlich, dass oft Männchen noch in diesem Kleide zur Fortpflanzung schreiten. Da. gegen glaube ich nicht, dass schwarzkehlige Weibchen normalerweise, sondern nur als seltene Fälle von sogenannter Hahnenfedrigkeit vorkommen. Einen Beweis für meine Ansicht sehe ich auch in dem Umstand, dass die beiden von Tristram beschriebenen Lifou-Spezies, die schwarzkehlige lusmieri und die rotkehlige intermediu. sich genau durch dasselbe Merkmal, nämlich Beschränkung der Weissfärbung an den Schwanzfedern, von der schwarzen und der roten caledonischen Form unterscheiden, was nicht als zufällig aufgefasst werden kann. Im übrigen haben wir noch keinen rechten Einblick in die Art und Weise des Farbenkleidwechsels bei den Mymrat, welcher ebenso verwickelt zu sein scheint, wie bei den Trpsifhon'-Arten derselben Familie.

Es sind im ganzen fünf Arten beschrieben worden, nämlich von Caledonien $1 \%$ caledonica Bp. und ferspicillata Gray und von den Loyalty's riridinitens Gray, luguieri Tristr. und intermediu Tristr. In dieser Weise führt sie Sharpe in seiner Handlist, 75. p. 268 ff., auf. Früher hatte derselbe Autor, 68, p. 378, M. caledonica, persficillatı und riridinitens unter dem ältesten Namen, caledonica Bp., vereinigt. Die beiden Tristram'schen Arten waren damals noch nicht aufgestellt. Die Lay ards, 41, p. 512, führen für Caledonien auf: $M$. calcdonica Bp. und rividinitcns Gray, obschon die letztere Art von Gray, 22, p. I6r, als von den Loyalty's stammend, beschrieben worden ist und für die Loyalty-Inseln, 37, p. 226: 1\%. Inguieri Tristr. und intermediu Tristr.

Oustalet, 53, p. 219, sagt, nach Untersuchung der Typen komme er zum Ergebnis, dass perspicillata, viritimitens und caledonica nur eine Spezies darstellen; 1\%. perspicillata sei das q, rividinitens das of von calcdonica. W iglesworth, 82, p. 22, nimmt 2 Arten mit je einer Unterart an, nämlich $M$. calcdonica in Caledonien mit Subspezies ziridinitons auf den Loyalty's und forspicillato in Caledonien mit Subspezies intermcdid auf Lifou. Meiner Meinung nach handelt es sich überhaupt nur um eine Spezies mit je einer Unterart in Caledonien und auf jeder der drei Loyralty-Inseln.

\section{Myiagra caledonica Bp.}

Verbreitung: Neu-Caledonien, Loyalty's und Neu-Hebriden.

26a. ${ }^{*}$ Myiagra caledonica typica Bp.

Hiervon ist perspicillute Gray, 22, p. I6r, das ô, während die Bonaparte'sche caledonica das rotkehlige $q$ darstellt (Abbildung bei Brenchley, 7, Taf. VIII). Ferner ist 
die von den Layards für Caledonien angegebene 1\%. viridinitens ebenfalls das $\hat{\sigma}$ von calculomica, indem sie übersahen, dass Gray diese Art von den Loyalty's beschrieben hatte.

Verbreitung: Neu-Caledonien, ganze Insel.

ㅇ, $q$, $q$ Oubatche, 9. Mai, I8. u. 20. Juli I9II.

q Hienghiène, Juni I9II.

a juv. Oubatche, II. Mai I9II.

Alle diese mit rotbrauner Kehle.

* Oubatche, 28. August I9II, im schwarzen Kleide.

Häufig beobachtet bei Yaté, März ı Iıı.

Maasse (Mittelzahlen von 5 Indiv.): Long. tot. I42 (I35-149), ala 66 (64-68), cauda $66(64-70)$, culmen I3 $($ I $2-$ I 4$)$, Lat. rostri $8(7,5-8,5)$.

Auf Taf. II, Fig. II, ist die halbe Schwanzunterseite dieser Art dargestellt. Die äusserste Feder hat eine weisse Aussenfahne, und ihre breite Innenfahne ist etwa auf $\%$ ihre Länge weiss; bei der zweiten und dritten Feder beschränkt sich die Ausdehnung der weissen Farbe am Endteil mehr und mehr, bei der vierten ist nur noch ein ganz schmaler Endsaum, bei der fünften ein feines Spitzchen weiss; die innerste ist ganz dunkel gefärbt.

\section{6b. *Myiagra caledonica viridinitens Gray.}

Von Gray, 22, p. I62, als . 1 . viridinitins von den Loyalty's beschrieben. Das ist die Art, von welcher Tristram, 77, p. I88, das ô als „1\%. Ingmicri und p. I89, das $q$ als 21 . intermedia beschrieben hat.

Verbreitung: Lifou. Die anderen Loyalty-Inseln, Maré und Ouvéa, beherbergen ihre eigenen Unterarten.

q Quépénéé, Lifou, ıo. April igra.

Long. tot. c. I35, ala 7I, cauda 67, culmen I4, latit. rostri 8, im typischen Kleid von Tristram's intermedia; das schwarze 0 , welches $.1 \%$. luguieri entsprechen würde, besitze ich nicht. Das Kastanienbraun der Kehle und Oberbrust ist etwas tiefer herabreichend als beim caledonischen Vogel, sonst stimmt die Färbung überein, mit Ausnahme der Schwanzfedern, Taf. II, Fig. I3. Die äusserste Feder hat einen ganz schmalen, weissen Aussensaum, an der Spitze und am Spitzenteil der Innenfahne breiter werdend, die zweite und dritte schmale helle Endsäume, die übrigen nur minime weisse Spitzchen. Man vergleiche damit die Schwanzfärbung der typischen 11. cale. donica, Fig. II.

Dieser Färbungsunterschied in den Schwanzfedern, auf den schon Tristram bei seinen beiden Lifou-Arten aufmerksam gemacht hat, ist ein konstanter. Die Tristram'sche Beschreibung der Schwanzfedern bei M. Inguicri und intemedia stimmt mit meinen Befunden überein, ebenso die von Gray für seine riridinitens.

Tristram gibt als Maasse: Long. tot. $\hat{o}$ (M. Muguicri) $142, q$ (seine intermedia) I32, ala 68 und 69, cauda 7 I und 67. Das stimmt mit den oben angegebenen überein. 
Ich kann mich nicht entschliessen, der Lifou-Form mehr als den Rang einer Subspecies zuzuerkennen, obschon sie, wie gesagt, schon drei Speciesnamen erhalten hat, viridinitons Gray (ô), luguien Tristram (ô) und intermedia Tristram ().

26c. *Myiagra caledonica uveaensis nov. Subsp.

Verbreitung: Ouvéa, nördlichste Insel der Loyalty's.

đ Fayaoué, Ouvéa, I7. Mai I9I2.

Logischer Weise hätte diese Subspecies zwischen. M. caledonica typica und rimilintens ihren Platz finden sollen, da sie in der Färbung des Schwanzes diese Beiden vermittelt, allein ich wollte die beiden längst bekannten Formen vorausnehmen.

Beschreibung des $\hat{f}$ (das $q$ kenne ich nicht): Oberseite und Kehle schwarzgrün, Unterseite weiss, wie bei allen ausgefärbten Männchen der Species. Primärschwingen am Aussensaum deutlich hell gerändert, Sekundärschwingen mit schneeweissen, schmalen Säumen, die gegen die Wurzel der Innenfahne zu breiter werden (ähnlich wie bei caledonica typ. und viridinitens) und mit weissen Spitzchen. Schwanz, Taf. II, Fig. Iz: Äusserste Feder mit ganz schmalem, weissem Aussensaum und viel breiterer, weisser Spitze und langem Innensaum, die folgende ohne weissen Aussensaum, aber an der Spitze und am Endteil der Innenfahne breit weiss gerändert; an den drei folgenden nimmt sukzessive dieser weisse Saum ab bis zur Form einer feinen Spitze, innerste Feder uniform schwarz.

Maasse: Long. tot. C. I44, ala 74, cauda 75, culmen 14,5, lat. rostri 9; Schwanz und Flügel sind etwas länger und der Schnabel breiter als bei allen anderen Formen.

26 d. ${ }^{7}$ Myiagra caledonica mareensis nov. Subsp.

Verbreitung: Maré, Loyalty-Inseln.

ô, ô Netché, Maré, 24. Nov. und 7. Dez. IgI I. Das $q$ kenne ich nicht.

Oberseite schwarzgrün, Kopf glänzender, ebenso Kinn, Kehle und Oberbrust, Rest der Unterseite weiss. Primär und Sekundärschwingen uniform braun, ohne weisse Ränder, hierin abweichend von den anderen Formen. Schwanz, Taf. II, Fig. If: Äusserste Feder ohne hellen Aussensaum und nur mit schmalem, weissem Rand an der Spitze und dem Endteil der Innenfahne; ähnlich die zweite; bei der dritten ist das weisse Rändchen noch spurweise erkennbar; die drei inneren sind uniform dunkelbraun gefärbt. Diese Merkmale sind bei beiden Exemplaren konstant.

Ma asse: Long. tot. c. $15^{8}$ und 146 , ala 70 und 69,5 , cauda 72,5 und 68 , culmen I 4,5, Lat. rostri 7,5. Die Maré-Form ist etwas grösser als die von Lifou. Diese Subspecies steht melanura Gray von den Neu-Hebriden sehr nahe, die selber nur eine Unterart von caledonica darstellt; allein melomura hat die Schwanzfedern ganz dunkel gefärbt, wenigstens die Vögel von Erromango und Vanua Lava (Sharpe, 68, p. 379); die von Aneiteum haben die Aussenfeder schmal mit weiss gesiumt. Auch die Form von Tanna ist jedenfalls nahe verwandt. 
Die Bemerkung von Sharpe, 1. c., p. 380, dass die Ausdehnung der weissen Farbe am Schwanz offenbar variiere und daher kein starker spezifischer Charakter sei, ist für die Species ganz richtig, nicht aber für die lokalen Unterarten, bei denen dieses Merkmal sehr konstant ist.

Wenn wir die vier auf Tafel II, Fig. II-I4, abgebildeten Schwänze der vier besprochenen Myiagra-Formen betrachten, so zeigt sich, dass die Ausdehnung der weissen Farbe sukzessive abnimmt von der caledonischen Form über die von Ouvéa, der nördlichsten Loyalty-Insel, nach Lifou, der mittleren Insel und endlich nach Maré, der südlichsten, bei der das Weiss im Verschwinden begriffen ist. Wir haben hier also die Erscheinung einer geographischen Formenkette vor uns, wie mein Vetter $\mathrm{Paul}$ Sarasin und ich solche seiner Zeit von mehreren celebensischen Landmolluskenarten beschrieben, abgebildet und in ihrer phylogenetischen Bedeutung ausführlich gewürdigt haben, siehe P. u. F. Sarasin, Materialien zur Naturgeschichte der Insel Celebes, Band II, Die Landmollusken von Celebes, p. 229, Wiesbaden I899.

\section{Campophagidae.}

\section{Gen. Graucalus Cuvier ( + Artamides Hartl.).}

Verbreitung: Von Afrika und Madagaskar durch Vorderindien mit Ceylon, Hinterindien bis Süd-China und Formosa, Indoaustralischer Archipel und Philippinen, Australien, Tasmanien, Neu Seeland, Bismarck-Archipel, Salomonen, Neu-Hebriden, Lifou, Neu-Caledonien. (Sharpe, 75, III, p. 286 und 290).

\section{7. ${ }^{*}$ Graucalus caledonicus (Gm.).}

Verbreitung: Neu-Caledonien, gemeiner Waldvogel der ganzen Insel und lle des Pins; die Identität mit Vögeln von den Neu-Hebriden (Tristram, 77, p. 183 und 192 und 78 , p. 185 , Sharpe, 74, p. 342) scheint mir noch der Bestätigung zu bedürfen wegen der Artverschiedenheit des Graucalus auf dem zwischenliegenden Lifou.

ad. (sex. ?) Oubatche, 5. April IgII.

o Wald oberhalb Oubatche, $800 \mathrm{~m}, 7$. Juli Igr.

Maasse: Long. tot. c. 362 und 370, ala I86 und I94, cauda I 75 und 195, culmen 29 und 26.

\section{8. *Graucalus lifuensis Tristram. \\ Tristram, 77, p. I90.}

Verbreitung: Lifou, Loyalty's.

Tristram beschreibt diese Art als einfärbig glanzlos schwarz, intensiv russig, ohne jeden aschgrauen Ton, und die Layards, 37, p. 227, sagen, dieser Unterschied von der schiefer- oder aschgrauen caledonischen Spezies falle sofort in die Augen. Die beiden Exemplare, die ich von Lifou besitze: $\hat{0}, \hat{0}$, Quépénéé, Lifou, I9. und 
25. April I9I2, stimmen damit in keiner Weise überein; die ganze Oberseite ist vielmehr schiefergrau wie bei caledonicus, Oberkopf etwas dunkler, Schwanzfedern zugespitzt, dunkelbraun mit weissen Enden, die an Grösse von den inneren nach den äusseren zunehmen; Primärschwingen braun mit weissem Saum, welch' letzterer an den Sekundär. schwingen nach innen zu immer an Breite zunimmt; auch die Primärdecken und Schulter* federn mit starkem, weissem Rand; ganze Unterseite uniform schiefergrau wie die Ober: seite, etwas dunkler an der Kehle und den Unterschwanzdecken; Unterseite der Schwungfedern mit breitem, weissem Innensaum, untere Flügeldecken schiefergrau mit hellen Spitzen; Beine und Schnabel schwarz, Unterschnabel an der Wurzel hornbraun.

Nach Analogie mit anderen Arten der Gattung hatte ich den Verdacht, dass die genannten, von der Tristram'schen Beschreibung abweichenden Charaktere bloss Jugendmerkmale seien. Herr W. R. Ogilvie Grant, der die Güte hatte, eines meiner Stücke mit den Londoner Materialien zu vergleichen, hat dies durchaus bestätigt.

Ma as se: Long, tot. c. 355 und 352, ala I 73 und I 7 I, cauda I 55 und I 65 , culmen 26.

Tristram gibt als Maasse: Long. tot. 356, ala I89, cauda 178 , also für Flügel und Schwanz etwas höhere Zahlen. Die caledonische Spezies (siehe oben) ist etwas grösser.

\section{Gen. Edoliisoma Jacq. u. Pucher.}

Verbreitung: Philippinen, Celebes, kleine Sunda-Inseln, Molukken, Neu-Guinea und Papuasische Inseln, Salomonen, Neu-Caledonien, Nordost-Australien (Sharpe, 75. III, p. 294).

29. "Edoliisoma anale (Verreaux u. Des Murs).

Verreaux u. Des Murs, 79, p. 395, Campephaga analis.

Verbreitung: Neu-Caledonien, Waldvogel, aber nicht nur in den Hochwäldern der Berge, wie Layards, 4I, P. 5It, angeben, indem mein Exemplar aus einer Hohe von nur $200 \mathrm{~m}$ stammt. Ich beobachtete ihn auch am Mont Canala in $700 \mathrm{~m}$ Höhe am 4. November IgII.

o Fuss des Mont Humboldt, $200 \mathrm{~m}$, I6. September Igr I, im schiefergrauen Kleid der Erwachsenen, ohne Reste des fleckigen Jugendkleides, übereinstimmend mit der Beschreibung bei Layards, 4o, p. I7I. Im übrigen ist das Tier durchaus ein verkleinertes Abbild eines Grancalus und könnte auch zu dieser" Gattung gestellt werden, wie es die Layards tun, zumal auch die Geschlechter gleich gefärbt sind, was bei den meisten und typischen Eilolizoma nicht der Fall ist.

\section{Gen. Diaphoropterus Oberh.}

Verbreitung: Südost-Neu-Guinea, Salomonen, Neu-Hebriden, Loyalty's, NeuCaledonien und Norfolk (Sharpe, 75, III, p. 305). 
30. Diaphoropterus naevius (Forst.).

Verbreitung: Neu-Caledonien, Loyalty-Inseln und Neu-Hebriden.

\section{0a. *Diaphoropterus naevius typicus (Forst.).}

Verbreitung: Neu-Caledonien, ganze Insel. Da die Loyalty-Formen leichte Abweichungen zeigen, ist dasselbe von denen der Neu-Hebriden zu erwarten.

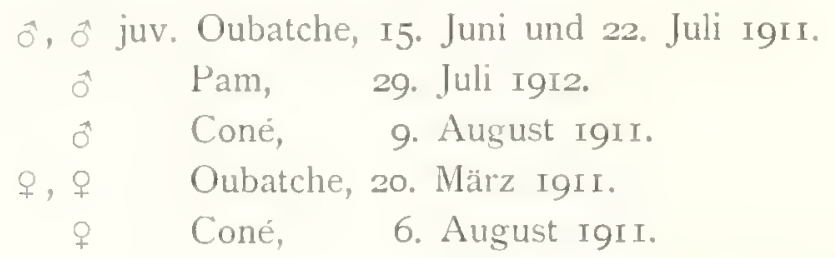

Tristram, 77, p. 183, machte zuerst auf die Färbungsunterschiede der Weibchen und jungen Männchen, gegenüber den alten Männchen aufmerksam. Im Katalog von Sharpe, 68, p. IIo, ist als erwachsenes Männchen ein weiblicher Vogel (oder junges Männchen) beschrieben mit hellrostroten Flügeldecken und Flügelfederrändern, welche beim erwachsenen, schwarzen Männchen schneeweiss sind. Dasselbe gilt für Lalage montrousieri von Verreaux und Des Murs, 79, P. 43I, denn beim erwachsenen Männchen fehlt jeder bräunliche oder rötliche Ton auf den Flügeln und ist durch reines Weiss ersetzt; Oberseite schwarz, mit Ausnahme des hellgrauen Bürzels, Unterseite weiss, auf Brust und Bauch mit etwas Gelb übergossen.

Ma as se, Mittelzahlen der 7 Exemplare: Long. tot. I 7 I (I62-I 78 ), ala 85 (83-87), cauda 85 (82-88), culmen 12,3 (II, 5 - I 3 ).

30 b. * Diaphoropterus naevius simillimus nov. Subsp.

Verbreitung: Alle drei Loyalty-Inseln. Für Lifou und Maré ist die Species von den Layards, 37, p. 228, für Ouvéa von Joua n, 28, p. 216, angegeben.

$$
\begin{aligned}
& \text { o Netché, Maré, 26. Nov. IgII. } \\
& \text { o Quépénéé, Lifou, 7. Mai Igı. } \\
& \text { a Fayaoué, Ouvéa, I3. Mai I9I2. }
\end{aligned}
$$

Maasse (Mittelzahlen): Long. tot. I69 (I64-r77), ala 85,5 (85-86,5), cauda 76 (74-80), culmen I2,3 (II,5- - 3); ausser dem etwa lürzeren Schwanz mit der caledonischen Form übereinstimmend. Beim Weibchen, besonders bei dem von Maré, sind die weissen Säume der Primär- und namentlich der Sekundärschwingen wesentlich schmäler als beim caledonischen Vogel, ähnlich die hell rötlichbraunen des Weibchens von Lifou. Am Schwanze zeigt sich eine Reduktion in der Ausdehnung der weissen Spitzen der äusseren Schwanzfedern, wie eineVergleichung der Fig. 9, Taf. II, Schwanzunterseite von D. nacvins typicus und Fig. Io von D. nacrins simillmus zeigt. Beim Maré-Vogel ist diese Reduktion noch stärker als beim abgebildeten von Ouvéa; es sind aber nicht alle Federn vor- 
handen. Ich würde dieser Sache wenig Gewicht beimessen, wenn es nicht dieselbe Erscheinung wäre, welche ich bereits an Vertretern der Gattungen IIyiagra und Pscudo. gerygonc auf den Loyalty's namhaft gemacht hätte. Es deutet dies auf einen gesetzmässigen Vorgang, und wenn wir solchen auf die Spur kommen wollen, ist es notwendig, auch die scheinbar unbedeutendsten Abweichungen nicht zu übersehen.

\section{Artamidae.}

\section{Gen. Artamus Vieill.}

Verbreitung: Vorderindien, Ceylon, Hinterindien, Süd-China, Hainan, Philippinen, Palaus, Indoaustralischer Archipel, Australien, Tasmanien, Neu-Caledonien, Loyalty's, Neu-Hebriden, Fidji (nach Sharpe, 75, IV, p. 260).

\section{I. Artamus melanoleucus (Forst.).}

Verbreitung: Neu-Caledonien, Loyalty's, Neu-Hebriden.

Überaus häufiger Vogel in Caledonien, meist in kleinen Gesellschaften, dicht nebeneinander gedrängt, auf Niaulibäumen, Hägen und Telegraphendrähten sitzend, oder schwebend wie ein kleiner Sperber, mit unschönem Gezirp. Bei den häufigen Wald- und Grasbränden sieht man ihn dicht am Feuerrand auf die aufgeschreckten und fliehenden Insekten Jagd machen. An der Westküste, z. B. bei Coné, schien er mir seltener zu sein als an der Ostküste, vielleicht bereits verdrängt durch die hier massenhaft lebenden, importierten Acridothcres. Für Lifou von den Layards, 37, p. 226, angegeben. Auf Maré beobachtete ich ihn oft auf den hohen Araucarien des Seestrandes.

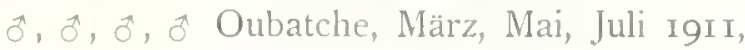

$$
\begin{aligned}
& \text { \& Hienghiène, Juni IgrI, } \\
& \text { đ Quépénéé, Lifou, i8. April igr2. }
\end{aligned}
$$

Das Exemplar von Lifou zeigt keine Abweichung von den caledonischen. Das. selbe sagt Tristram, 77, p. I92, von einem Exemplar von Vaté, Neu-Hebriden.

\section{Laniidae.}

\section{Gen. Pachycephala Vig. u. Horsf.}

Verbreitung: Kleine Sunda-Inseln, Celebes, Molukken, Neu-Guinea und Papua. sische Inseln, Australien, Tasmanien, Salomonen, Neu-Itebriden, Fidji, Tonga, Samoa, Paumotu, Loyalty's (Lifou), Neu-Caledonien, Lord Howe, Norfolk (nach Sharpe, 75, IV, p. 3031 . 


\section{2. "Pachycephala xantherythraea (Forst.)}

I. xanthethrac bei Forster; $P$. assimilis bei Verreaux u. Des Murs, 79, p. 394, neben. tonthethrack aufgeführt (vgl. Lay ards, 38, p. 460); farbige Abbildung bei Brenchley, 7, Tal. XIl:

Verbreitung: Neu-Caledonien, ganze Insel, sehr häufig und nicht im mindesten scheu.

$$
\begin{aligned}
& \hat{o}, \hat{o}, \hat{o}, \hat{o}, \hat{o} \text { juv. Oubatche, März, Mai, Juli IgI I } \\
& \text { q, }, \text {, } \quad \text { " " " " }
\end{aligned}
$$

Die Weibchen und jungen Vögel haben den Rücken, namentlich Kopf und Mantel, mit etwas Olivenfarbe übergossen, Kinn und Kehle weiss, Oberbrust isabell, Hinterbrust und Bauch rötlich, die ganze Unterseite mit dunkelbraunen Längsstreifen in der Mitte der Federn, am Bauch spärlicher werdend.

\section{3. *Pachycephala morariensis Verreaux u. Des Murs.}

Verreaux u. Des Murs, 79, p. 393.

Verbreitung: Neu-Caledonien, häufiger Waldvogel der ganzen Insel, namentlich im Bergwald.

Oustalet, 53, p. 219, hat diese Art mit der folgenden vereinigt, aber, wie unten gezeigt werden soll, mit Unrecht.

$\overrightarrow{0}$ und $q$, $q$ Wald oberhalb Oubatche, 500-1000 m, 29. April und 20. Mai I9II.

o Wald am Mt. Canala, $700 \mathrm{~m} .4$. Nov. IgII.

ô Yaté, I6. März I9Iz.

Maasse, Mittel der $3 \hat{8}$ : Long. tot. ca. I64, ala 8I, cauda 70 , culmen 13,

$$
\text { Mittel der } 2 \text { \%: " " ca. I60, „8I, " 69, " } 13 .
$$

Das Weibchen ist sehr abweichend gefärbt vom farbenbunten Männchen, wie ein solches bei Bren chley, 7, Taf. XII, Fig.r, nicht übel abgebildet ist. Oberseite und Schwanz olivenbraun, heller an den Oberschwanzdecken, Kopf mehr graubraun, Flügelfedern braun, mit Olivenfarbe gesäumt, besonders breit an den inneren Sekundärschwingen, Kinn und Kehle weiss, manchmal mit dunkleren Fleckchen, Brust hell graubraun, Flanken dunkler, mit Olivengelb übergossen, Bauch schmutzig hellgelb, untere Schwanzdecken reiner hellgelb, Flügelbug gelblich weiss, untere Flügeldecken weiss, zuweilen etwas gelblich. Diese Beschreibung beruht auf der Vergleichung von 5 Exemplaren, den beiden Weibchen unserer Sammlung und drei Weibchen des Pariser Museums.

\section{4. "Pachycephala caledonica (Gm.).}

Verreaux und Des M urs führen in ihrer Liste neben Pachycephala xantherythraea $1=$ assimilis) und moramiensis drei Eopsaltria-Arten auf, nämlich Aavigastra Verr. u. Des Murs (siehe unten Nr. 36), E. a'ariegatı Gray und E. (?) caledonica (Gm.) (Aluscicapa caledo- 
nica $\mathrm{Gm}$.). Gray bei Brenchley, 7, p. 378, vereinigte seine variegata mit caledonica (Gm.); Oustalet, 53, p. 2I9, deutete E. ariegati $=$ caledonica als das Weibchen von Pachycephala moraricnsis V. u. D. M. und übertrug daher auf diese letztere Art den älteren Namen calidonica Gm. Sharpe ist ihm hierin in der Handlist, 75, IV, p. 305, gefolgt, ebenso Wiglesworth, 83, 443 , und ich selber hielt gleichfalls, da ich keine Exemplare von calcdonicu $(\mathrm{Gm}$.) besass, diese Deutung Oustalet's für richtig, bis ich im Pariser Museum solche in die Hand bekam und erkannte, dass die Layards, 4I, P. 5I7, ganz im Rechte sind mit ihrer Angabe, E. calidonica (Gm.) sei ein Vogel, der auf den ersten Blick schwierig zu unterscheiden sei von Weibchen der Puchucchlula morariensis; indessen seien die rötlichen Primärschwungfedern ein sicherer Führer. Sie fügen bei, es sei unerfindlich, warum dieser Vogel mit Eopsaltria flazigastra in e ine Gattung zu. sammengestellt werde.

Die drei Pariser Exemplare, die ich vor mir habe, zwei als Weibchen bezeichnete von Nouméa und ein dem Geschlecht nach unbestimmtes von der Ile des Pins, zeigen mir zunächst, dass es sich in der Tat um eine Pachycefhala- und nicht um eine EopsaltriuArt handelt; Schnabel- und Flügelbildung stimmen völlig mit der ersteren Gattung überein. Die Tiere gleichen sehr den Weibchen von P. morariensis, aber der Kopf ist dunkel olivengrün, nicht graubraun, und die Schwungfedern, namentlich die sekundären, sind kastanienbraun oder rostrot gesäumt, die innersten sogar in toto so gefärbt, während sie bei morarimsis-Weibchen olivengrün sind. Bei geschlossenem Flügel el"scheint ein grosser Teil davon rotbraun, wodurch jede Verwechslung mit moraricnsis-Weibchen a usgeschlossen ist. Auf der Unterseite erscheint die Kehle, namentlich an den Seiten, gelblicher; manche Federchen sind dunkel gesäumt. Die Geschlechter scheinen annähernd gleich gefärbt zu sein. Das bei Brenchley, 7, Taf. XIII, Fig. I, farbig abgebildete Exemplar ist wahrscheinlich ein Männchen.

Maase (Mittelzahlen der drei Exemplare von Paris): Long. tot. c. 155 , ala 8o, cauda 68, culmen If. Layards, 1. c., p. 517, geben: L. t. I7I, a. 82, c. 7o, Gray, 1. c., p. 378 : L. t. 146, a. 82, c. 53 .

Verbreitung: Neu-Caledonien und Ile des Pins; nach den Layards, I. c., ist $P$. calcdonica die seltenste Würgerart der Insel. Ich habe sie nicht gefunden. Die Fundorte der drei Pariser Exemplare liegen alle im Süden der Insel.

35. *Pachycephala littayei E. L. U. E. L. C. Layard.

Layards, 35, p. 255; schön abgebildet bei Tristram, 77, 'Taf. VI.

Verbreitung: Lifou, Loyalty's.

o Nathalo, Lifon, 30. April rgiz.

Long. tot. c. I90, ala 99,5, cauda 78, culnen 17 .

Layards, 1. c. geben "I II, " 97, " 80,

an anderer Stelle, 37, p. 229, Länge I99. 
Es ist höchst sonderbar, dass sich auf Lifou diese schöne Art, die an Grösse die caledonischen erheblich übertrifft, herausgebildet hat, während die letzteren, wie es scheint, den Loyalty-Inseln fehlen.

\section{Gen. Eopsaltria Swainson.}

Verbreitung: Australien, Louisiaden, Neu-Caledonien, nach Sharpe, 75, IV, p. 3i5. Diese Verbreitung ist unnatürlich und wird sich noch erweitern. Gadow, I9, p. I75ff., rechnet zu Eopsaltria Arten folgender Verbreitung: Australien, Neu-Caledonien, Neu-Hebriden, Neu-Guinea und Aru.

\section{6. *Eopsaltria flaviventris Verreaux u. Des Murs.}

Verreaux u. Des Murs, 79, p. 392, E. Harigastra.

Verbreitung: Neu-Caledonien, in allenWaldungen der Insel häufig und nicht scheu.

đ Tchalabeltal, Nord-Caledonien, 5. Mai igi i.

qu. ad. (sex. ?) Coné, I4. August IgII.

ad. (sex.?) Wald am Panié, 500 m., 29. Juni igri.

ad. (sex.?) Yaté, 24. März igrz.

Männchen und Weibchen sind gleich gefärbt. Junge Vögel haben öfters helle Endspitzen an den Flügeldecken.

Maase, Mittelzahlen der 5 Individuen:

Long. tot.ca. I37 (I30-I4I), ala 72(69-75), cauda 6r (54-65), culmen Io $(9-$ Io,5).

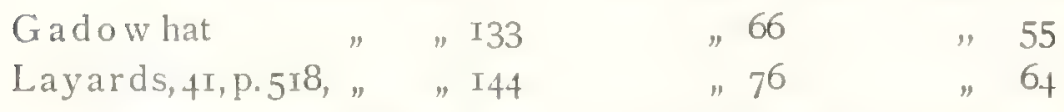

Eopsaltria faviantris ist die kleinste aller caledonischen Laniidenarten.

\section{Prionopidae.}

Gen. Clytorhynchus Elliot.

Verbreitung: Neu-Caledonien und Neu-Hebriden, Sharpe, 75, IV, p. 272.

\section{Clytorhynchus pachycephaloides Elliot.}

Von D. G. Elliot, If, Taf. XIX, beschrieben und abgebildet.

Verbreitung: Neu.Caledonien, ganze Insel, aber nicht häufig.

q Oubatche, 28. August I9II.

Das Exemplar stimmt gut mit der Diagnose überein. Long. tot. ca. I96, ala 83, cauda 90, culmen I7. Layards, 36, p. IIo, geben für ein Männchen und ein Weibchen: Long. tot. I9I u. I84, ala 95 u. 87, cauda 95 u. 93. Ga dow, I9, p. II2, für das Männchen: Long. tot. I78-203, ala 89, cauda 84, culmen I9. Alle diese Zahlen sind grösser als die Elliot'schen: Long. tot. 165 , ala 89 , cauda 76. 


\section{Zosteropidae.}

\section{Gen. Zosterops Vig. u. Horsf.}

Verbreitung: Afrika, Madagaskar, Comoren, Maskarenen, Seyschellen, Süd. Arabien, Vorderindien, Ceylon, Hinterindien, China, Ost-Sibirien, Japan, Philippinen, Carolinen, Mariannen, Indoaustralischer Archipel, Australien, Tasmanien, auf Neu-Seeland und Chatham eingewandert nach Finsch, I6, p. 2, Salomonen, Neu-Hebriden, Fidji, Loyalty's, Neu-Caledonien, Lord Howe, Norfolk (nach Sharpe, 75, V, p. Iff.).

\section{Zosterops xanthochroa Gray.}

G. R. Gray, 22, p. I6I.

Verbreitung: Neu-Caledonien; im Norden der Insel haben wir diese Art, vielleicht zufällig, nicht erhalten, im Süden ist sie häufig, auch auf Ile des Pins.

$$
\text { § Yaté, I9. März 1912. }
$$

Gadow, 20, p. I74, nennt die Färbung der Oberseite grasgrün; das ist nicht richtig, sie ist olivengrün, wie auch Finsch, 1. c., P. I3, korrekt angegeben hat; farbiges Bild bei Brenchley, 7, Taf. VII.

\section{9. "Zosterops minuta E. L. u. E. L. C. Layard.}

Layards, 35, p. 259; farbige Abbildung bei Tristram, 77, Taf. IV.

Verbreitung: Lifou, Loyalty's. Die Annahme des Vorkommens dieser Art auf Maré (Finsch, I6, p. 30, Sharpe, 75. V, p. II) beruht nur darauf, dass die Layards, 37. p. 225, den Namen von Zosterops in der Maré-Sprache anführen. Ich habe die Spezies auf Maré nicht angetroffen und glaube kaum, dass sie vorkomme.

$\hat{o}, \hat{o}, \hat{o}, \hat{o}, \hat{o}$ Quépénéé, Lifou, Ende April und Anfang Mai rgrz.

o, o Nathalo, Lifou, Anfang Mai igrz.

Die La yards (siehe Tristram, 77, p. I86) sagen, Z. mimutr sei eine Zwischen. form zwischen $Z$. fawifrous der Neu-Hebriden und xanthochroa von Caledonien.

4o. Zosterops lateralis (Lath.).

Verbreitung: Australien, Tasmanien, Chatham, Lord Howe-Ins., Neu-Caledonien, Loyalty's, Neu-Hebriden, Fidji (siehe unten).

\section{0a* Zosterops lateralis griseonota Gray. \\ Z. grisconolu, G. R. Gray, 22, p. I6I.}

Verbreitung: Neu-Caledonien, ganze Insel; bei Oubatche war diese Art ungemein häufig. Der Darm erwies sich als sehr reich an Parasiten, namentlich an Cestoden, was jedenfalls mit ihrer, neben Körnern reichlich aus Insekten bestehenden Nahrung zusammenhäng̣t. 
$\hat{o}, \hat{o}$ Oubatche, I3. Mai und If. Juli I9II.

ô Coné, 5. August I9II.

2, q Oubatche, 3. April und I7. Mai I9II.

q Coné, 7. August IgII.

Z. grisionota wird von Gadow, 20, p. I58, als Form $\gamma$ zu Z. westernensis (Q. u. G.) gezogen, welch' letztere Art ihrerseits von Finsch, I6, p. 39, zugleich mit cacnlescons, unter latcralis (Lath.) rangiert wird. Finsch, 1. c., p. 4o, vereinigt Z. grisconota mit Aariceps Peale von Fidji. Es bestehen aber doch gewisse Unterschiede zwischen diesen beiden, wie schon Finsch und $\mathrm{Hartlaub,} \mathrm{I7,} \mathrm{p.} \mathrm{53,} \mathrm{angegeben} \mathrm{haben.} \mathrm{Z.} \mathrm{grisconota} \mathrm{ist}$ etwas grösser und hat einen längeren Schnabel. Unsere 6 caledonischen Exemplare geben folgende Mittelzahlen: Long. tot. ca. I23, ala 60,3, culmen 9,25. Die beiden genannten Autoren, I7, p.53, geben für einen Vogel von Fidji: Long. tot. ca. II5, ala 56, culmen I2, I5 (pieds du roi); G a d ow, 20, P. I57U. I58, für ein Männchen und ein Weibchen von Fidji: Long. tot. II 3 und $x_{3}$, ala $5^{8}$ und 58 , culmen Io,6 und II,7. Die Abbildung bei Finsch, I6, p. to, eines Kopfes von Z. Aavicefs zeigt eine viel plumpere Schnabelform, als sie griseonota zukommt, welche weit mehr der auf derselben Seite gegebenen Abbildung von latcralis entspricht. Ferner sind die unteren Schwanzdecken bei fnaiccps gelb (Gadow, 1. c.) oder blass olivengelblich ( $\mathrm{F}$ insch und Hartlaub, 1. c.), bei grisconote weiss, gegen die Spitzen zu mehr oder weniger deutlich hellgelb getönt. Es scheint mir darum vorsichtiger, einstweilen Z. grisconota aufrecht zu erhalten und als Subspezies zu lateralis (zicsternensis + caemlescens bei Gadow) zu stellen. Weitere Lokalformen dieser Art wären dann Hariceps Peale von Fidji, tephropleura J. Gd. von Lord Howe-Ins. und wohl noch andere mehr, so auch, wie unten folgen wird, zwei Formen von den Loyalty-Inseln, vermutlich auch solche von den Neu-Hebriden, die in der Literatur zu grisionota gestellt werden.

tob.* Zosterops lateralis nigrescens nov. Subsp.

Verbreitung: Maré und Ouvéa, Loyalty-Inseln.

$$
\begin{aligned}
& \text { ^ Netché, Maré, I4. Dezember I9Ir. } \\
& \text { †, }+ \text { Netché, Maré, 27. November und 6. Dezember IgII. } \\
& \hat{\jmath}, \hat{\jmath}, \hat{o} \text { Fayaoué, Ouvéa, I3.-I5. Mai igrz. } \\
& \text { q, q Fayaoué, Ouvéa, I3.-I5. Mai ıgı́. }
\end{aligned}
$$

Hierzu 4 Exemplare in Sprit, ebendaher.

Diese Subspezies steht der vorhergehenden, griseonota von Caledonien, sehr nahe, unterscheidet sich aber durch dunklere Färbung und stärkeren Schnabel. Mantel etwas dunkler grau, obere Schwanzdecken etwas dunkler grün; namentlich aber sind der Oberkopf, der Nacken und die Kopfseiten sehr merklich dunkler grün gefärbt, der Oberkopf sogar direkt schwarzgrün, Zügel in viel grösserer Ausdehnung schwarz als bei 
grisconota, unterhalb des breiten, weissen Augenringes ein schwarzer Fleck, Kehle trüber gelb, das Grau auf der Oberbrust ausgedehnter.

Maasse, Mittelzahlen von 3 Exemplaren von Maré und 9 von Ouvéa: Long. tot. I25 und I24, ala 59,3 und 60, culmen 10,5 und II. Eine Vergleichung mit den oben gegebenen Maassen von grisconota zeigt, dass Körperlänge und Flügellänge übereinstimmen, wogegen der Schnabel bei nigrescens merklich länger ist als bei der caledonischen Form; er ist auch stärker und plumper. Auf Taf. I, Fig. I u. 2, sind die Köpfe von $Z$. latcralis griseonota und nigresecns in Farben dargestellt.

Das Nest, welches wir in Maré am 6. Dezember I9II erhielten, ist ein typisches Zosterops-Nest, napfförmig, aus feinen Halmen gebaut, aussen mit Moos und Wollenflocken bekleidet; einige lange Federn sind wie zum Schmuck hineingesteckt.

Zosterops lateralis migrescens bildet einen deutlichen Übergang von der caledoni. schen griseonota zu der folgenden Subspezies, melanops von Lifou.

4o c. Zosterops lateralis melanops G. R. Gray.

Zosterops melanops, Gray, 23, I859.

Verbreitung: Lifou, Loyalty.Inseln; nicht so selten, als die Layards, 37 , p. 225, glauben.

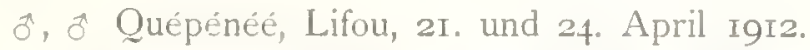 \\ 오, ㅇ Quépénéé, Lifou, 21. und 26. April т912.}

Ohne die Kenntnis von nigrescens musste melanops als eine sehr gut markierte Spezies erscheinen, während sie jetzt nur als Ende einer Entwicklungsreihe sich darstellt. Die Schwarzfärbung des Oberkopfes, bei nigrescens beginnend, ist bei melanops nahezu vollendet, bei welch' letzterer Form das Grün nur noch leicht durchschimmert und den Hinterrand des schwarzen Nackens umsäumt. Die Figuren I - 3 auf Taf. I zeigen diesen Prozess deutlich. Auch die Kopfseiten von melanops sind zum überwiegenden Teile schwarz. Der sehr breite (nicht schmale, wie Finsch, I6, p. 39, aus Versehen angibt) weisse Augenring leuchtet aus der dunklen Farbe stark heraus. Auch das Schiefergrau der Oberseite ist etwas dunkler als bei nigrescens, wie es bei der letzteren Form dunkler ist als bei grisconota; ebenso das Grau der Oberbrust ausgedehnter.

Ma asse, Mittelzahlen der 4 Exemplare: Long. tot. ca. I23, ala 60,5, culmen 10,5. Schnabel hellbraun mit dunklerer Spitze, der untere weisslich.

Die drei Subspezies: grisconota von Neu-Caledonien, Migresccns von Maré und Ouvéa und melanops von Lifou bilden eine Formenkette mit zunehmender Schwarzfärbung, ganz entsprechend der oben beschriebenen Kette der vier IryagraFormen. 
4I. "Zosterops inornata E. L. U. E. L. C. Layard.

Layards, 35, p. 259; farbige Abbildung bei Tristram, 77, Taf. IV.

Verbreitung: Lifou, Loyalty's. Finsch, r6, p. 42, gibt auch Maré an, aber das beruht wiederum bloss auf der Angabe eines Zosterops-Namens in der Maré-Sprache (37, p. 224) durch die Lay ards.

ô Quépénéé, Lifou, 8. Mai ıgiz.

o Nathalo, Lifou, 28. April igra.

Das Tier ist von den anderen \%osterops-Arten so abweichend, dass es wohl besser wäre, dasselbe generisch oder subgenerisch abzutrennen. Zügel und Wange sind sehr wenig befiedert, der Augenring nur von spärlichen weissen Federchen gebildet; Schnabel enorm kräftig, so lang als der Kopf, Oberschnabel schwarz, der untere rötlichweiss, mit schwarzer Spitze; Beine rötlichgelb. Wie schon Tristra m, 77, p. I86, erwähnt, nähert sich die Art den Glycyphila an; nur ist der Schnabel lange nicht so fein und nicht so stark gebogen, wie bei diesen.

Masse: Long. tot. ca. I35 und I4I, ala 65 und 69, cauda 56 und 54, culmen I7 und I6. Tristram, 77, p. I86, nennt ihn den Riesen der Familie (Länge I40), ebenso die Layards, 37, p. 224 (Länge im Fleisch 152). Nach F insch, I6, p. 5, sind die grössten Glieder der Familie Z. strema J. Gd. von Lord Howe-Insel (c. I5O), Z. albo. gularis J. Gd. von der Norfolk-Insel (c, I50) und \%. temirostris J. Gd. ebendaher (c. I30). Alle diese Arten sind, wie \%, inomata, Bewohner kleiner Inseln. Eine ähnlich kräftige Entwicklung, wie \%. imormata unter den Zosterops-Arten, hatte auf Lifou Pachycephala littayci unter den Pachycephala-Arten gezeigt. Eine Gesetzmässigkeit in der Abhängigkeit der Körpergrösse von der Inselgrösse und den hierdurch geschaffenen Lebensbedingungen lässt sich indessen nicht feststellen, denn Lifou beherbergt, wie eingangs schon gesagt, neben der grossen $Z$. inornata auch die kleinste Art unseres Gebietes, Z. minuta Layard.

\section{Meliphagidae.}

\section{Gen. Myzomela Vig. u. Horsf.}

Verbreitung: Celebes, Molukken, Kleine Sunda-Inseln, Carolinen, Mariannen, Palaus, Neu-Guinea und Papuasische Inseln, Australien, Salomonen, Neu-Hebriden, Fidji, Rotuma, Samoa, Loyalty's, Neu-Caledonien (nach Sharpe, 75, V, p. 66 ff.).

42. "Myzomela caledonica Forbes.

W. A. Forbes, 18, p. 260.

Verbreitung: Neu-Caledonien, ganze Insel, im Hochwald sowohl, als im Niaulibusch und auf offenen Flächen. Die Angaben des Vorkommens auf den Neu-Hebriden 
bedürfen der Bestätigung, da schon die zwischenliegenden Loyalty-Inseln eine andere Spezies besitzen. Das Fleisch der frisch erlegten Vögel riecht aromatisch.

o Wald oberhalb Oubatche, ca. $500 \mathrm{~m} ., 2$. Oktober I9II.

ô juv. Wald am Panié, ca. $500 \mathrm{~m} ., 27$. Juni I9I I.

Die Art steht .1\% sangminolenta (Lath.) von Australien nahe, von Gadow, 20, p. 132, als Subspezies derselben aufgefasst.

43. "Myzomela lifuensis E. L. u. E. L. C. Layard.

$$
\text { La yards, } 35 \text {, p. } 258 .
$$

Verbreitung: Lifou, von uns auch auf Ouvéa nachgewiesen; auf Maré noch etwas zweifelhaft (Layards, 37, p. 223).

$$
\begin{aligned}
& \text { \& Nathalo, Lifou, 30. April IgI2. } \\
& \text { o Fayaoué, Ouvéa, I5. Mai I9I2. }
\end{aligned}
$$

Auch diese Art zeigt die nun schon mehrfach konstatierte Ërscheinung, dass bei den Vögeln der Loyalty-Inseln die schwarze Farbe auf Kosten der hellen Töne stärker hervortritt.

\section{Gen. Glycyphila Swains.}

Verbreitung: Australien, Tasmanien, Neu-Guinea, Aru, d'Entrecasteaux, NeuCaledonien, Loyalty's, Neu-Hebriden (nach Sharpe, 75, V, p. 7 I ff.).

\section{4. *Glycyphila undulata (Sparrm.).}

Gl. fasciati (Forst.) bei Layards und anderen Autoren.

Verbreitung: Neu-Caledonien, ganze Insel, nicht selten, meist in kleinen Gesellschaften.

$$
\begin{aligned}
& \widehat{o} \text {, ô juv. Oubatche, 24. März und I6. Mai rgIr. } \\
& \text { q Oubatche, I4. Mai rgII. } \\
& \text { ô, ô Yaté, I8. und 21. März 19i2. } \\
& \text { q Yaté, 19. März I9I2. }
\end{aligned}
$$

\section{5. *Glycyphila incana (Lath.).}

Verbreitung: Ganze Insel Neu-Caledonien und alle drei Loyalty-Inseln.

Diese Spezies ist wohl die an Synonymen reichste des Gebietes: chlorofhuea (Forst.), modesta Gray, farotincta Gray, caledonica Gray, poliotis Gray, satelles 'Tristram.

Die Layards, 4I, p. 505, welche eine grosse Menge von Exemplaren verglichen haben, kommen zum Schluss, dass neben Gl. undulata (fasciata) nur e ine andere Spezies im Gebiet vorkomme, welche sie chlorofhen (Forst.) nennen; sie variere stark nach Alter, Geschlecht und Jahreszeit. Sie überlassen auch Tristram die volle Verant. wortung für seine Gl. satclles von Lifou, 37, 224. Sharpe, 75, V, p. 72 und 73, hält in der Handlist neben undulatu noch drei Arten fest: incum von Neu-Caledonien und 
Lifou, poliotis von den Loyalty's und satelle's von Lifou. Die Diagnosen bẹi Gadow, 20, p. 216 und 2I7, von income (Lath.) und foliotis Gray geben keinen Anhalt zur Unterscheidung der beiden Arten; die Hauptdifferenz (p. 210): crown ashy grey, incana, crown olive-brown, poliotis, ist ein Geschlechtsunterschied. Die adulten Männchen haben den Oberkopf aschgrau, die Weibchen und Jungen olivenbraun.

Ich hatte anfangs geglaubt, die Tristram'sche Spezies satclles, 77, p. I85, von Lifou beschrieben, neben incana aufrecht erhalten zu können, indem sich in Oubatche neben grösseren Exemplaren merklich kleinere fanden, welche auch in der Färbung die Merkmale von satelles aufwiesen, Oliventon der Unterseite, gelblichen Bauch, gelblichen Ton von Kinn und Kehle und olivenbraune Färbung von Kopf und Oberseite. Aber es zeigte sich, dass diese Exemplare weibliche oder junge Männchen waren, so dass hier bloss ein Alters- und Geschlechtsunterschied vorliegen dürfte.

8 Exemplare von Maré, Lifou und Ouvéa unserer Sammlung zeigen keinerlei Abweichung von der caledonischen incana, und von den Loyalty's sind doch die beiden Arten poliotis und satelles beschrieben worden.

$\hat{\jmath}, \hat{\partial}, \hat{o}$ juv. Oubatche, Io. Mai, I6. Juli, 24. Mai IgII.

ㅇ, $q$, $q$ Oubatche, I4. Mai, 8. und I8. Juli I9r.

ad. (sex. ?) Oubatche, 20. März igi i.

Maasse (Mittelzahlen der 7 caledonischen Exemplare): Long. tot. ca. I37 (127-146), ala 66,5 (6I,5-72), cauda $60(54-66)$, culmen 16,6 (I5-19,5).

Gadow, 20, p. 216, gibt für incana von Caledonien, Männchen und Weibchen: ala 77 und 71 , cauda 64 und 59 , culmen $18-20$ und 17.

Gray, 22, p. I60, für seine modesta: Long. tot. I40, ala 76.

ô Netché, Maré, 24. November rgII.

2 ad. (sex. ?) Netché, Maré, I9. und 22. November IgII.

o Quépénéé, Lifou, 7. Mai ı 9 ıз.

đ Fayaoué, Ouvéa, I5. Mai I912.

3 ad. (sex. ?) Fayaoué, Ouvéa, I2. und I3. Mai I912.

Maasse der Loyalty-Vögel (Mittelzahlen der 8 Exemplare): Long. tot. ca. I45 (I42-I5I), ala $70(69-72)$, cauda $63(60-66)$, culmen I8,6 (I8-I9,5). Die Zahlen sind (vielleicht zufällig) um eine Kleinigkeit grösser als die der caledonischen Vögel.

Gadow, 20, p. 2I7, gibt für seine poliotis von den Loyalty's: ala 66, cauda 59, culmen I7-Ig.

Tristram, 77, p. 185, für satelles von Lifou: Long. tot. I36, ala 64, cauda 56. Es ergeben alle diese Maasse eine ziemlich grosse Schwankungsbreite der Körperdimensionen.

Nest: Maré, 20. November I9II. Das Nest bildet einen Beutel, aufgehängt an zwei gabelförmig sich kreuzenden Ästchen, einem stärkeren und einem schwächeren, 
gebaut aus Gras und anderem Faserwerk, Blättern, Baumwolle und Federn, ca. $9 \mathrm{~cm}$ lang, innen am Grunde austapeziert mit weisser Baumwolle.

\section{Gen. Philemon Vieillot.}

Verbreitung (Ph. + Tropidorhychus): Molukken, Kleine Sunda-Inseln, NeuGuinea und umgebende Papuasische Inseln, Australien, Salomonen, Loyalty-Inseln, NeuCaledonien.

46. "Philemon lessoni (Gray).

Tropidorlinuchus lessoni, G. R. Gray, 22, p. I6I.

Verbreitung: Überaus häufig in ganz Neu-Caledonien, seltener auf Maré und Lifou (vergl. auch Layards, 37, p. 224).

$$
\begin{aligned}
& \hat{o}, \hat{o}, \hat{o}, \hat{o}, \hat{o} \text { juv. Oubatche, März bis Mai IgI I. } \\
& q, q j u v ., q \text { juv. Oubatche, März bis Mai IgII. } \\
& \text { o Yaté, I6. März I9I I. } \\
& \text { o Netché, Maré, 7. Dezember igir. } \\
& \text { q juv. Quépénéé, Lifou, 3. Mai rgrz. }
\end{aligned}
$$

Gen. Leptomyza Stejneger.

(Leptomis Hombr. und Jacq.).

Verbreitung: Samoa, Fidji, Neu-Caledonien.

47. ${ }^{*}$ Leptomyza aubryana (Verreaux u. Des Murs).

Leptornis aubrams, Verreaux und Des Murs, 79, p. 432.

Verbreitung: Neu-Caledonien, Waldbewohner der ganzen Insel, vornehmlich in den Bergwäldern, aber auch in tieferen Lagen.

ô juv. Ngoi-Tal am Humboldt, ca. 200 m., 20. September IgII.

q Wald oberhalb Oubatche, 20. Mai IgII.

Maasse, ơ u. $q$ : Ala I56 u. I57, cauda i6g u. I64, culmen $3^{8}$ u. 40.

Am frisch geschossenen Weibchen wurde notiert: Nackte Haut um das Auge blass orange, nach hinten zu und an der Ohrfalte tiefer orange, Oberschnabel schwarz, Unterschnabel mit gelber Wurzel und blaugrauer Spitze, Beine gelblich grau. Die Orangefarbe der nackten Haut blieb auch am getrockneten Balge erhalten, während bei unserem männlichen Vogel am Balg diese Stelle hellgelb erscheint; der Unterschnabel ist bei diesem letzteren Exemplar in viel grösserer Ausdehnung hell gefärbt als beim anderen. Auch sonst zeigen die beiden Exemplare allerlei Unterschiede. Das Weibchen ist etwas dunkler braun gefärbt, namentlich an den Flügeln und Flügeldecken, die bei 
unserem männlichen Vogel einen wesentlich helleren Ton haben als der Rücken. Endlich, und das ist der Hauptunterschied, hat der weibliche Vogel hinter der Ohrfalte einen Busch dunkelbrauner Federn, während diese beim anderen leuchtend hellgelb sind, gegen die Wurzel zu gelbbraun und zu unterst schwärzlichbraun werdend. Auf Taf. I, Fig. 5 und 6, sind die beiden Köpfe zur Darstellung gebracht worden. Die Unterschiede sind so auffallend, dass ich längere Zeit an die Möglichkeit der Existenz zweier verschiedener Arten glaubte, zumal die Fundstellen der beiden Exemplare weit voneinander entfernt liegen. In der Literatur finden sich abwechselnd dunkle und hellgelbe Ohrdecken erwähnt. Das Bild bei Brenchley, 7, Taf. VI, auf welchem, nebenbei gesagt, die nackte Haut viel zu rot gemalt ist, zeigt einen dunkelbraunen Ohrbusch; Schalow, 62, p. 247, beschreibt die Ohrgegend als matt rotbräunlich gefärbt; Verreaux und Des Murs, 79, p. 432, sagen, hinter dem Ohr befinde sich ein hellrötlicher Fleck; in Gadow's Katalog des Britischen Museums, 20, p. 267, wird angegeben, eines der beiden Exemplare habe einige wenige blassgelbe Federn am

unteren und hinteren Rand der Ohröffnung. Die Layard's, 39, p. r33, sagen von einem Exemplar, es scheine ein gelber Ohrbusch vorhanden zu sein und an anderer Stelle, 4I, p. 507, von einem Weibchen, seine Ohrdecken seien leicht mit gelben Haaren markiert gewesen.

Eine Vergleichung der Pariser Materialien zeigte mir, dass es sich weder um zwei verschiedene Arten, eine mit gelben, und eine mit dunkelbraunen Ohrdecken, noch um eine Geschlechtsdifferenz handelt, sondern bloss um Altersunterschiede. Namentlich lehrreich erwies sich das typische Exemplar von Verreaux und Des Murs. Dieses besitzt nämlich dunkelbraune Ohrdecken und darunter versteckt noch einige goldgelbe Federchen, die mit den Spitzen hervorschauen. Zwei andere Exemplare zeigten dunkle Ohrdecken, aber einzelne Federchen hatten noch kurze helle Spitzchen. Bei unserem Exemplar färben sich die gelben Federn, wie schon gesagt, gegen die Basis zu dunkel. Es ist also ohne Zweifel der so auffallende, gelbe Ohrbusch als ein Jugendmerkmal aufzufassen, welches allmählig verschwindet, ebenso wie die heller braune Färbung der Flügel, die hellgelbe Farbe der nackten Haut an den Kopfseiten und anderes mehr.

\section{Timeliidae.}

\section{*Gen. Megalurulus Verreaux.}

Verbreitung: Neu-Caledonien.

48. *Megalurulus mariei Verreaux.

Megalumbus mariac (Druckfehler für mariei), Verreaux, 8o. Seine farbige Abbildung, Taf. I, Fig. 2, ist nicht sehr gut, weil zu hell rostrot. 
Verbreitung: Neu-Caledonien, die ganze Insel bewohnend, aber nicht häufig. Die Layards, fI, p. 5 II, konstatierten ihn an der Westkưste, unsere Exemplare stammen von der Ostkuiste.

\section{8 (?) Hienghiène, 6. Juni I9II. \\ q (?) Hienghiène, 6. Juni I9II. \\ of Oubatche, 3. April I9II.}

Grösse und Färbung sind etwas variabel. Die Maasse zeigen folgende Schwankungen: Long. tot. I72-I95, ala 62-67,5, cauda 90-93, culmen I2-I4,5. Das typische Exemplar in Paris hat L. t. ca. I70, a.68, c. 85, culm. If. Die Färbung variiert insofern, als der rostrote Ton der Oberseite verschieden stark prononziert ist; die Kehle, beim Erwachsenen reinweiss, zeigt beim Exemplar von Oubatche, welches noch jung sein dürfte, dunkle Fleckchen und einen leicht gelblichen Ton; das Rostrot der Oberbrust kann ein deutliches Band bilden oder sich auf je einen seitlichen Fleck beschränken; die Flanken sind bald mehr rostrot, bald dunkel graubraun.

\section{Turdidae.}

\section{Gen. Merula Leach.}

Verbreitung: Europa, Afrika, Asien, Indoaustralischer Archipel und Philippinen, Sta. Cruz-Inseln, Neu-Hebriden, Fidji, Samoa, Loyalty's, Neu-Caledonien, Lord Howe. Insel, Norfolk-Insel, Süd- und Zentral-Amerika. (Nach Sharpe, 75, IV, p. II 7 ff.)

\section{9. ${ }^{*}$ Merula xanthopus (Forst.).}

Verbreitung: Neu-Caledonien, nach den Layards, fI, p. 509, über die ganze Insel verbreitet. Im Norden ist sie jedenfalls selten, denn wir haben sie nicht erhalten.

Die Layards geben folgende Maasse: Long. tot. 235, ala I I5, cauda 9I, rostr. 29. Seebohm, 65, p. 277, gibt: ala ro8-ir4, cauda 80-86, culmen 19-27.

Drei männliche Exemplare, die ich in Paris maass, schwankten in der Flügellänge von Io8,5-II6, Schwanz 84-94, culmen 20-2I.

50. ${ }^{*}$ Merula mareensis (Layard u. Tristram).

Verbreitung: Maré, Loyalty's. Die Angabe "Neu-Hebriden“ ist noch unsicher.

50a. "Merula mareensis typica (Layard u. Tristram).

Turdus morensis, Layard und Tristram, 4t.

Verbreitung: Maré, Loyalty-Inseln.

Diese Art ist nach Layard und Tristram, 44, p. 472 , leicht kenntlich an einem Fleck weisser und rotbrauner Federn auf der Bauchmitte, welche Farben sich auch auf 
die unteren Schwanzdecken erstrecken, weiter an den sehr hellen Schåften der Schwanzfedern. Diese Merkmale unterscheiden nach den genannten Autoren die Art von 1\%. inicornsis (Q. U. G.). Seebohm, 65, p. 250, bezeichnet die Bauchmitte als fast weiss, die unteren Schwanzdecken als braun mit blass kastanienbraunen Spitzen und Schäften. Herr W. R. Ogilvie Grant schreibt mir über die Maré-Amsel das folgende: Das erwachsene Männchen unterscheidet sich vom Männchen der $M$. samocnsis durch die mehr russschwarze oder braunschwarze Farbe der Oberseite, die viel braunschwärzere Farbe der Brust usw. und durch die weissen Federenden unten am Bauche und an den unteren Schwanzdecken.

Ich habe nur ein junges Exemplar erhalten, im Kileid des ersten Jahres, Netché, Maré, 7. Dezember rgi . Es mögen einige Angaben über das noch nie beschriebene Jugendkleid folgen: Oberseite dunkel schwarzbraun, einige Flügeldeckfedern mit rotbraunen Spitzchen, Ohrgegend mit Rostrot gefleckt, Kinn und Kehle mit einem mittleren, rötlichweissen Längsstreif, eingefasst von je einem schwarzen, übrige Unterseite mit rostroten, an den Enden breit schwarzgefleckten Federn. Auf der Bauchmitte geht dieses Rostrot in Weiss über, einen deutlichen hellen Fleck bildend; Schnabel und Beine hellbraun.

Maasse der M. marensis nach Layard und Tristram, 1. c.: Long. tot. I84, ala ro2, cauda 76, rostr. 29. Seebohm, 65, p. 250, gibt für ein Männchen und ein Weibchen: ala Ioz und 95, cauda 76 und 66.

5ob. "Merula mareensis larochensis nov. Subsp.

Verbreitung: Maré, Loyalty's.

3 Lat Roche, Maré, 2. Dezember IgII.

Bei La Roche an der Ostseite des kleinen Kalkinselchens Maré erhielt ich ein Exemplar einer Amsel, das sich von der typischen marecnsis durch das Fehlen des hellen Bauchflecks unterscheidet, den wir als für diese letztere Form charakteristisch ansehen müssen.

Die Oberseite ist, wie bei marensis tyf., dunkel schwarzbraun, Kopf um em kleines dunkler als der Rücken, Schwanzfedern etwas heller braun als Rücken und Schwanzdecken, mit dunkelbraunen, unterseits rötlichen Schäften, Schwungfedern etwas heller als die Flügeldecken und mit Hellbraun gesäumt; 2. Primärfeder sehr wenig länger als die 6.; 3. 4. und 5. am längsten. Unterseite heller braun als die Oberseite; Kinn, Kehle, Halsseiten und Oberbrust rötlichbraun, die Federränder etwas heller; Brust, Bauch und untere Schwanzdecken einfärbig braun, Schäfte der unteren Schwanzdecken gleich gefärbt wie die Feder, Mittelspitzen der unteren Schwanzdecken etwa I mm weit hell bräunlichweiss gefärbt; Schnabel und Haut um das Auge leuchtend hell goldgelb, Spitze etwas dunkler, Beine blasser hellgelb als der Schnabel.

Ma asse: Long. tot. c. 195 , ala 103 , cauda 83 , tarsus 33.5, culmen I8. Die Maasse sind denen von .1\%. mareensis typica nicht unähnlich, aber die Färbung von Bauch und 
unteren Schwanzdecken scheint es mir ratsam zu machen, von einer Vereinigung mit dieser Form abzusehen, obschon vielleicht die Vermutung des Herrn Ogilvie Grant das Richtige treffen könnte, nach welcher es sich um einen sehr alten V'ogel handeln würde, welcher das Weiss am Bauch und an den unteren Schwanzdecken bis auf die feinen hellen Spitzen verloren hätte.

- Von ifcmla samocnsis Tristram, 77, p. 188, unterscheidet sich der Vogel durch dieselben oben bei marccusis tyt. aufgezählten Merkmale, sowie durch die feinen, hellen Spitzen der unteren Schwanzdecken. Ein Exemplar von stmocnsis, das ich im Pariser Museum verglich, hatte Kehle und Brust von einer reicher rotbraunen Farbe und den Schnabel weniger leuchtend gelb als unser Stück. Der Typus von 1\%. íaniorcnsis Q. u. G., der sich auch in Paris befindet, steht ihm ebenfalls nahe; es ist ein Weibchen von sehr hellhrauner Farbe, dessen untere Schwanzdecken weisse Spitzen von viel grösserer Ausdehnung haben als bei lurochensis. Hierher in die Nähe gehört wohl auch die von Sharpe, 74, p. 347, als . M. mrensis bezeichnete Amsel von Mallicollo und Santo (Neu-Hebriden). Eine gründliche Revision der pazifischen Amseln wäre sehr erwünscht. Es handelt sich wohl vielfach um Lokalformen einer und derselben Spezies.

5I. Merula pritzbueri (E. L. U. E. L. C. Layard).

Turdus fritobucri, E. L. u. E. L. C. L.ayard, 35, p. 254; siehe auch Layard, 30; Abbildung bei Tristram, 77, Taf. V.

Verbreitung: Lifou, Loyalty-Inseln. Dieselbe Art oder nahe Verwandte auf den Hebriden.

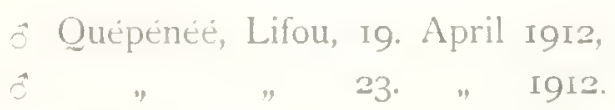

Diese schöne, isabellköpfige Amsel ist auf Lifou nicht selten; namentlich bei Regenwetter sieht man sie öfters auf den Wegen.

Maasse (Mittel der 2 Männchen): Long, tot. c. 195, ala 99,5, cauda 80, culmen 17,25.

La yards, 35, p. 254, geben für ein Männchen: L.t. 203, a. 91, c. 82; an anderer Stelle, 37, p. 226: Gesamtlänge im Fleisch 222.

Die Insel Ouvéa hat höchst wahrscheinlich auch ihre Amsel. Ich glaube sie gesehen zu haben, erhielt sie aber nicht.

\section{Ploceidae.}

\section{Gen. Erythrura Swains.}

Verbreitung: Südliches Hinterindien, Java, Sumatra, Borneo, Timor, Tenimber, Ternate, Batchian, Halmahera, Carolinen, Palaus, Neu-Guinea, Salomonen, Neu-Hebriden, Fidii, Samoa, Loyalty's, Neu-Caledonien (nach Sharpe, 75, I, P. $448 \mathrm{ff}$. und 7o p. 380.) 


\title{
52. *Erythrura psittacea (Gm.).
}

Verbreitung: Neu-Caledonien, ganze Insel; frisst Grassamen und nach den Layards, 4I, p. 522, auch Casuarinasamen. Über die Seltenheit Grassamen fressender Vögel in Neu-Caledonien und die daraus sich ergebenden Schlüsse. vergleiche man p. 3 .

\author{
Oubatche, I5. Mai I9II. \\ Hienghiène, 6. Juni Igr I. \\ und \& Canala 20. und 28. Okt. I9II.
}

Layards, 4I, p. 522, beobachteten Nestbau im April, August, Oktober und November; wir sahen Nester und Junge im Oktober und Januar; die Vögel scheinen somit das ganze Jahr hindurch zu brüten. Dieselben Autoren beschreiben das Nest als eine grosse, lose, domförmige Masse, aus Gras und weichen Materialien gebaut. In Canala brüteten die Vögel auf Balken und in Nischen von Schuppen, so bei uns in den unbewohnten, offenen Erdgeschossräumen unseres Hauses, zusammen mit Collocalien. Die Nester waren hier grosse, wie Sperlingsnester aussehende, aus Stroh, Bambusblättern und Collocaliafedern lose zusammengefügte, rundliche oder ovale Massen, nicht domfürmig, sondern mit einer oben offenen und mit Hühnerfedern ausgefütterten Delle versehen. Die Vögel scheinen sich also in ihrem Nestbau den Umständen anzupassen. Das domförmige Nest mit Flugloch, wie es bei vielen Verwandten vorkommt, dürfte das typische sein. Junge erhielten wir am 29. Oktober und Io. Januar.

Die Nestjungen von Erythrura zeichnen sich durch höchst eigentümliche Bildungen am Schnabelrande aus. Jederseits erscheinen am Schnabelwinkel zwei hell himmelblaue, wie Perlmutter glänzende Perlen (siehe das Profilbild eines Nestlings, Taf. I, Fig. 8). Der Schnabelrand verbreitert sich gegen den Winkel zu wulstartig und bildet, namentlich am Unterschnabel, ein seitlich frei vorspringendes Läppchen oder Flügelchen von etwa $I^{1 / 2} \mathrm{~mm}$ Breite. Die Perle des Oberschnabels sitzt beinahe am Winkel selbst, die des Unterschnabels etwas weiter nach vorne gerückt, am Vorderrand des erwähnten Flügelchens. Die Form der Perlen ist eine rundlich ovale; ihr grösster Durchmesser, in der Längsrichtung des Schnabels gelegen, beträgt reichlich $I^{1 / 2} \mathrm{~mm}$ (zuweilen bis gegen $2 \mathrm{~mm}$ ), der quere etwas weniger, die Höhe reichlich I mm. Die Basis der Perle ist von einem schwarzen Pigmentring, dessen Breite etwas variiert, umgeben. Ihre blaue Farbe erhält sich auch an in Spiritus konservierten Exemplaren, sogar an solchen, die mit Chromsäure behandelt worden sind.

Die Perlen bleiben während des ganzen Nestlebens bestehen; selbst vollständig befiederte Junge zeigen sie noch wohl entwickelt; beim erwachsenen Vogel sind sie dagegen verschwunden.

Die Nestjungen bieten, namentlich bei geöffnetem Schnabel, mit ihren blauen Perlen einen höchst grotesken Anblick (Taf. I, Fig. 7). Man erkennt an diesem Bilde die wulstförmige Erweiterung des Schnabels gegen den Winkel zu und sehr deutlich das kleine Flügelchen des Unterschnabels, an dessen Vorderrand die Unterschnabelperle 
sitzt. Hierzu die auffallende Färbung dieser Teile, sowie des Rachens und der Zunge, die ich im Leben als "orangerot" notierte; der übrige Schnabel ist schwarz mit heller Spitze. Der Oberschnabel zeigt innen drei blauschwarze, runde Pigmentflecke; zwei kleinere sitzen hinten am Gaumen, zwei auf der Zunge nahe ihrer Wurzel, zwei ganz kleine hinten an der Innenseite des Unterschnabelwulstes (diese letzteren fehlen öfters).

Es ist selbstverständlich, dass die glänzenden blauen Perlen sofort an Leuchtorgane denken lassen (siehe unten bei der Literaturbesprechung); allein es sind keine selbstleuchtenden Gebilde; in absoluter Finsternis sind sie unsichtbar und phosphoreszieren nicht; erst wenn Licht einfällt, erglänzen sie; es sind, wie ich sie nennen möchte, „Reflexionsperlen", welche imstande sind, im Halbdunkel einfallendes Licht zu sammeln und zu reflektieren. Über ihre Bedeutung siehe unten.

Der histologische Bau der Reflexionsperlen ist einfach. Nebenstehende Figur + zeigt einen senkrechten Schnitt durch das genannte Organ des Oberschnabels; darunter erkennt man das Flügelchen (fl.) des Unterschnabels, welches weiter nach vorne zu den Unterschnabelreflektor tragen wird. Die halbkugelige Perle besteht aus Bindegewebe, welches deutlich zwei Schichten erkennen lässt. Eine oberflächliche (ob) ist aus dicht nebeneinander geschichteten, starken Fasern aufgebaut, welche der Tuberkelwölbung parallel laufen, wobei, namentlich auf Flachschnitten, mehrere sich kreuzende Systeme erkenubar sind. Diese stark lichtbrechende Schicht nimmt ron den Seiten gegen die Mitte an Dicke zu und bildet somit eine Art Mütze über der weit mächtigeren, tieferen Schichte (ub). Diese stellt eine lockere Gewebsmasse dar, aus unregelmässig sich kreu.

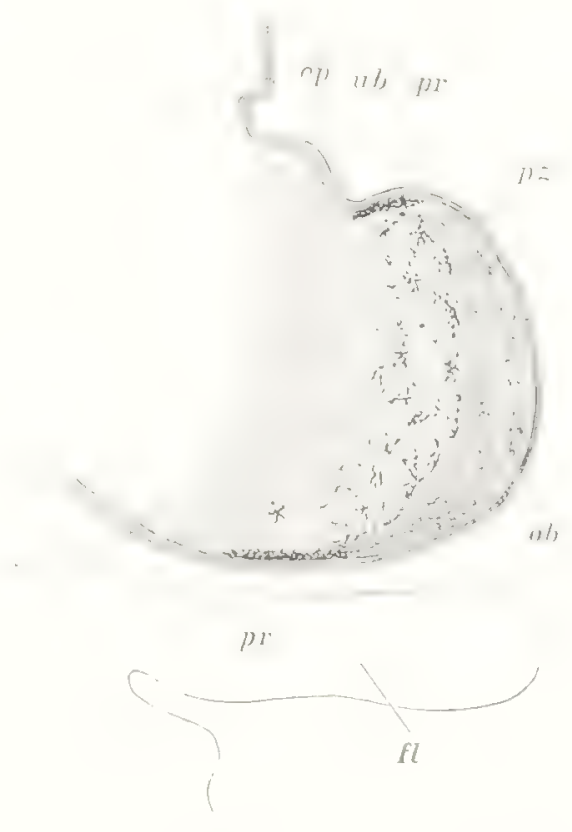

IFig. 4 .

Querschnitt durch eine Reflexionsperle. ca. to fache Vergrösserung. zenden Fasern aufgebaut, mit einigen Nerven und Blutgefüssen. Die oberflächliche, dichte Lage enthält kein Pigment. Sternfürmige Pigmentzellen (pz) treten vielmehr erst an der Grenze der beiden Bindegewebsschichten auf und im oberen Teil der lockeren Bindegewebszone; sie sind im Innern des Tuberkels ziemlich locker gestellt, bilden aber doch, wie auf Flachschnitten leicht zu sehen ist, in ihrer Gesamtheit cine zusammenhängende, schwarze Lage. Ferner bildet das l'igment in dichter Anhäufung einen Ring unmittelbar unter der Epidermis um die Basis des ganzen Organs herum. Die Breite dieses Pigmentrings (pr) variiert, wie schon gesagt, etwas. Im IBereich der blauen l'erle ist die Epidermis (ep) stark verdünt; sie trïgt cine durchsichtige Ilornlage. 
Die blaue, wie Perlmutter glänzende Farbe der Reflexionsperlen beruht nicht etwa auf der Anwesenheit eines blauen Farbstoffes, , sondern rein auf physika. lischen Vorgängen. Das Blau entsteht offenbar durch das trübe Medium der dichten Bindegewebskuppe vor der schwarzen Pigmentschicht, ganz so, wie das bei auffallendem Lichte leuchtende Blau der Seeigelaugen durch die trübe Füllung schwarzer Pigmentbecher zustande kommt, während dieselben Augenflecke bei durchfallendem Lichte getblich erscheinen (vgl, P. und F. Sarasin, die Augen und das Integument der Diadematiden, Ergebnisse naturwissenschaftlicher Forschungen auf Ceylon, H.1. 1, 1. 01.

Die Züchter von Prachtfinlien sind schon mehrfach auf die blauen Perlen am Schnabelwinkel der Nestjungen aufmerksam geworden. Butler, Io, dessen Arbeit mir leider nicht zugänglich war, dürfte der erste gewesen sein, der sie namhaft gemacht hat und zwar bei dem australischen Ploceiden, Poëthila gouldiae (Gould). Rey, 56, erwähnt sie von jungen afrikanischen (z. B. Lagonosticta mimima Cab.), indischen und australischen Prachtfinken; bei den meisten Arten seien es jederseits drei, selten nur zwei; bei manchen seien sie alle rein weiss (?), bei anderen eine oder zwei blau, aber immer porzellanglänzend und in Grösse zwischen einem Mohn- und einem kleinen Hirsekorn schwankend. Brandes, 6, und Andere erwähnen die Perlen von Poëphila mirabitis Hombr. u. Jacq.; Brandes beschreibt sie als prächtig blauglänzend und schwarz umgrenzt, je zu zweien an den Schnabelrändern gelegen, also genau wie bei unserer Erythrura; auch seine photographische Abbildung zeigt ganz entsprechende Verhältnisse. Charruaud, 12, ein sehr erfolgreicher Vogelzüchter, sah die blauen Perlen und zwar stets zwei jederseits, ausser bei Pö̈hila mirabilis und gouldiue, auch bei unserer Erythrura und bei - tmatim (Lagonostita) larata (Rüpp.). Die meisten Autoren geben an, bei flüggen Jungen seien diese Tuberkel verschwunden oder wenig mehr sichtbar, so Knauer, 29 und Lewek, 46; bei unserer Erythrur hat ein völlig befiederter Nestling sie noch ebensogut ausgebildet als die jüngeren. Ausserhalb der Familie der Ploceiden scheinen bisher diese Organe nicht zur Beobachtung gekommen zu sein.

Lewek, ł6, p. I69, beobachtete, dass die blauen Papillen junger Goulds-Amadinen, ins Halbdunkel gebracht, noch schöner leuchteten als im vollen Tageslicht; als er das Nest so weit verdunkèlte, dass er die drei Jungen nicht mehr von ihrer Unterlage unterscheiden konnte, erschienen die Wärzchen wie kleine Glühlämpchen. Er neigt aber doch zur Ansicht, dass es nicht selber Licht produzierende Organe seien, sondern solche, die imstande seien, das zerstreute Licht, das in das Nest komme, zu sammeln und in verstärktem Maasse zu reflektieren. Auch Rey, 56, lässt nach dem Referat von Böttger diese Frage offen, ebenso G. Brandes, 6, der aber nach seinen histologischen Befunden (siehe unten) bemerkt, es sei an eigene Lichtproduktion kaum zu denken. Knauer, 29, macht auf die Widersprüche der Züchter, das Leuchten betreffend, aufmerksam und sagt, es sei bloss eine durch Strahlenreflexion verursachte 
Lichterscheinung, kein selbständiges Phosphoreszieren; er zieht den hübschen Vergleich mit dem Leuchten des Leuchtmooses. Chun, I3, hat dann zuerst experimentell die Frage des Selbstleuchtens negativ entschieden. Er beobachtete in der geschlossenen Dunkelkammer keine Spur von Leuchten; sobald aber etwas Licht durch einen schmalen Spalt eindrang, erschien der charakteristische Reflex. Chu n erinnert an das "Glühen" der Augen von Sphingiden und Tiefseekrustern im Halbdunkel.

Histologische Untersuchungen der Reflexionsperlen verdanken wir Brandes und Chun. Der erstere beschreibt die Tuberkel als eine enorme Cutisverdickung, die teilweise von einem Mantel schwarzen Pigmentes umgeben sei; unmittelbar unter der Epidermis seien die Bindegewebsfasern zu einem dichten Stratum angeordnet, unter welchem sich isolierte Pigmentzellen fänden. Chun, I3, p. 63, sagt, die blauen, halblugelig sich vorwölbenden Tuberkel seien an ihrer Basis von einem schwarzen Pigmentring umgeben; dieses Pigment liege dicht der Epidermis an, welche im Bereich der ge. wölbten Tuberkel auffällig dünner werde, so wie ich es auch gefunden habe. Das Bindegewebspolster lasse eine Scheidung in zwei Lagen erkennen, oberflächlich eine Lage konzentrisch geschichteter, breiter Bindegewebsbalken, welche nach der Mitte zu an Dicke zunehme und sich wie eine Linse hinter die Epidermis einschiebe. Statt "konzentrisch geschichtet" ist es richtiger" zu sagen "der 'luberkeloberfläche parallel", denn bei jeder Schnittrichtung erscheinen sie in dieser IV eise verlaufend. Unter dieser dicht geschichteten Lage folgt nach Chun ein dickes Polster wirr sich kreuzender. feiner Bindegewebsfibrilen mit Blutkapillaren und einigen wenigen Nervenästen. Weiter erwähnt Chun die zwischen den beiden Lagen auftretenden, verästelten Pigmentzellen, welche zusammen eine Art Tapetum bilden. Der Bau der von Brandes und ron Chun untersuchten Organe stimmt also in allen wesentlichen Punkten genau mit dem bei Erythrura überein.

Was die Funktion der Reflexionsperlen angeht, so sind die Autoren darin einig, dass diese glänzenden Tuberkel, ebenso wie die grelle Färbung der Schnäbel vieler Nestjungen und die dunklen Flecke im Innern des hellgefärbten Rachens und auf der Zunge (vgl. hierfür z. B. Colling wood Ingram, 26 und Butler, sol, den ätzenden Eltern das Auffinden des Schnabels der Jungen erleichtern sollen, also Leitmale für die Fütterung darstellen. Nur Butterfield, II, p. 534, vertritt, soviel ich sehe, die Ansicht, das Aufsperren des buntgefärbten Rachens mit seinen auffallenden Flecken sei ein Schreckmittel; Kinder 2. B. hätten Angst daror. Es scheint mir nicht undenkbar, dass beide Zwecke, Erleichterung der Fütterung und Abwehr von Feinden, zugleich erreicht werden könnten, wonach z. B. ins Nest eindringende Schädlinge, wie Mäuse oder Schlangen, durch den bizarren Anblick (vgl, Taf. I, Fig. 7) in Angst versetzt werden dürften. Für Fütterungszwecke allein scheint mir eine liombination von Reflexionsperlen, greller Schnabelfarbe und dunkler Flecke im Schnabelinnern, wie sie unsere Emthmra zeigt, beinahe aber das zu erreichende Ziel hinauszuschiessen. 
53. Erythrura cyaneifrons E. L. u. E. L. C. Layard.

Layards, 35, p. 260; siehe auch Layard, 30, p. 375.

Verbreitung: Lifou, Loyalty-Inseln und Neu-Hebriden, Tanna (Layards, 37, p. 230), Efate und Ambrym (Sharpe, 74, p. 347).

Ich habe die Art auf Lifou gesehen, aber nicht erhalten. Von Maré und Ouvéa ist einstweilen noch keine Erythrura bekannt.

\section{Sturnidae.}

\section{Gen. Aplonis Gould.}

Verbreitung: Tenimber, Neu-Guinea, Papuasische Inseln, Palaus, Mariannen, Carolinen, Salomonen, Neu-Hebriden, Fidji, Tonga, Samoa, Savage Ins, Rarotonga, Gesellschaftsinseln (?), Neu-Seeland (?), Norfolk Ins., Lord Howe Ins., Neu-Caledonien, Loyalty's (nach Sharpe, 75, V, p. 526).

\section{4. *Aplonis caledonica Bp.}

Der historisch ältere Name, strinto (Gm.), ist, weil völlig sinnlos, zu streichen, vgl. Sharpe, 70, p. 127, welcher trotzdem striuta beizubehalten vorschlägt. Das Tier hat schon eine ganze Reihe von Namen erhalten, woran teilweise die abweichende Färbung der Weibchen und jungen Vögel schuld ist. So ist A. riridigrised Gray, 22, p. I64, das Weibchen oder das Männchen im Jugendkleid von A. caledonica. Man vergleiche für die Synonymie Layards, 37, p. 229, 4I, p. 5I9, Schalow, 62, p. 246, Oustalet, 53, p. 220 und Andere.

Verbreitung: Neu-Caledonien, ganze Insel, Die Angabe der Layards, 37, p. 229, A. calidonica komme, wenn auch selten, auf Lifou vor neben atronitens, bezieht sich sicherlich auf die unten zu beschreibende kleine Varietät von atronitcns.

đo Oubatche, 2I. April I9Ir.

ㅇ Oubatche, 2I. April I9II.

Die Unterseite des Weibchens ist grau, mit olivenbräunlich übergossen.

Maasse: of Long. tot. ca. 192, ala Ior, cauda 7I, culmen I5. $_{5}$

ㅇ " " 192, " 97, " $65, \quad$, 15 .

Sharpe, 7o, p. 128, gibt:

of Long. tot. I9I, ala I04, cauda 67, culmen I6.

ㅇ " $" 182$, " $102, \quad$ " 64, " 16 .

Layards, 41, p. 520: 203, " 102, , 76 .

\section{Aplonis atronitens Gray.}

Verbreitung: Loyalty-Inseln. 


\section{5a. Aplonis atronitens typica Gray.}

G. R. Gray, 22, p. I64.

Verbreitung: Lifou, Maré (Layards, 37, p. 229); wir fanden die Art auch auf Ouvéa, sie bewohnt also alle drei Loyalty-Inseln.

$$
\begin{aligned}
& \hat{\jmath}, \hat{\jmath}, \hat{o} \text { Netché, Maré, I8. und I9. November I9ri. } \\
& \text { ô juv. Quépénéé, Lifou, 3. Mai I9r2. } \\
& \text { q Nathalo, Lifou, 29. April I9r2. } \\
& \text { o Fayaoué, Ouvéa, I3. Mai I9I2. }
\end{aligned}
$$

Ma asse: Mittelzahlen von 4 o : Long. tot. ca. 203,5 (201-208), ala 107,5 (103-110), cauda $70(69-71)$, culm. I9,75 (18,5-21). Ein + misst: Long. tot. ca. I92, ala 104, cauda 65; Gray gibt, 22, p. I64: Long. tot. 209, ala Io8, Sharpe, 70, p. J28: Long. tot. 203, ala II5. cauda 63, culm. I7. Die Layards, 37, p. 229, haben sogar als Gesamtlänge 229.

1. atronitens ist also merklich grösser als 4 . calidonica, hat längere Flügel und einen längeren Schnabel. Das Männchen ist ähnlich, aber reicher gefärbt und ist sofort von dem von caledonica daran zu unterscheiden, dass die Schwanzfedern oben braun und nicht schwarzgrün gefärbt sind; sie sind auch auf der Unterseite heller; auch die Schwungfedern sind heller und reiner braun. Abweichender von calidonica ist das Weibchen; seine Oberseite, Rücken usw., ist braun, nicht schiefergrau, die Flügel brauner, Sekundärschwingen und Flügeldecken uniform braun, ohne aschgraue Ränder, Unterseite olivenbraun, nicht wie bei caledonica grau und bloss mit olivenbräunlich übergossen. Bei beiden Arten gleichen junge Männchen den Weibchen.

\section{5b. ${ }^{*}$ Aplonis atronitens minor nov. Subsp.}

Verbreitung: Lifou und Ouvéa, Loyalty-Inseln.

$$
\begin{aligned}
& \text { o juv. Quépénéé, Lifou, 24. April t9i2. } \\
& \text { ô, ô Fayaoué, Ouvéa, I3. Mai I9r2. } \\
& \text { q Fayaoué, Ouvéa, I5. Mai I912. }
\end{aligned}
$$

Masse, Mittel der 3 ô:

Long.tot.ca. I 77 (I 75-I79), ala Io7 (106,5-Io8), cauda $65(62-67)$, culmen $18,2(18-18,5)$ ㅇ " " I7I " $99 \quad$ "60 69

Diese Varietät ist also wesentlich kleiner als die typische atronitus; der Schnabel ist stark, namentlich der Oberschnabel sehr hoch. In der Färbung schliesst sie sich an atronitens und nicht an caledomica an, indem Schwanz und Flügel dieselbe braune Farbe haben wie bei der ersteren Art (siehe oben); beim ô geht der Kragen von Federn mit grüner, metallischer Mittelspitze weiter auf den Rücken hinunter, und die ganze Oberseite ist metallischer; das Letztcre gilt auch fur das $q$, bei welchem die Federn des Rückens grünschillernde Säume besitzen. 


\section{Colvidae. \\ *Gen. Physocorax Bp.}

Verbreitung: Neu-Caledonien.

\section{Physocorax moneduloides (Less.)}

Verbreitung: Neu-Caledonien, ganze Insel, hăufig; er geht bis hoch in die Bergwälder hinauf, ich habe ein Pärchen noch bei rooo m Höhe beobachtet; sein Geschrei erinnert an das Bellen junger Hunde. Im Magen fanden sich Früchte und Heuschreckenreste. Nach den Layards, 4I, p. 520, welche höchst interessante biologische Mitteilungen über den Vogel machen, frisst er auch die auf Bäumen ausgesetzten Leichen der Eingeborenen. Dieser Bestattungsmodus ist übrigens heutzutage fast oder ganz verschwunden.

ô Wald oberhalb Oubatche bei $700 \mathrm{~m}$, I8. April igri.

ô Oubatche, I6. Mai 19II.

o Oubatche, I6. Mai rgir.

juv. Oubatche, 20. April IgII.

Häufig beobachtet in der Gegend von Coné an der Westküste und bei Yaté im Süden. Maasse, Mittel der 20 :

Long.tot.ca. $430(420-4+40)$, ala $247,5(2+5-250)$, cauda I97,5(195-200), culmen $44(43-45)$ \& " " t " 240 " 180 " 4I

Das $q$ ist also etwas kleiner als das $\hat{\sigma}$, aber nicht um einen Dritteil, wie Verreaux und Des Murs, 79, p. 432, angeben. Die Layards, 4I, p. 52I, haben kleinere Maasse als die meinen; sie geben für ein $0^{\hat{~}}$ : Long. tot. ca. 38I, ala 242, cauda I78, culmen 44; das q sei gewöhnlich kleiner. Die Layard'schen Exemplare stammen jedenfalls von der Westseite der Insel; ihre kleineren Maasse widersprechen daher ihrer Mitteilung, 3I, p. 338, dass nach Aussage Bekannter die Krähen der Westküste viel grösser seien als die der Ostküste.

Es ist wohl kaum nötig zu bemerken, dass die in caledonischen Vogellisten gelegentlich auftauchenden Corriden, wie Gasola typica Bp., Coraus corone Wagl., Corans coronoide's (Gld.) $=$ anstralis Gld., der Insel nicht zukommen.

\section{Treronidae.}

*Gen. Phaenorhina G. R. Gray.

Verbreitung: Neu-Caledonien und Ile des Pins.

57. "Phaenorhina goliath G. R. Gray.

Carpophaga (Phatnorhina) goliath, G. R. Gray, 22, p. 165.

Verbreitung: Waldvogel der ganzen Insel, vom Küstenwald (beobachtet bei Yaté) bis in die höchsten Bergiwälder. Sein tiefer, an ein dumpfes Feuerhorn erinnern- 
der Ruf ist in allen Bergwäldern zu hören. Der Notu (dies der eingeborene Name) ist nicht scheu und bleibt sitzen, bis die Eingeborenen Wurfstöcke und Steine nach ihm schleudern. Am 2. November I9ıx erhielten wir am Mont Canala bei ca. 650 m Höhe ein Notu-Nest. Es war etwa $3 \mathrm{~m}$ hoch auf einem Baum in einer Gabel zwischen dem Stamm und einem Ast angebracht, in seiner Konstruktion ein echtes Taubennest, aus Reisig gebaut, oben etwas abgeflacht, ca. $12 \mathrm{~cm}$ hoch und von etwa $30 \mathrm{~cm}$ Durch. messer. Es war ein einziges, noch fast nacktes Junges darin. Nach Aussage der Ein. geborenen bebrütet der Notu stets nur ein Ei. Im April waren bei Oubatche die Tiere so fett, dass die Bälge nicht konserviert werden konnten.

우우 Am Fuss des Mont Humboldt, 200-500 m, 16. und 18. September I9II.

\section{Gen. Globicera Bp.}

Verbreitung: Neu-Guinea und umgebende Papuasische Inseln, Palaus, Carolinen, Marshall, Salomonen, Neu-Hebriden, Loyalty's, Neu-Caledonien, Fidji, Tonga, Samoa, Gesellschaftsinseln (nach Sharpe, 75, I, p. 63).

\section{Globicera pacifica (Gm.).}

Verbreitung: Südost-Neu-Guinea, Louisiaden, Salomonen, Neu-Hebriden, Fidji, Tonga, Samoa, Lifou, Neu-Caledonien?

Ich habe kein Exemplar erhalten. Die Layards, 4I, p. 528, sagen, diese Art, welche sie als Carpofhaga acnea G. R. Gray bezeichnen, sei ein seltener Besucher des Südens der Insel und komme wahrscheinlich von den Loyalty's her; sic sahen Exemplare mit der Etikette "Lifou" in der alten Kolonialsammlung von Nouméa, 37, p. 23 I. Im Museum von Nouméa befindet sich jetzt noch eines, das als von Lifou stammend bezeichnet ist. Die Layards scheinen aber selber kein Exemplar erbeutet zu haben, sie hörten bloss von einem bei Nouméa erlegten (37, p 23I). Auch Marie, der in seiner Liste, 47, p. 328, Carpophaga annea mit einem ? aufführt, hatte sie selber nicht gesehen.

\section{*Gen. Drepanoptila Bp.}

Verbreitung: Neu-Caledonien und lle des Pins.

59. Drepanoptila holosericea (T’emm. U. Knip).

Verbreitung: Diese schönste aller caledonischen Tauben bewohnt die ganze Insel; sie zieht den Hochwald ror, ist aber auch im Niauli-Busch anzutreffen.

o Tchalabeltal im Niauliwald, 5. Mai 19 I .

q Tchalabeltal im Niauliwald, 5: Mai igr r. (Beine grau mit rotviolettem

Ton, Schnabel schwarz, Iris braun.)

o Am Mont Canala, ca. $700 \mathrm{~m}, 4$. November igri.

q Wald oberhalb Oubatche, ca. $500 \mathrm{~m}, 2$. Oktober igr I. 
Gen. Ptilopus Swains.

Verbreitung: Kleine Sunda-Inseln, Banda, Kei, Neu-Guinea, Nord- und OstAustralien, Salomonen, Neu-Hebriden, Loyalty's, Neu-Caledonien, Palaus, Carolinen, Mariannen, Fidji, Tonga, Samoa, Savage-Ins., Hervey, Gesellschaftsinseln, Paumotu, Narquesas (nach $\mathrm{S}$ harpe, 75, I, p. 56 ff.).

6o. Ptilopus greyi G. R. Gray.

Verbreitung: Neu-Caledonien, Ile des Pins, Loyalty's, Neu-Hebriden, Santa Cruz. Auf Lifou häufig. Die Layards, 37, p. 23I, geben auch den Namen in der Maré-Sprache an; ich habe sie auf Maré nicht gesehen und auch auf Ouvéa nicht. Auf Caledonien erscheint sie nach den Layards, 4I, p. 527, als Wandervogel. Ich besitze die Art nur von Lifou, nicht von Caledonien.

ô, ô Quépénéé, Lifou, 24. April und 8. Mai rgiz.

o, q Quépénéé, Lifou, 19. April und ro. Mai rgiz.

Ganz unsicher ist das Vorkommen der folgenden Plilopus-Art, welche Schalow, 62, p. 245, in einer von einem Händler bezogenen, neu-caledonischen Sammlung vorfand: Ptilopus fasciatus Peale von Samoa (nach Wiglesworth, 82, p. 5o, Pt. porphyracous clementinae Jacq. u. Pucher, von Fidji).

\section{Columbidae.}

\section{Gen. Columba L.}

Verbreitung: Kosmopolitisch.

61. ${ }^{*}$ Columba hypoenochroa (Gould).

Verbreitung: Neu-Caledonien und Loyalty-Inseln.

6ra. Columba hypoenochroa typica (Gould).

V'erbreitung: Ganze Insel Neu-Caledonien und lle des Pins. Layards, 37, p. 23I, geben auch Lifou an und den Namen in der Maré-Sprache; doch könnte es sich dabei um die folgende Subspezies handeln.

o Tal von Tchalabel, Nord-Caledonien, 4. Mai igri. Long. tot. ca. 425, ala 230, cauda I80, culmen 20,5. Salvadori, 59, p. 316, hat für ein ${ }^{3}$ : Long. tot. 407, ala 240, cauda I63, culmen I 7 . Die Layards, 4I, p. 528, geben als Grössenmittel: Long. tot. 445, ala 242, cauda 178; Schalow, 62, p. 245: o u. o Long. tot. 462 und 455, ala 248 und 239. Ein $q$ Exemplar im Pariser Museum mass: Long. tot. ca. 405, ala 224, cauda 165 . 
$6 \mathrm{Ib} .{ }^{*}$ Columba hypoenochroa uveaensis nov. Subsp.

Verbreitung: Ouvéa, Loyalty-Insel.

$\widehat{o}$ ad. und a junge Vögel, Fayaoué, Ouvéa, I6. Mai igiz.

Maasse of: Long. tot. ca. 380 , ala 240 , cauda 185 , culmen 19.5 .

Diese insulare Form ist also wesentlich kleiner als die caledonische, schlanker gebaut, verhältnismässig langflügeliger und langschwänziger als diese. Die Färbung der Unterseite ist sehr ähnlich derjenigen des Männchens der typischen Form; nur zeigen Kehle und Oberbrust reicher entwickelte, metallpurpurne Federränder; stellenweise ist auch grüner Metallglanz sichtbar. Ähnlich wie beim caledonischen Vogel ist auch der purpurne Oberkopf und der prächtig metallpurpurne Nacken, abweichend aber und viel grüner die Färbung des Rückens. Vorderrücken glänzend metallisch goldgrün, viel intensiver als bei der typischen hypocmochroa; die Federn des Hinterrückens und der oberen Schwanzdecken sind leuchtend malachitgrün gesäumt. Der bronzeviolette oder purpurne Glanz, der beim caledonischen männlichen Vogel den ganzen Hinterrücken und bei gewissen Beleuchtungen auch den Vorderrücken einnimmt, fehlt bei der OuvéaForm vollständig; die kleinen Flügeldecken sind deutlich grün gesäumt, bei der typischen Form nur undeutlich metallisch. Der Ouvéa-Form ähnlicher gefürbt als das caledonische Männchen ist das caledonische Weibchen, insofern, als dessen Oberseite auch viel grüner ist als beim Männchen, indessen sind dann Kopf und Unterseite ganz abweichend.

Beim Ouvéa-Vogel blieb die rote Schnabelfärbung, mit Ausnahme der Spitze, am getrockneten Balge sehr schön erhalten, beim Caledonier ist der trockene Schnabel gelb. Auch ist die Färbung der Beine und Füsse beim ersteren viel intensiver rot.

\section{Peristeridae. \\ Gen. Chalcophaps Gould.}

Verbreitung: Vorderindien, Ceylon, Hinterindien, Indoaustralischer Archipel und Philippinen, Australien, Salomonen, Neu-Hebriden, Loyalty's, Neu-Caledonien, Lord Howe-Ins. (S alvadori, 59, p. 5Ioff.).

\section{Chalcophaps chrysochlora (Wagl.).}

Verbreitung: Kleine Sunda-Inseln, südöstliche Molukken, Neu-Guinea, Australien, Salomonen, Neu-Hebriden, Loyalty's, Neu-Caledonien, Lord Howe-Ins.

Verbreitung im caledonischen Gebiete: Ganze Insel Neu-Caledonicn und Ile des Pins; gemein auf Lifou und Mare (Layards, 37, p. 232); icl habe diese Taube auch auf Ouvéa gefunden.

O Oubatche, 2I. April rgri.

* Quépénéé, Lifou, I9. April Igrz.

q Fayaone, Ouvéa, I5. Mai Igra. 


\section{Turnicidae.}

\section{Gen. Turnix Bonn.}

Verbreitung: Afrika, Madagaskar, Südost-Europa, Vorderindien, Ceylon, Hinterindien, China, Mandschurei, Formosa, Liu-Kiu, Philippinen, Sumatra, Billiton, Java, Celebes, Kleme Sunda-Inseln, Neu-Guinea, Bismarck-Archipel, Australien, Neu-Caledonien (nach Sharpe, 75, I, p. 48 ff.).

63. Turnix varia (Lath).

Verbreitung: Australien und Neu-Caledonien.

\section{3a. "Turnix varia novaecaledoniae Ogilvie Grant.}

W. R. Ogilvie Grant, 5o.

Verbreitung: Neu-Caledonien, in den Savannengegenden.

ơ Coné, 4. August rgIr.

Die Layards, 4I, p. 530, haben diese schon von Marie, 47, p. 328, in seiner Liste als Turnix varius (Temm.) aufgeführte Art nicht erhalten und lassen die Frage offen, ob es sich um Nachkommen importierter Tiere handle. Ogilvie Grant machte in seinem Katalog, 5I, p. 552, zu einem caledonischen Exemplar von Turnix varia (Lath.) von Australien folgende Anmerkung: "Timmix varia soll von Australien (nach NeuCaledonien) importiert worden sein, aber dieses Exemplar repräsentiert wahrscheinlich eine eigene, wenn auch nahe verwandte Art. Es unterscheidet sich dadurch, dass die meisten Federn des Rumpfes und der Oberseite fast ganz schwarz sind, gesäumt mit weisslich oder "buff“. Es ist auch ein kleinerer Vogel als das Männchen von $T$. varia, indem der Flügel nur $82 \mathrm{~mm}$ misst, statt $89-9 I^{\prime \prime}$. Schon in seiner Arbeit über das Genus Turnix, 50, p. 474, hatte er auf dieses Exemplar aufmerksam gemacht und ihm im Register den Namen T. nozaccalcdoniac gegeben.

In der Tat ist die caledonische Form von der australischen abweichend und ganz wohl als eigene Spezies oder Subspezies, je nach Auffassung, charakterisierbar.

Maasse unseres ô: Long. tot. ca. I54, ala 8I,5, culmen I2. Der Katalog des Britischen Museums gibt für ein australisches ${ }^{t}$ : Long. tot. I60,5, ala 9I; ein ausgestopftes Exemplar im Basler Museum hat eine Flügellänge von 94. Die caledonische Form ist also in der Tat etwas kleiner als die australische; ferner ist die Färbung ab. weichend. Bei unserem caledonischen Männchen erscheint die allgemeine Farbe der Oberseite als schwarz; der Oberkopf hat ein mittleres, hellbraunes Längsband, begleitet von zwei breiteren schwarzen, deren Federchen rostrot gerändert sind; Kopfseiten gelblichweiss, schwarz gefleckt; Federn des Mantels und Rückens und obere Schwanzdecken schwarz, mit kastanienbraunen oder rostroten Bändern und Flecken, mit gelblich- 
weissen Säumen und meist mit rostroten Enden; Schwanzfedern grau, mit vielen feinen schwarzen Querbändern und einzelnen hellen Flecken; Flügeldecken schwarz, mit rostrotem Herz und hellem Saum; Schwungfedern braun, mit hellem Aussensaum; die inneren Sekundärschwingen mit Rostrot und Isabell gebändert und gefleckt; an den Halsseiten ein kastanienbrauner Fleck, mit Schwarz und Gelblichweiss gebändert und gefleckt; Kinn und Kehle weiss; übrige Unterseite isabellfarben, auf der Brust mit viel Grau gemischt; Flanken kastanienbraun, schwarz und hellgelb gefleckt; untere Flügeldecken graubraun, gegen aussen zu mit Schwarz gesäumt.

\section{Rhinochetidae.}

*Gen. Rhinochetus Verreaux u. Des Murs.

Verbreitung: Neu-Caledonien.

64. ${ }^{*}$ Rhinochetus jubatus Verreaux u. Des Murs.

J. Verreaux u. O. Des Murs, 79, p. 440.

o Am Mont Humboldt, ca, $200 \mathrm{~m}$ hoch, I9. September I9II.

q Am Humboldt, ca. I I00 $\mathrm{m}$ hoch, I8. September I9I I.

o Mont Canala, ca. $800 \mathrm{~m}$ hoch, 7. März IgIz.

Schnabel und Beine sind im Leben hell korallenrot, die Iris tiefrot, aber nach dem Tode sofort orangegelb werdend.

Maasse: $\hat{0}$, ô Long. tot. ca. 555 und 575, ala 285 und 280, cauda 2 ro und 2 Io, culmen $5^{8}$ und 6r; 9 Long. tot. ca. $55^{\circ}$, ala 3 ro, cauda 210 , culmen 58,5 . Sharpe, 72 , p. 247, gibt für ein ad. 8 : Long. tot. 559, ala ca. 254, cauda 207 , culmen 59.5, also sehr åhnliche Zahlen. Unser Weibchen hat ungefähr die nämliche Grösse wie unsere männlichen Vögel. Auch die Länge der Haube ist dieselbe und die Färbung übereinstimmend; nur sind Hals und Brust etwas grauer, der Bauch etwas heller isabellfarbig als beim ausgefärbten Männchen, was aber bloss ein Altersunterschied sein dürfte. Herr B. Amstein in Nouméa, der viele Jahre lang ein Pärchen lebend gehalten und (siehe unten) auch zur Fortpflanzung gebracht hat, sagte, er könne Männchen und Weib. chen nicht nach ihrem Gefieder, sondern nur daran unterscheiden, dass das Männchen am Morgen mit seinem Ruf beginne und das Weibchen antworte. Pouget, 84, 10.167, glaubte, den Ruf des Männchens und des Weibchens auch durch verschiedene Töne wiedergeben zu können.

Unser männliches Exemplar vom Mont Canala ist trotz seiner. Grösse noch nicht ganz ausgefärbt, indem auf Rücken und Flügeldecken eine Anzahl Federn noch die schwarze und kastanienbraune Bänderung des Jugendkleides aufweisen; auch ist die Haube noch verhälnismässig kurz. Das braune, gebänderte Jugendkleid von Khimochetus ist von R. Burckhardt, 9, Taf. II, sehr schön zur Darstellung gebracht worden; 
es handelt sich dabei um ein anatomisch erwachsenes Individuum, und der genannte Autor sagt mit Recht, es zeige dies, ein wie später Erwerb das graue Prachtkleid des Khmochtus sei (p. 9). Dieses lange Beibehalten des braunen Jugendkleides hat zu der in Caledonien sehr verbreiteten Sage geführt von der Existenz zweier Khinochctus. Arten, eines grösseren, grauen „Busch-Kagu“ und eines kleineren, braunen, gebänderten „GrasKagu“ (siehe Bennett, 5, p. xq2, Mitteilung eines Herrn F. Joubert). Bei allen unseren Exemplaren sind die Flügel- und meist auch die Schwanzfedern arg zerstossen und abgenützt, vermutlich vom Durchstreifen des dichten Unterholzes.

Verbreitung und Biologisches: Schon Marie, 47, p. 323, dem wir die besten Beobachtungen über den Kagu (dies ist der eingeborene Name des Tieres) verdanken, berichtet, dass dieser Vogel bloss den Süden der Insel bewohne. In der Tat Laben wir ihn bei Oubatche im Norden Neu-Caledoniens, wo wir 7 Monate lang unser Hauptquartier hatten, vergeblich gesucht. Der nördlichste Punkt, wo wir den Kagu erhielten, womit natürlich nicht gesagt sein soll, dass dies tatsächlich seine Nordgrenze bedeute, war Canala, etwas nördlich vom südlichen Dritteil der Insel gelegen, wo er in den Bergwäldern des Mont Canala (1062 m) und seiner Nachbarberge nicht selten zu sein scheint. An der Südostseite des Berges bei ca. $650 \mathrm{~m}$ Höhe kampierend, hörten wir sein Geschrei, und von der Westseite erhielten wir ein Exemplar aus dem oberen Negropo-Tal. Dann bewohnt er so ziemlich das ganze grosse und menschenleere Serpentingebiet, welches den südlichen Dritteil der Insel einnimmt, wo er nicht durch Anlage von Minen und die durch diese bedingte Entwaldung und Beunruhigung verdrängt worden ist. Dass es aber nicht allein die durch die Serpentinformation hervorgerufenen Existenzbedingungen sein können, welche dem Kagu ausschliesslich zusagen, beweist sein Vorkommen am Mont Canala, welcher eine aus alten Schiefern bestehende Enklave im Serpentingebiet bildet. Ob der Kagu jemals den Norden der Insel bewohnt hat, ist, solange man kieine fossilen Reste aus diesem Gebiete besitzt, nicht zu sagen. Eine Ausrottung durch die Eingeborenen erscheint nicht ausgeschlossen, wenn man bedenkt, dass sie im Norden sehr zahlreich sind und früher noch viel zahlreicher" waren, während das südliche, für jede Kultur ungeeignete Serpentingebiet nur stellenweise, so längs eines schmalen Küustensaumes und in einigen Flusstälern mit Schwemmland, Ansiedelungen gestattete. (Weiteres über die Ausrottung des Kagu unten.)

Eines der jetzt noch reichsten Kagugebiete ist jedenfalls die ungeheure Waldund Buschregion des Mont Humboldt ( $\mathrm{I} 63+\mathrm{m}$ ) und des ihn umgebenden Berggewirrs der Serpentinformation. Als wir am Nachmittag des I7. September I9I in der Höhe von IIoo $m$ am Humboldt unsere Hütte aufschlugen, hörte man plötzlich Gebell von Hunden unserer eingeborenen Begleiter; die Leute eilten zur Stelle und fanden einen Kagu, den ein Hund mit den Pfoten festhielt; zwei Andere sahen sie entfliehen. Der Kagu hatte sich aus Angst vor dem Hunde platt auf den Boden niedergelegt, und dieser, ein wohldressiertes Tier, drüclite ihn mit der Pfote gegen die Erde, bis sein Herr herankam. Der Kagu war völlig unverletzt und krächzte heiser, beruhigte sich aber 
bald, als man ihn an einem Bein bei unserer Hütte festband und liess sich berühren und streicheln. Nur wenn er einen Hund erbliclite, wurde er aufgeregt, stellte seine prächtige, silbergraue Federhaube, breitete seine Flügel seitlich aus und knurrte oder krächzte ärgerlich. Wenn man ihn erschreckte, legte er sich flach auf die Erde nieder urd bedeckte mit den beiden nach vorn im Bogen ausgebreiteten Flügeln den Vorderkörper und den Kopf, offenbar sich in dieser Stellung sicher fühlend. Ich habe ihn in dieser Angststellung photographiert, Fig. 5. Diese Stellung ist auch in London an einem gefangenen Exemplar beobachtet worden, siehe Bennett, $4, \mathrm{p} .3+2$. Dass sie vollkommen typisch ist, bestätigte mir auch Herr Amstein in Nouméa, indem er erzâhlte, er habe einmal am Mont Dore, südlich von Nouméa, einen, wie er glaube, ausgehungerten und vielleicht kranken Kagu angetroffen, und dieser habe sich gleich auf die Erde gelegt, den Kopf mit den Flügeln zugedeckt und sich ruhig ergreifen lassen. Im Walde ist sonst der Kagu in der Regel nur mit Hunden zu fangen, da er sofort im dichten Unterholz verschwindet. Dagegen hatte sich während unserer Besteigung des Humboldt ein Kagu aus dem Walde in das breite und geröllreiche Bett des Ngoi.

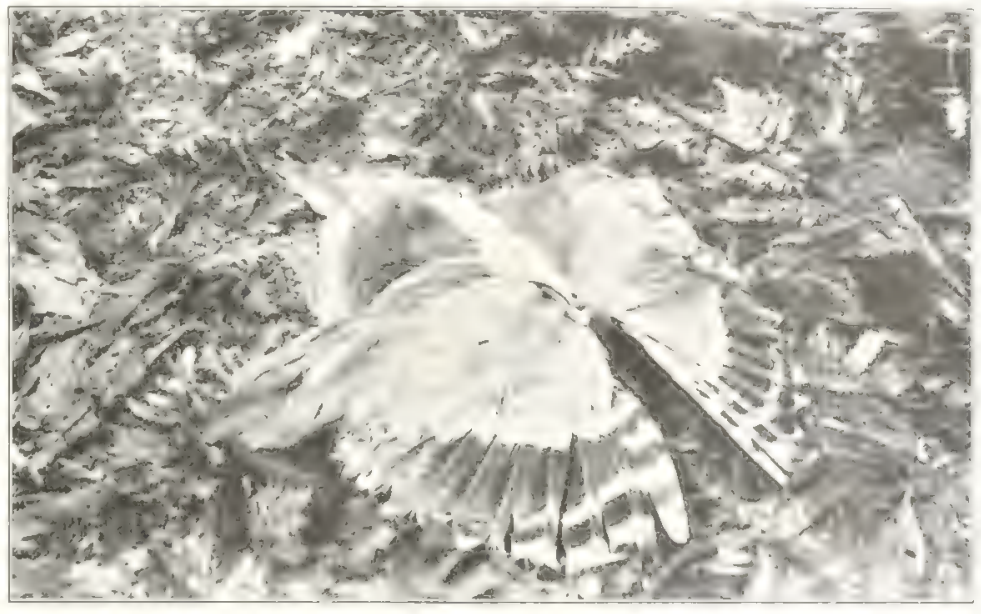

Fig. 5 .

Kayu in Angststellune:

Flusses, an welchem unser Hauptquartier stand, verlaufen und wurde hier von den dort zurückgebliebenen Kanaken mit der Hand, ohne Hilfe von Hunden, lebend erfasst.

Der Kagu ist fast wehrlos; er weiss keinen ernstlichen Gebrauch zu machen von seinem langen Schnabel, noch von seinen kräftigen Beinen. Auch hat er, offenbar weil er vor Ankunft des Menschen in Neu-Caledonien keinen Verfolger zu fürchten hatte, verlernt, seine Flügel zum Fliegen zu benützen. Nach Beobachtungen von Marie, 47, p. 325 und Mitteilungen von Bennett, 3, p. 107, kann er sich damit nur cinige Fuss hoch erheben. Wohl aber dienen sie ihm dazu, seinen Lauf zu beschleunigen.

Der Kagu lebt in kleinen Gesellschaften, die in den frühesten Morgenstunden ihr eigentümliches Geschrei hören lassen, das wie das Bellen junger Hunde kingt. Marie transskribiert es richtig als ein öfters wiederholtes "ua, ua, ua". Am "Tage habe ich ihn nie gehört. Daneben hat er noch cinen anderen, wie ein tiefes "Gu" klingenden Ruf, der jedenfalls die Veranlassung zu seinem eingeborenen Namen „Kagu“ gegeben hat. 
Über die Nahrung verdanken wir ebenfalls Marie die genauesten Angaben; sie besteht aus Heuschrecken und anderen Insekten, Würmern, Schnecken und zwar sowohl beschalten, als Nacktschnecken. Die grossen und schweren Placostylus-Schalen schlägt er nach Marie an der schwächsten Stelle der vorletzten Windung auf und zieht das Tier heraus. Wenn er Regenwürmer sucht, hackt er mit dem Schnabel ein kleines Loch in die Erde und gibt mehrere kurze Schläge hinein, wie um den Wurm zu rufen, sagt Marie; dann bleibt er einige Minuten lang ganz ruhig beobachtend, und, wenn nichts kommt, wiederholt er sein Klopfen. Er macht sich also, wie unsere Amsel, die Erscheinung zunutze, dass eine Erschütterung des Erdbodens die Würmer erschreckt und veranlasst, sich nach der Oberfläche zu retten. Das Fleisch des Kagu wird sowohl von den Europäern, als von den Eingeborenen als Braten hochgeschätzt.

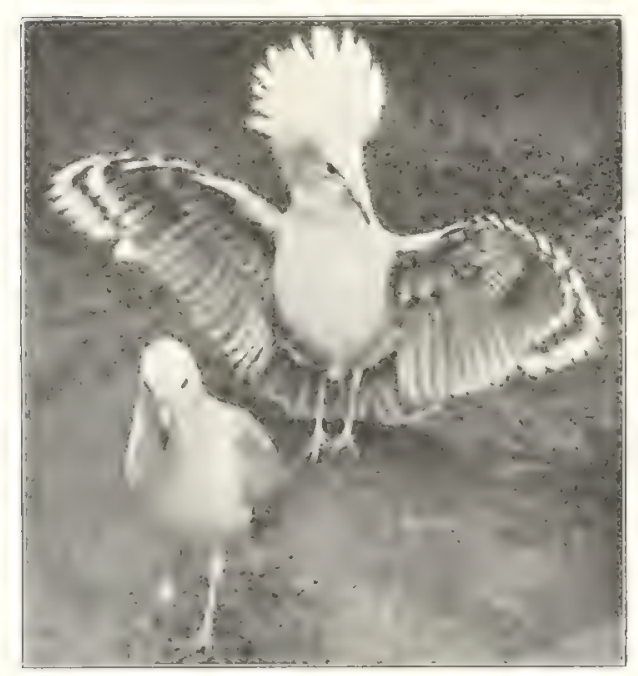

Fig. 6.

Kagri's, nach Photographie in Nomméa.

Nest und $\mathrm{Ei}$. Es ist uns gelungen, das längst vergeblich gesuchte Nest des Kagu samt seinem Ei zu erhalten und zwar durch einen Eingeborenen von Naquéty, unweit von Canala; es ist auf Taf. III, Fig. I7, in halber Grösse zur Abbildung gebracht worden. Das Nest war auf der Erde unter Buschwerk angelegt; es ist von rundlicher Form, ca. $35 \mathrm{~cm}$ im Durchmesser haltend und etwa i2 hoch. Die Unterlage besteht aus kreuzweise durcheinander gesteckten dürren Ästen, darunter solchen von $2^{1 / 2} \mathrm{~cm}$ Durchmesser. Es scheint, dass diese Äste vom Vogel selbst in der gewünschten Länge abgebrochen worden sind. Auf dieser Unterlage ruht eine dicke Schicht grosser Blätter, das eigentliche Nest bildend; darauf lag ein einziges Ei.

Das erste Rhmochetus. Ei ist von Bartlett beschrieben und abgebildet worden (2. Taf. XII, Fig. 3) nach einem im Londoner Garten gelegten Stücke; das unsrige, Taf. III, Fig. I8, ist das erste aus der Freiheit erhaltene. Es zeigt ein stumpferes und ein etwas verschmälertes Ende, misst 62,5 mm in der Länge, bei 48,5 grösster Breite; die Grundfarbe ist rötlich, bespritzt mit unregelmässigen, grösseren und kleineren, dunkelbraunen und grauen Flecken, von welchen die letzteren aus tieferen Schalenschichten durchschimmern. Mit diesem Ei konnte ich vier in der Gefangenschaft in Nouméa gelegte Eier vergleichen; ihre Länge schwankte von 59,5 bis 62,5 mm, die grösste Breite von 45,5 bis 47,5; in der Verteilung und der Anzahl der dunklen Flecke stimmt keines genau mit dem anderen überein.

Gefangenschaft. Der Kagu gewöhnt sich nach allen Angaben sehr leicht an die Gefangenschaft und lässt sich ohne Schwierigkeit mit rohem, in Streifen ge- 
schnittenem Fleisch, Würmern und Schnecken ernähren. Der erfolgreichste Kagupfleger ist ohne Zweifel Herr B. Amstein in Nouméa. Er hat ein Pärchen über 20 Jahre lang gehalten, und sie haben bei ihm Eier gelegt, ausgebrütet und zwei Junge aufgezogen, die noch leben. Ihm verdankt das Basler Museum auch das Nestjunge, welches seinerzeit von Rud. Burckhardt, 8, beschrieben worden ist. Wir haben sowohl die Alten, als das junge, in Gefangenschaft aufgezogene Paar gesehen; es sind prächtige, gesunde Tiere. Das nebenstehende Bild, Fig. 6, zeigt zwei dieser Kagu's, davon einen mit aufgerichteter Haube und ausgebreiteten Flügeln. Es ist das die Stellung, die er annimmt, sowohl um beim Liebesspiel und auch dem Menschen gegenüber zu gefallen, als auch, wenn er etwas Auffallendes bemerkt und sich zur Wehr setzen will. Die Haltung der ausgebreiteten Flügel ist in der Regel dem Leibe paralleler, als es auf dem Bilde zu sein scheint; er hebt und senkt sie abwechselnd, wie Schilde (vgl. Bennett, 4, p. 343) und erinnert dann etwas an den Pinguin mit seinen seitlich herab. hängenden Flossen. Die ersten lebenden Kagu's kamen I86 nach Frankreich (Pouget, 84, p. I62). Man hat mehrmals Kagu's längere Zeit in Europa am Leben erhalten lönnen.

Über das Brutgeschäft berichtete mir Herr Amstein, das Nest sei an einer dunklen Stelle unter dem Hause auf dem Erdboden angelegt gewesen und habe aus Blättern und ausgerupften Federn bestanden. Offenbar fehiten dem Vogel in Gefangenschaft die dürren Äste, mit denen er in Freiheit die Unterlage des Nestes erstellt. Männchen und Weibchen brüten abwechselnd, und beide teilen sich in die Fütterung des Jungen. Der Kagu legt und bebrütet stets nur e in Ei, aber wiederholt dies etwa dreimal im Jahr vom August bis Januar, also in der trockenen Jahreszeit. Wenn er badet, ist das Wasser nachher mit einer Schicht von weisslichem Staube, von den Puderdunen herstammend, bedeckt. Dieselbe Beobachtung machten schon Pouget, 84, p. 168 und Bartlett, I, p. 2I9, an gefangenen Kagu's.

Aussterben und Schutzmassregeln. Nach Jouan, 27, p.97, Marie und Anderen kommt der Kagu nicht nur in den Wäldern der Berge, sondern auch in der Nähe der Küste vor. Das Letztere dürfte heute nur noch an wenigen Stellen, wenn überhaupt, Geltung haben; unsere Exemplare stammen alle aus dem Inneren. Sicherlich ist der Kagu, seit es Menschen auf Caledonien gibt, verfolgt worden. Die Eingeborenen lieben sein Fleisch sehr und wussten schon vor Einführung des Hundes mit Schlingen seiner habhaft zu werden. (Mitteilung von F. Joubert an Bennett, 5, p. I f2.) So kann es wohl sein, dass er in manchen Gebieten schon vor der europäischen Besiede. lung durch die Kanaken vernichtet worden ist (siehe oben). Die eigentlich liritische Periode für den Kagu begann aber erst I853 mit der französischen Okkupation der Insel, welche das Gewehr und vor allem den Hund, der früher unbekannt war, nach Caledonien brachte. Das Gewehr hat man durch Gesetz auf die Europäer beschranken können, nicht aber den Hund. Mit dessen Hilfe ist, wie oben erzahlt, der Kagu kinder. leicht zu erbeuten. Weit mehr noch aber fallen den ohne den Menschen wildjagenden Hunden zum Opfer, wahrscheinlich auch verwilderten Katzen. Hierzu kommt die Mode 
der Damen in Nouméa, gefangene Kagu's als Spielzeug zu haltén; der hohe Preis, der hierfür bezahlt wird, lockt natürlich die Eingeborenen, solche zu fangen. Endlich trägt die enorme Waldverwüstung im südlichen Serpentingebiet, dem eigentlichen Kaguheim, durch die Minenunternehmungen, die ganze Bergketten entwalden, viel dazu bei, den kagu zu verdrängen, ganz abgesehen davon, dass mit der Minenbevölkerung sofort auch der Hund seinen Ëinzug hält.

So geht dieses herrliche Geschöpf, das zoologisch als uralte, mit Mesites von Madagaskar und Enrypyon von Süd-Amerika verwandte Form von höchstem Interesse ist, einem sicheren Ende entgegen, wenn nicht bald energische Massregeln zu seiner Erhaltung getroffen werden. Jagdverordnungen mit Schonzeiten, wie solche schon bestehen, nützen nichts, denn erstens gelten sie nur für den europäischen Jäger, und zweitens werden sie nicht befolgt. Das einzige Mittel ist vielmehr die Schaffung von Reservationen, in welchen jede Jagd, von Weissen sowohl, als von Schwarzen, aufs strengste verboten werden müsste, ebenso wie das Betreten mit Hunden. Freilich dürften, wenn ein Erfolg erzielt werden soll, unter keinen Umständen die Kosten für einen oder mehrere verantwortliche Wächter gespart werden.

Soweit ich Caledonien kenne, würde mir als die bei weitem geeignetste Schutzzone das menschenleere und kagureiche Gebiet des Humboldt und der südlich sich daran reihenden Waldgebirge erscheinen. Im Norden liesse sich dieses Gebiet abgrenzen durch das Tal des Ngoiflusses, im Süden durch den Lauf der Ouinné, im Osten durch die Küste, und nach Westen zu würde sich gleichfalls ein Flusstal finden lassen, das als Grenze dienlich wäre. Eine Schwierigkeit könnte in diesem Gebiete dadurch entstehen, dass wahrscheinlich über kurz oder lang Minengesellschaften auch hier ihre Tätigkeit entfalten werden, wofür dann besondere Bestimmungen getroffen werden müssten. Vor Minen sicher wäre das Waldgebiet des Mont Canala und seiner Nachbarberge, und die in dessen Nähe befindlichen Kanakendörfer könnten leicht von der weiteren Verfolgung des Kagu abgehalten werden, wenn man ihren "Grand Chef" veranlassen würde, den Kagu mit seinem Tabu zu belegen und die Haltung von Hunden zu verbieten. Sicherlich könnten auch noch andere Gebiete in Betracht kommen, und wenn es der Kolonialregierung ernstlich daran gelegen ist, die Vernichtung des Kagu zu verhindern, so steht ihr in ihrem topographischen Bureau ein vortreffliches Organ zur Verfügung, um ein passendes Schutzgebiet ausfindig zu machen und in praktischer Weise abzugrenzen.

Rallidae.

\section{* Gen. Tricholimnas Sharpe.}

Verbreitung: Neu Caledonien.

65. ${ }^{*}$ Tricholimnas lafresnayanus (Verreaux u. Des Murs).

Von J. Verreaux und O. Des Murs, 79, p. 437, als Gallirallus lafresnaymus beschrieben, wurde diese Ralle später von Gray der Gattung Eulabcornis zugeteilt, 
endlich von Sharpe zu einer eigenen Gattung erhoben. Eine farbige Abbildung des Tieres findet sich bei Brenchley, 7, Taf. XXI.

Verbreitung etc.: Nach den Layards, 4I, p. 535, ist diese Ralle ein zwar seltener, aber allgemein verbreiteter Waldvogel von nächtlicher Lebensweise. Sie erhielten in Nouméa Exemplare, die mit Fallen gefangen oder mit Hunden waren erjagt worden. Die zwei Exemplare in der Sammlung Tristram's, 78, p. 29, stammen vom Mont Dore, südlich von Nouméa, Exemplare in Paris von Dumbéa und von St. Louis, nördlich und südlich von Nouméa.

Layards hielten den Vogel auch lebend, ihn mit Schnecken, rohem Fleisch und Gedärme fütternd. Auch Jouan, 28, p. 246, berichtet von einem Exemplar, das 7 bis 8 Monate in Nouméa gelebt hat. Schon bei Verreaux und Des Murs findet sich die Angabe, das Tier solle nach einer Mitteilung die Grösse eines Truthahns erreichen können. Verreaux und Des Murs geben indessen bloss $380 \mathrm{~mm}$ als Länge an, Sharpe, 72, p. 5I, für ein o 432 und für ein +367 . Auch die Pariser Exemplare zeigen keine darüber hinausgehenden Dimensionen.

Verreaux und Des Murs geben als eingeborenen Namen "N'dino", Jouan nach Vieillard und Deplanche "N'diuo". Wir haben das Tier vergeblich gesucht. Zwei alten, sehr kundigen, eingeborenen Jägern bei Thio (Ostküste) haben wir das Tier beschrieben; sie gaben an, es wohl zu kennen; es sei früher häufig gewesen, aber durch die Hunde ausgerottet worden; man habe es "Assion" genannt. N'dino dürfte eine Bezeichnung der Stämme bei Nouméa sein. Es ist somit möglich, dass diese Form bereits das Schicksal erreicht hat, welches den Kagu bedroht. Da indessen alle bekannten Exemplare vom südlichen Teil der Westküste herstammen, von wo wir keine Sammlungen besitzen, so bin ich nicht im Stande, Bestimmtes darüber zu sagen.

\section{Gen. Hypotaenidia Reichenb.}

Verbreitung: Südindien, Ceylon, Ost-Bengalen, Hinterindien, Süd-China, Formosa, Palaus, Mariannen, Philippinen, Indoaustralischer Archipel, Australien, Tasmanien, Neu-Seeland, Auckland-Ins., Macquarie-Ins., Salomonen, Neu-Hebriden, Loyalty's, NeuCaledonien, Fidji, Samoa, Tahiti (nach Sharpe, 72. p. 32 ff und 75, I, p. 95.)

\section{Hypotaenidia philippinensis (L.).}

Verbreitung: Philippinen, Palaus, Mariannen, Celebes, Direction. Ins. Westl, von Borneo, Cocos-Ins., Timor, Molukken, Torres Str, Australien, Neu-Secland, BismarckArchipel, Salomonen, Neu-Hebriden, Fidji, Samoa, Tonga, Loyalty's, Nen-Caledonien (Mauritius accid.), nach Meyer und Wiglesworth, 48, p. 696.

Verbreitung im neucaledonischen Gebiet: Neu-Calectonien, ganze Insel, häufig, nach Layards, 4I, p. 536, auch auf den Guano-Inseln (Huon etc.), nördlich von Caledonien und sogar auf den Chesterfield-Inseln. Lifou (Layards, 37, p. 232). Wir haben den Vogel auch auf Ouvéa gefunden. 
und of juv., Oubatche, I8. Juli und I6. Mai I9I.

* Fayaoué, Ouvéa, I2. Mai I9I2.

q " " $"$ I3. Mai igr2.

Bei den Ouvéa-Exemplaren ist das rostrote Oberbrustband sehr stark ausgeprägt, bei den beiden caledonischen nur spurweise angedeutet.

\section{Gen. Porzana Vieill.}

Verbreitung: Fast kosmopolitisch.

67. Porzana tabuensis ( $\mathrm{Gm}$.).

Verbreitung: Australien, Tasmanien, Neu-Seeland, Chatham, Norfolk, Fidji, Tonga, Samoa, Neu-Hebriden, Neu-Caledonien, Philippinen, Carolinen (Sharpe, 72, p. İ3, Wiglesworth, 82, p. 60).

Nicht in unserer Sammlung.

\section{Gen. Poliolimnas Sharpe.}

Verbreitung: Malakka, Indoaustralischer Archipel, Philippinen, Palaus, Carolinen, Australien, Neu-Hebriden, Fidji, Samoa, Loyalty's, Neu-Caledonien.

\section{Poliolimnas cinereus (Vieill.).}

Verbreitung: Wie die Gattung. In Neu-Caledonien sowohl Ostküste (Verreaux u. Des Murs, 79, p. 437, Porana lencophrys Gould), als Westküste (La yards, 4I, p. 537, Ortygometra quadristrigata Horsf.). Auf Lifou durch die La y ards, 37, p. 232, nachgewiesen.

Nicht in unserer Sammlung.

\section{Gen. Porphyrio Briss.}

Verbreitung: Afrika, Madagaskar, Mittelmeerländer, ostwärts nach Vorderindien und Ceylon, Hinterindien, Süd-China, Philippinen, Palaus, Indoaustralischer Archipel, Australien, Neu-Seeland, Chatham, Norfolk, Lord Howe, Salomonen, Neu-Hebriden, Fidji, Samoa, Tonga, Loyalty's, Neu-Caledonien (nach Sharpe, 72, p. I92 ff., 75, I, p. I08).

69. Porphyrio calvus caledonicus nov. Subsp.

Die Bestimmung des caledonischen Sultanshuhnes und"der Porflyrio-Arten überhaupt ist in der Literatur eine sehr schwankende, wofür man unter anderem die Aus. führungen von Meyer und Wiglesworth, ${ }_{4} 8, \mathrm{p} .7 \mathrm{I} 7$, ff. vergleichen möge. Sie schlagen vor, alle Formen von Java bis in den pazifischen Ozean hinein unter caluns Vieillot zu vereinigen.

Marie, 47, p. 328, hatte von Caledonien 2 Arten aufgeführt, bellus Gould und melanonotus Temm., von denen er nur die letztere selbst in Händen gehabt hat. Von melanonotus unterscheidet sich jedoch die caledonische Art - es kommt nur eine vor - sofort durch den kobaltblauen Kehl- und Oberbrustfleck, während bei ersterer die Unterseite einfärbig ist, von bellus die gelbe und gelbrote Färbung der Beine und Füsse. 
Die Layards, 4r, p. 536, nennen das Tier riticnsis Peale: es sei zwar grösser als der Vogel von Fidji, wie dieser grösser als der von Samoa, aber nicht abtrennbar, zumal sie ein identisch gefärbtes Exemplar, aber kleiner als alle diese, von Vaté, Neu Hebriden erhalten hätten; dieselbe Form, wie in Caledonien, geben sie für Lifou an, 37, p. 232. Auf den Hebriden kommt, neben der erwähnten von Vaté, noch eine grosse Form vor, ancitennensis Tristram. Wiglesworth, 82, p. 62, stelit den caledonischen Vogel als fragliche Subspezies zwischen samoensis Peale von Tonga, Samoa und Fidji und samoensis aneitcumensis Tristr. von den Hebriden. Sharpe, 72, p. 204, vereinigt die Vögel der Hebriden, von Neu-Caledonien, Fidji und Tonga unter dem Namen smurudimus Temm. mit solchen von Nord-Celebes, den Molukken, Neu-Guinea und Salomonen. Daneben hält er den kleinen P. samocnsis von Samoa als Spezies aufrecht. P. smumgdimus ist nach Meyer und Wiglesworth 1. c. synonym mit catius Vieill. Unter diesen Umständen scheint es mir das Beste zu sein, den caledonischen Vogel als eine lokale Subspezies dieser weitverbreiteten Art zu beschreiben. Ob die Sultanshühner von Lifou (Layards 1. c.) und Maré (Sclater, 64, p. 330) zu derselben Form gehören, kann ich nicht sagen, da ich keine Exemplare von den Loyalty's besitze.

* Coné, I5. August I9II,

o Oubatche, 3I. August IgIr,

q Coné, II. August igi I.

Adultes Männchen: Mantel, Rücken, Bürzel und Schwanz sehr dunkel schwarzbraun, die Federn, namentlich gegen ihren Rand zu, mit Olivengrün übergossen; an vielen Federn zahlreiche schwarze Querbänder sichtbar; Flügeldecken und Schwungfedern von derselben schwarzbraunen Farbe wie der Rücken; die drei ersten Primär" federn mit matt hellblauer Aussenfahne; Deckfedern der Primärschwingen mit teilweise dunkelblauer Aussenfahne; Afterflügel mit grünblauen Aussenfahnen; Flügelbug schün hellblau; Hinterkopf, Nacken, Schläfen und Zügelgegend dunkelbraun; Backen und Kinn mit hellblauen Federchen überstreut; Kehle und Oberbrust hellblau, deutlich kon. trastierend mit dem prachtvollen Blauviolett der Unterbrust und den noch reicher gefärbten Körperseiten; Halsseiten und Hinterhals ebenfalls blau violett; Bauchmitte schwarz; Tibiae heller blau als die Körperseiten; untere Schwanzdecken weiss; Schwanz und Flügel unterseits schwarz; untere Flügeldecken hellblau, gegen ihre Basis zu bräunlich und grünlich; Schnabel und Stirnschild korallrot, Schnabelspitze heller; Beine und Füsse gelb und gelbrot, die Gelenkenden dunkíler gefärbt.

Weibchen: Rücken und Flügel heller braun, die ganze Färbung weniger reich; Körpergrösse kleiner.

Maasse, Â: Long. tot. ca. 450, ala 255, tarsus 96, Mittelzehe Io3, culmen und Schild 68. Ein zweites of, wahrscheinlich noch nicht völlig ausgewachsen, ergab niedrigere Maasse:

Long. tot. 38r, ala 244, tars. 85. Mittelzehe ro 4, culm. u. Schild 6r.5. 9: Long. tot. 360 , ala 230 , tars. 85, Mittelzehe 96, culm. u. Schild 59. 
L. ay ard, 43, p. 292, gibt für ein caledonisches Exemplar folgende Maasse an: L. t. 432, ala 257, tars. 9I, Mittelzehe i ro, culm. und Schild 66.

Es geht aus diesen Maassen hervor, dass der caledonische Porphyrrio eine grosse fiorm darstellt.

\section{Charadriidae.}

\section{Gen. Arenaria Briss.}

Verbreitung: Fast kosmopolitisch.

\section{Arenaria interpres (L.).}

Verbreitung: Ebenso, im Süden meist als Wanderer; mehrfach von Caledonien namhaft gemacht.

\section{Gen. Charadrius L.}

Verbreitung: Fast kosmopolitisch.

7r. Charadrius fulvus Gm. (dominicus P. L. S. Müll.).

Verbreitung: Wanderel aus Nord-Asien her; von den Layards, 4I, p. 532, in Caledonien auch als Brutvogel nachgewiesen; Lifou, Layards, 37, p. 232.

ô Oubatche, I3. April igri, Übergang zum Hochzeitskleid.

o Canala, 7. Januar igi2.

q Quépénéé, Lifou, 19. April 19i2.

\section{Gen. Numenius Briss.}

Verbreitung: Fast kosmopolitisch.

\section{Numenius variegatus (Scop.).}

Verbreitung: Wanderer von Norden her; nach den Layards, 4I, p. 533, selten in Neu.Caledonien (.I. uropygriulis).

\section{Gen. Limosa Briss.}

Verbreitung: Fast kosmopolitisch.

\section{Limosa novaezealandiae Gray.}

Verbreitung: Wanderer von Norden her; kommt sowohl auf Neu-Caledonien, als auf Mare vor (Layards, 4I, p. 534 und 37, p. 232, L. uropygialis.).

\section{Gen. Heteractitis Stejn.}

Verbreitung: Von Nordwest-Amerika und Ost-Sibirien südwärts. 
74. Heteractitis incanus (Gm.) (= braipes Vieill.).

Verbreitung: Wanderer von Norden her, sowohl von Neu-Caledonien bekannt, als von Lifou (La yards, 37, p. 232).

\section{Gen. Heteropygia Coues.}

Verbreitung: Von Nordamerika und Ostsibirien südwärts.

75. Heteropygia acuminata (Horsf.).

Verbreitung: Wanderer von Norden her; in Marie's, 47, Liste aufgeführt (Schocnichus australis Gould), im Pariser Museum als von Neu-Caledonien stammend katalogisiert.

Von allen den erwähnten Charadriiden befindet sich nur Charadrins fultus in unserer Sammlung:

\section{Oedienemidae.}

\section{Gen. Orthorhamphus Salv.}

Verbreitung: Cocos-und Andaman-Ins., Indoaustralischer Archipel, Philippinen, Salomonen, Neu-Caledonien, Nord-Australien (nach M e y e r u. W igleswort h, 48, p. 73ł).

\section{Orthorhamphus magnirostris (Vieill.).}

Verbreitung: Wie die Gattung. Von Neu-Caledonien schon lange bekannt, nach den Layards, 4I, p. 532, auch im Norden auf den Huon-Inseln. Ich habe ihn nicht erhalten.

\section{Ardeidae.}

\section{Gen. Demiegretta Blyth.}

Verbreitung: Küsten des Indischen und Pazifischen Ozeans von der bengalischen Bai bis Australien und den pazifischen Inseln, nordwärts bis Japan und Korea, Sharpe, 73, p. I36.

\section{Demiegretta sacra $(\mathrm{Gm}$.)}

Verbreitung: Wie die Gattung. Im Pazifischen Ozean werden als Fundorte angegeben: Salomonen, Neu-Hebriden, Neu-Caledonien, Fidji, Samoa, T'onga, Ellice, T'ahiti. Layard, 37, p. 232, glaubte, die Art auch auf Lifou zu crkennen (ulbulinitu Gray). Man sieht in Caledonien häufiger die graue Form als die weisse; an den Küusten, besonders wo Mangroven wachsen, ist dieser Reiher nicht selten.

\section{o Küste bei Pam, 29. Juli igis.}

Das Exemplar ist die weisse frorm und zeigt sehr bedeutende Dimensionen: Ala 320, tarsus 94, Mittelzehe 77, culnen 100. 
Sharpe, 73, p. Ifo, gibt als Maasse für ein ad. 0 : ala 254, tarsus 7o, culmen 68. Er führt auch die Tarsuslängen zahlreicher Exemplare auf, aus denen hervorgeht, dass bloss ein V'ogel von der lle des Pins mit einer larsuslänge von 94 an Grösse unserem Stück gleichkommt. Es ist die Form, welche Gray, 22, p. I66, Ardea (Ilerodias) albolimcata nannte, Ile des Pins, Tarsuslänge 89.

\section{Gen. Notophoyx.}

Verbreitung: Australien, Tasmanien, Neu-Seeland, Norfolk, Neu-Caledonien, Lifou, Neu-Guinea, Aru, Kei, Kleine Sunda-Inseln bis Lombok, Molukken, Celebes (Meyer u. Wiglesworth, 48 , p. 8 íffo).

\section{Notophoyx novaehollandiae (Lath.)}

Verbreitung: Wie die Gattung, Neu-Guinea wahrscheinlich. Die Art findet sich für Caledonien schon bei Verreaux und Des Murs, 79, p. 439 und Marie, 47, P. 328, verzeichnet. Die Layards, 4I, P. 53I, fanden sie sowohl ander West-, als an der Ostküste, auch auf Lifou, 37, p. 232.

\section{Gen. Nycticorax Rafin.}

Verbreitung: Fast kosmopolitisch.

\section{Nycticorax caledonicus (Gm.).}

Verbreitung: Von Australien und Tasmanien bis Neu-Seeland, Lord Howe-Ins., Neu-Caledonien, Neu-Guinea, westwärts durch die Molukken nach Celebes, Sangi, NordBorneo, Timor, Keeling (vergl. Meyer u. Wiglesworth, 48, p. 842)

Von Caledonien ist dieser Reiher schon lange bekannt; ich beobachtete ihn zwischen Canala und La Foa; zahlreiche Exemplare finden sich im Museum von Nouméa. Auf den Loyalty's scheint er noch nicht beobachtet worden zu sein.

\section{Gen. Butorides Blyth.}

Verbreitung: Fast kosmopolitisch.

\section{8o. Butorides stagnatilis (Gould.).}

Verbreitung: Nord- und Ost-Australien, Neu-Guinea, Molukken, Kleine SundaInseln, Salomonen, Neu-Caledonien, Fidji, Tonga, Gesellschaftsinseln, Sh a rpe, 73, p. 184.

Layards, 4I, p. 53I, beobachteten die Art bei Nouméa (B. jaramica Horsf.); Finsch u. Hartlaub, I7, p. 210, erwähnen sie als von der Novara-Expedition aus Caledonien mitgebracht. Mehrere Exemplare befinden sich im Museum von Nouméa.

\section{Gen. Botaurus Briss.}

Verbreitung: Fast kosmopolitisch.

8r. Botaurus poeciloptilus (Wagl.).

Verbreitung: Australien, Neu-Seeland, Neu-Caledonien, Sharpe, 73, p. 259. 
Die Layards, 4I, p. 53I, erhielten ihn bei Nouméa. Caledonische Exemplare finden sich auch im Pariser Museum.

\section{Apokryphe species.}

Esreth breapes Verr. u. D. Murs, Revue et Mag. de Zoologie 1862, findet sich in Marie's, 47, p. 328, Liste aufgeführt und ist seither verschollen. Die Layards, 4I, p. 532, sagen, sie wüssten nicht, was für eine Art damit gemeint sei. In Sharpe's Katalog und Handlist ist nichts darüber zu finden. Herr Dr. A. Menegaux hatte die Güte, auf meine Bitte hin im Pariser Museum nach dem Verreaux'schen Exemplar zu suchen, allein es war nicht zu finden. Es dürfte also irgend eine irrtünliche Bestimmung vorliegen.

\section{Anatidae.}

\section{Gen. Dendrocygna Sw.}

Verbreitung: Tropisch kosmopolitisch.

\section{Dendrocygna arcuata (H lorsf.)}

Verbreitung: Philippinen, Borneo, Celebes, Java, Sumba, Timor, Molukken?, Neu-Guinea, Australien, Neu-Caledonien, Fidji (nach M e y er u. Wi g l es w o rt h, 48, p. 869).

Von Marie, +7 , als Dondrochym gouldi Bp. aufgeführt; weder von den La y a r ds. 4r, p. 538, noch von uns gefunden, dagegen im Pariser Museum als von Caledonien stammend bezeichnet.

\section{Gen. Anas L.}

Verbreitung: Kosmopolitisch.

\section{Anas superciliosa Gm.}

Verbreitung: Australien, Tasmanien, Neu-Seeland, Chatham, Norfolk, Lord Howe-Ins., Neu-Caledonien, Neu-Hebriden, Fidji, Tonga, Samoa, Gesellschaftsinsehn, Neu-Guinea bis Salomonen, Molukken (Buru), Palaus, Celebes, Kleine Sunda-Inseln, Javal (Meyer u. Wiglesworth, 48, p. 873).

3 Oubatche, I8. Mai I9I I.

o Conefluss, I8. August i9I I.

Sehr verbreitet in Neu-Caledonien, zweifelhaft auf L.ifou (Layards, 37, p. 233).

\section{Gen. Nettion Kaup.}

Verbreitung: Kosmopolitisch.

84. Nettion gibberifrons (S. Müll.).

Verbreitung: Australien, Neu-Seeland, Neu-Caledonien, Neu-Guinea, Kleine Sunda-Inseln, Java, Celebes (Meyer u. Wiglesworth, f8, p. 87.5). 
Weder von den Layards, noch von uns in Caledonien gefunden, aufgeführt bei Verreaux u. Des Murs, 79, p. $4+2$ und Gray, 22, p. 166, als Lnas punctata var., bei Marie, 47, p. 328, als IMareca castanca Gould.

\section{Gen. Spatula Boie.}

V'erbreitung: Kosmopolitisch.

\section{Spatula rhynchotis (Lath.).}

Verbreitung: Australien, Tasmanien, Neu-Seeland (Salvadori, 6o, p. 316), Neu-Caledonien.

Wir erhielten die Art nicht, welche schon Marie, $47, \mathrm{p} .328$, in seiner Liste auffüht; L a y ards, fI, p. 538, bekamen ein junges Exemplar aus der Nähe von Nouméa; auch in Paris von Neu-Caledonien vorhanden.

\section{Gen. Aythya (Nyroca) Boie.}

Verbreitung: Kosmopolitisch.

86. Aythya australis (Eyton).

Verbreitung: Australien, Tasmanien, Neu-Seeland, Auckland, Neu-Caledonien, Neu-Guinea und Papuasische Inseln westlich bis Waigiu (SaIvadori, 6o, p. 35I).

In Marie's Liste, 47. p. 328, als Iyroct anstrulis Gould aufgeführt, weder von den Layards, noch von uns erbeutet. Dr. F. Speiser (siehe unten) brachte ein Exemplar von den Neuen Hebriden, wahrscheinlich von Santo, mit.

\section{Podicipedidae.}

\section{Gen. Podicipes Lath.}

Verbreitung: Kosmopolitisch.

\section{Podicipes novaehollandiae Steph.}

Verbreitung: Australien, Tasmanien, Neu-Caledonien, Sangi, Talaut, Java (Meyer u. Wiglesworth, 48, p 9r8, P. guluris, Ogilvie Grant, 52, p. 5I9).

In Marie's Liste, 47, p. 328, als $P$. gularis Gould aufgeführt, auch von den Layards, 4I, p. 537, gefunden; Exemplare befinden sich im Museum von Nouméa.

\section{Marine Vögel.}

Auf die rein marinen Gruppen der Laridac, Procellaridac, Puffindac, Phalacrocomidire, Sulidae, Fregatidar und Phacthonidac gehe ich nicht ein, da sie mit der Fauna Neu-Caledoniens nichts zu tun haben; ich erwähne nur Oestrclata rostrata (Peale), einmal weil Salvin, 6I, p. 4o, das Vorkommen auf Neu-Caledonien in Zweifel zieht, da die 
Layard'schen Exemplare noch im Flaumstadium und somit nicht sicher bestimmbar ge. wesen seien und andererseits wegen einiger biologischer Beobachtungen.

Salvin gibt als Verbreitung der genannten Art an: Zentraler Pazifischer Ozean, Tahiti. Für Neu-Caledonien ist der Vogel schon in Marie's Liste, 47. p. 328, namhaft gemacht; Die Layards, fI, p. 538, erhielten den erwachsenen Vogel nicht, sondern nur Nestjunge, die sie dieser Art zuschreiben, von der sie sagen, sie brüte auf lieinen Felsinseln und nach Hörensagen auch auf den Bergen des Innem.

Am 7. März igiz bekamen wir in Canala zwei erwachsene Weibchen und ein Nestjunges, welche von Eingeborenen in einem Seitentälchen des Negropo-Tales mit Hilfe von Hunden in Erdlöchern, in denen sie brüteten, waren erbeutet worden. Nach Angabe der Eingeborenen graben sie Löcher in die Erde und legen je ein Ei hinein. Auch am Humboldt wurde uns erzählt, es brüte ein Meervogel, den die Kolonisten "canard de rocher" nennen, hoch oben in den Bergen an felsigen Stellen. Wahrschein. lich ist es dieselbe Art, vielleicht auch Oestreluta mollis (Gould), von der die Lay ards, fr, p. 539, angeben, sie brüte in grosser Zahl in der Gipfelzone des Mont Mou bei Nouméa in Erdlöchern.

Eines der uns gebrachten Weibchen war noch lebend; aus Furcht vor seinen Bissen hatten die Eingeborenen die Spitze des Oberschnabels durch die Haut des Unterschnabels durchgesteckt. Vermutlich ist diese ()estrelitir der rätselhafte Vogel, von dem dic Kolonisten im Negropo-Tal behaupten, er greife den Menschen an und reisse Fetzen aus der Haut.

Meine Exemplare stimmen gut mit der Beschreibung von ()estriluta rustrutu (Peale) bei Salvin, 1. c., überein. Die Beine sind im Leben hellrosa gefärbt, mit einem schwarzen Fleck an der Aussenseite des unteren Tarsusendes, die Füsse tiefschwarz. mit Ausnahme eines hellrosa Fleckes, der die Basalphalangen der beiden inneren Zehen und die zwischenliegende Haut umfasst; er begleitet als schmaler Saum auch den Innenrand der zweiten Phalange der Innenzehe; Iris tief dunkelbraun.

Ma asse (Mittel der beiden 9): Long. tot. ca. 376, ala 292, cauda 127, tarsus +7 , Mittelzehe und Klaue 58, culmen 35. Salvin gibt nach Coues: Long. tot. 356 , ala 279, cauda 118, tarsus 4 , Mittelzehe und Klaue 56, culmen 33.

Der junge Nestvogel ist eine mausgraue Flaumkugel; Unterbrust und Bauch sind reinweiss, Beine und Füsse rötlichgelb, der Schnabel schwarz, mit einer hellen Unterschnabelspitze.

Unter den Lariden, welche übrigens an den caledonischen Küusten keine grosse Rolle spielen, ist die am häufigsten in die Augen fallende die weit rerbreitete. \$\%m bersil Licht.

\section{Importierte Vögel.}

Es sind zu verschiedenen Zeiten von den Kolonisten Vügel eingeführt worden. teils zu Jagdzwecken (australische Tumix, Layards, fi, p. 530, Finmm, L, a yads, 
34, p. 359, Firncolimus (?) ron Réunion, Jouan, 28, p. 233; usw.), teils zur Zerstörung der schädlichen Heuschrecken, teils endlich als Singvögel. Von allen diesen haben sich nach meinen Erfahrungen bloss drei gehalten und vermehrt.

\section{Acridotheres tristis (L.).}

"Merle des Moluques" der Kolonisten. Dieser Star ist der eigentliche Charalitervogel der Westküste geworden. Auf den Grasflächen bei Coné trifft man ihn in zahlreichen Schwämen an; bei Bourail sahen wir ihn des Abends in ungezäblten Massen in dichten Bambusgebüschen mit grossem Lärm sich zum Schlafen versammeln (21. Januar i912). Ostwärts nach den Bergen zu nimmt er rasch an Zahl ab und überschreitet sie nicht, so dass er an der Ostküste fehlt. Ursprünglich eingeführt zum Vertilgen von Heuschrecken, ist er stellenweise eine Landplage geworden, da er, wie man sagt, die Maiskörner nach dem Säen aus der Erde holt. Es wäre interessant, das genaue Jahr der Einführung dieses jetzt so massenhaft vorkommenden Vogels zu kennen. Die L a y ards, 34, p. 359, erwähnen ihn 1877 als "Merle des lles Philippines", ohne ihn noch gesehen zu haben; er war also offenbar damals selten. Lemire, $45, \mathrm{p} .47$, sagt I884, die Versuche mit dem „Merle des Moluques" hätten nur unbedeutende Resultate ergeben; man habe nur eine kleine Zahl importiert und die Jäger zerstörten sie. Die Einführung hat vermutlich in den siebziger Jahren stattgefunden.

\section{Estrilda astrilda (L.).}

"Bengali“ der Kolonisten; bewohnt in zahlreichen kleinen Schwärmen das offene Gras- und Buschland an beiden Küsten. Bei Oubatche war er ungemein häufig. Die Beschreibung bei Sharpe, 7o, p. 392, stimmt gut auf die caledonischen Exemplare, nur sind ihre Maasse grösser als die von Sharpe angeführten. Sharpe gibt für ein o und ein 9 : Long. tot. 106 und Io6, ala 43 und 42 , cauda +4 und +2 , culmen 7,5 und 8,5. Dagegen weisen sechs caledonische Exemplare folgende Mittelzahlen auf: Long. tot. II5 (IIO-II8), ala $47,7(46,5-49)$, cauda $53(50-54)$, culmen 7, I $(6,5-7,5)$.

\section{Passer domesticus (L.).}

Der Sperling scheint nur in europäischen Siedelungen der Westküste vorzukommen; in La Foa z. B. ist er häufig. 


\section{Verzeichnis der Vögel Neu-Caledoniens und der Loyalty-Inseln.}

Zum Schlusse stelle ich noch eine Liste der Vögel Neu-Caledoniens und der Loyalty-Inseln zusammen, mit $\Lambda$ ngabe der Textseite, wo sie behandelt sind. Die endemischen Arten sind mit*versehen, Meervögel und importierte Arten sind weggelassen.

\section{Neu.Caledonien}

Circus gouldi wolfi (Gurney), p. 5

"Astur haplochrous (Sclater), p. 6.

Astur approximans Vig. u. Horsf., p. 7.

Haliastur sphenurus (Vieill.), p. 9

Falco melanogenys Gould, p. 9 .

Pandion haliaëtus leucocephalus (Gld.), p. Io

Strix flammea lulu Peale, p. so.

"Trichoglossus haematodus deplanchei Verr, u.

D. Murs, p. II

"Glossopsittacus (?) diadematus (Verr. u. D. Murs),

p. 12

"Cyanorhamphus saisseti Verr. 1T. D. Murs, p. I3

"Nymphicus cornutus (Gm.), p. I3

"Cacomantis bronzinus (Gray), p. I4

Chalcococcyx plagosus (Lath.), p. 15 .

Urodynamis taitiensis (Sparm.), p. 15 .

Halcyon sancta Vig. u. Horsf, p. I6.

*Aegotheles savesi Lay. u. Tristr., p. I7.

Collocalia leucopygia Wall., p. I7.

${ }^{*}$ Collocalia agnota Oberh., p. I8.

Collocalia uropygialis Gray, p. 18.

Collocalia fuciphaga (Thunb.), p. I9.

(? Hirundo tahitica Gm.), p. Ig.

"Rhipidura verreauxi Marie, p. I9.

"Rhipidura bulgeri Lay, p. 20.

"Pseudogerygone flavilateralis typica (Gray), p. 20.

\section{Loyalty-Inseln}

Astur approximans Vig. u. Horsf. (Lifou), p. 7.

Strix flammea lulu Peale (Lifou, Maré?), p. ro.

"Trichoglossus haematodus deplanchei Verr. u.

D. Murs (Lifou), p. II.

'Nymphicus uveaensis Lay. (Ouvéa), p It, siehe Anmerkung.

*Cacomantis bronzinus (Gray) (Lifou, Ouvéa), p. Iq. Chalcococcyx plagosus (Lath.) (Lifou), p. I5

Halcyon sancta Vig. u. Horsf. (Maré, Lifou, Ouvéa), p. 16.

Collocalia leucopygia IVall. (Maré, Lifou), p. I7

Collocalia uropygialis Gray (Lifou, ()uvéa), p. 18. Collocalia fuciphaga (Thunb.) (Lifou), p. 19 .

"Rhipidura verreauxi Marie (Lifoul), p 19

"Rhipidura bulgeri Lay. (Lifou), p. 20.

"Pseudogerygone flavilateralis typica (Gray) (Mari", p. 20.

"Pseudogerygone flavilateralis lifuensis Sar. (lifou), P 2I.

"Pseudogerygone rouxi Sar. (Ouvea), D22

Anmerkung: Die Layards schreiben mithenkis; da aber die Insel lTwea oder framzüsisch geschrieben Ouvéa heisst, setze ich stets merrnsis. 


\section{Net1-Caledonien}

"Ayiagra caledonica typica Bp., P. 2: :

Grancalus caledonicus (Gm.), p. 26.

"Edoliisoma anale (Verr. u. D. Murs), p. 27.

"Diaphoropterus naevius typicus (Forst.), p. 28.

Artamus melanoleucus (Forst.), p. 29

"Pachycephala xantherythraea (Forst.), p. zo.

Pachyceplala morariensis Verr. u. D. Murs, p. 30

*Pachycephala caledonica (Gm), p. 30.

"Eopsaltria flaviventris Verr. u. D. Murs, p. 32.

"Clytorhynchus pachycephaloides Elliot, p. 32.

"Zosterops xanthochroa Gray, p. 33.

"Zosterops lateralis griseonota Gray, p. 33.

*Myzomela caledonica Forbes, p. 36 .

*Glycyphila undulata (Sparrm.), p. 37.

*Glycyphila incana (Lath.), p. 37.

*Philemon lessoni (Gray), p. 39.

"Leptomyza aubryana (Verr. u. D. Murs), p. 39.

"Megalurulus mariei Verr., p. fo.

*Merula xanthopus (Forst.), p. 4I.

"Erythrura psittacea (Gm.), p. +t.

*Aplonis caledonica Bp., p. 48.

"Physocorax moneduloides (Less.), p. 50.

"Plraenorhina goliath Gray, p. 50.

Globicera pacifica (Gm.), p. 5 I.

"Drepanoptila holosericea (1'emm. u. Kinjp), P. 5 I.

't'topus greyi Gray; p. 52 .

"Columba hypoenochroa typica Gould, p. 52 .

\section{Loyalty-Inseln}

*Myiagra caledonica viridinitens Gray (Lifon), p. 24. "Myiagra caledonica uveaensis Sar. (Ouvéa), p. 25. "Myiagra caledonica marcensis Sar. (Maré), p. 25.

"Graucalus lifuensis Tristr. (Lifou), p. 26.

"Diaphoropterus naevius simillimus Sar. (Maré, Lifou, Ouvéa), p. 28 .

Artamus melanoleucus (Forst.) (Maré, Lifou), p. 29.

*Pachycephala littayei Lay., p. 3 r.

${ }^{*}$ Zosterops minuta Lay. (Lifou), p. 33.

${ }^{*}$ Zosterops lateralis nigrescens Sar. (Maré, Ouvéa), p. 34

*Zosterops lateralis melanops Gray (Lifou), p. 35 .

*Zosterops inornata Lay (Lifou), p. 36 .

"Myzomela lifuensis Lay. (Lifou, Ouvéa), p. 37.

*(ilycyphila incana (Lath.) (Maré, Lifou, Ouvéa), p 37.

*Philemon Jessoni (Gray) (Maré, Lifou), p. 39.

* Merula mareensis typica (Lay. L. Tristr.) (Maré), P. 4I.

"Ulerula mareensis larochensis Sar. (Maré), p. 42 Ierula pritzbueri (Lay.) (Lifou), p. 43.

Erythrura cyaneifrons Lay. (Lifou), p. $4^{8}$

"Aplonis atronitens typica Gray (Maré, Lifou, Ouvéa), p. 49.

${ }^{*} A$ plonis atronitens minor Sar. (Lifou, Ouvéa), p. 49.

Globicera pacifica (Gm.) (Lifou), p. 5 I.

I'tilopus greyi Gray (Lifou), p. 52 .

*Columba hypoenochroa uveaensis Sar. (Ouvẻa), p. 53 . 


\section{Neu-Caledonien}

Chalcophaps chrysochlora (IVagl.), p. 53.

*Turnix varia novaecaledoniae Ug. Grant, p. $5 t$

"Rhinochetus jubatus Verr. u D. Murs, P. $5 \bar{s}$.

*'Tricholimnas lafresnayanus (Verr. 1. D. Murs), p. 60

Hypotaenidia philippinensis (L.), p. 6r.

Porzana tabuensis (Gm.), p. 62.

Poliolimnas cinereus (Vieill.), p. 62.

"Porphyrio calvus caledonicus Sar, p. 62

Arenaria interpres (L.), p. 6 .

Charadrius fulvus Gm., p. 64

Numenius variegatus (Scop.), p. 64.

Limosa novaezealandiae Gray, p. 6 *.

Heteractitis incanus $(\mathrm{Gm})$, p. 65.

Heteropygia acuminata (Horsf.), p. 65 .

Orthorhamphus magnirostris (Vieill.), p. 65

Demiegretta sacra (Gm.), p. 65 .

Notophoyx novaehollandiae (Lath.), p. 66

Nycticorax caledonicus (Gm.), p. 66.

Buturides stagnatilis (Gould), p. 66.

Botaurus poeciloptilus (Wagh.), p. 66

Dendrocygna arcuata (Horsf.), p. 67.

Anas superciliosa Gm., p. 67.

Nettion gibberifrons (S. Müll.), p. 67

Spatula rhynchotis (Lath.), p. 68.

Aythya australis (Eyton), p. 68.

Podicipes novaehullandiae Steph., p. 68.

\section{Loyalty-Inseln}

Chalcophaps chrysuchlora (IVagl.) Mare, Lifun, Ouvéa), p. 53.

Hypotaenidia philippinensis (L.) (Lifou, (Ouvea), p. 6 I.

I'oliolimnas cinereus (Vicill.) (Lifun), [). 62

"Porphyrio calvus caledunicus Sar.? (Maré, Lifuu), p. 62.

Charadrius fulvus Gm (Lifon), p. $\sigma_{4}$.

Limosa novaezealandine Gray (Nare), p. 6 t.

Heteractitis incanus (Gm) (Lifou), 1) 65.

Demiegretta sacra (Gm) (Lifou), D. 6.5.

Notophoyx novaehollandiae (l.ath.) (Lifoul), P. 66.

Anas superciliosa Gim.? (I ifou), p. 67. 
Anhang.

\section{Über einige Vögel der Neuen Hebriden.}

Herr Dr. Felix Speiser, der sich drei Jahre lang auf den Neuen Hebriden zum Zwecke ethnologischer Forschungen aufgehalten hat, sandte dem Basler Museum eine kleine Anzahl von Vögeln, in Spiritus konserviert, ein. Ich lasse ein Verzeichnis derselben folgen. Leider fehlen bei einigen Stücken genaue Herkunftsangaben.

\section{Collocalia uropygialis Gray.}

2 Exemplare von Malo; die Art ist schon von vielen Inseln der Hebriden bekamnt.

\section{Cacomantis schistaceigularis Sharpe.}

Der Typus dieser von Sharpe, 74, p. 338, aufgestellten Art stammte von der Insel Espiritu santo, ebendaher das Speiser'sche Stück, das mit der Beschreibung gut übereinstimmt.

\section{Halcyon tannensis Sharpe.}

I Exemplar, wahrscheinlich von Santo. Die Übereinstimmung ist keine vollkommene; namentlich ist bei unserem Stück die Unterseite weiss, statt blass rostfarben, und alle blauen Töne sind dunkler und weniger grünlich. Auf diese letztere Differenz hat mich Herr E. Stresemann aufmerksam gemacht, der die Güte hatte, das Exemplar in London mit dem Typus von tannensis zu vergleichen. Indessen sind vielleicht die Farben durch den Spiritus alteriert. Nach Stresemann gehört II. tannchsis Sharpe als Unterart in die Gruppe von H. tristrami Lay.

Maasse: Long. tot. C. 2io, ala 99, cauda 72, culmen 4 I.

\section{Pachycephala intacta Sharpe.}

Die Sharpe'schen Stücke, 74, p. 3ł3, stammten von den Inseln Mallicollo und Santo; von Santo auch die beiden Speiser'schen Exemplare.

\section{Lalage banksiana Gray.}

I Exemplar, wahrscheinlich von Santo, gut übereinstimmend mit der Beschreibung und Abbildung bei Brenchley, 7, Taf. X. 


\section{Myzomela cardinalis (Gm.).}

$\hat{o}$ und $\hat{o}$ jur von der Insel Malo, November igi i.

7. Myzomela rubratra sanctaecrucis nov. Subsp.

Verbreitung: Santa Cruz.

of und juv.

Diese Form steht M. mbratra (Less.) von den Carolinen und Palaus und fulikr. rima Ramsay von den Salomonsinseln (nach Rothschild und Hartert, Unterart von mobatra) sehr nahe. of: Ganzer Kopf, mit Ausnahme der tiefschwarzen Zügelgegend, des schwarzen, inneren Kinnwinkels und des schmalen, schwarzen, vorderen Stirnrandes, Rücken, obere Schwanzdecken, Unterseite, mit Ausnahme der schwarzen Flanken und des schwarzen Bauches, leuchtend karminrot, Rest des Gefieders, Schnabel und Beine schwarz. Long. tot. ca. I30, ala 74, cauda 59, culmen I8.

juv.: Oberseite braun, auf dem Rücken einzelne rote Federn, Schwanzdecken rot, Schwungfedern mit olivigen Säumen, Unterseite grau, an Kinn, Kehle und Brust mit etwas Rot gemischt, Bauch und untere Schwanzdecken gelblich weiss, Schnabel und Beine braun; Long. tot. ca. I20, ala 66, cauda 52, culmen 17 .

Herr E. Stresemann, der die Exemplare nachträglich mit den verwandten Formen im Tring- und London-Museum freundlichst verglich, schrieb mir, es handle sich in der 'Tat um eine gut charakterisierte, neue Form der mbmtm, oder, wie er sie weitergreifend lieber nennen möchte, der ardinalis.Gruppe; kennzeichnend vor allen Formen dieser Gruppe seien die schwarzen, nicht roten Federn des innersten Kinn. winkels und der Vorderstime; .I. pulihrma sei kleiner und ihre roten Töne heller und etwas gelblicher.

\section{Globicera pacifica (Gm.).}

I Exemplar von Santo.

9. Aythya australis (Eyton).

I Exemplar von Santo. Diese Ente ist woh! für die Hebriden neu (vgl. p. 68). 


\section{Literaturverzeichnis.}

1. Bartlett, A. D., Note on the Habits and Afrinities of the Kagu (Rhinochetus jubatus), Proc. Zool. Soc. London, 1862, p. 218 .

2. - Notes on the Breeding of several species of Birds in the Society's Garden during the year 1867, ibid., London, r868, p. IIt

3. Bennett, G., Letters on the Kagu, ibid., London, 1862, p. 8 u. 107 .

4. - Notes on the Kagu, Ann. and Mag. Nat. Hist., (3), I3, I86 t, p. 342.

5. - Letter, respecting the Kagu, ibid., (3), I4, I86.4, p. I4I.

6. Brandes, G., Über Leuchtorgane am Vogelschnabel, Zeitschrift für Naturwissenschaft (Naturw. Verein für Sachsen und Thüringen), if, 1902, p. $45^{8}$.

- Brenchley, J. L., Jottings during the Cruise of H. M. S. Curaçoa among the South Sea Islands in I865, Birds by G. R. Gray, London, 1873 .

c. Burckhardt, R., Der Nestling von Rhinochetus jubatus, Nova Acta, Abh. d. Kais. Leop. Carol. Deutschen Akademie der Naturforscher, Halle, 77, 1900.

4. - Der Nestling von Psophia crepitans und das Jugendkleid von Rhinochetus jubatus, ibid., 79, $190 \mathrm{r}$

10. Butler, A. G., On the ornamentation of the mouth in the young Gouldian finch, The Avicultural Magazine, $5, \quad$ J 898 u 5 , 1907 .

II. Butterfield, IV. Ruskin, Protective Coloration of the Inside of the Mouth in Nestling Birds, Nature, 72 , 1905, p. 534 .

12. Charruaud, A., L.e Diamant merveilleux (F'oephila mirabilis) et le moineau de Gould (Chloebia gouldiae), Revue Française d'Ornithologie, 1909 u. 1910.

13. Chun, C., Über die sogenannten Leuchtorgane australischer Prachtfinken, Zool. Anz, 27, I904, p. $6 \mathrm{r}$.

I. Elliot, D. G., Descriptions of some new Genera and Species of Birds belonging to the Families Formicariidae, Pachycephalidae, and Sylviidae, Proc. Zool. Soc. London, 1870 , p. 242.

15. Finsch, O., Die Papageien, 3 Bände, Leiden 1857-1868.

16. - Zosteropidae, das Tierreich, I5 Lief., Berlin, ?901.

17. - u. Hartlaub, G., Beitrag zur Fauna Centralpolynesiens, Ornithologie der Viti-, Samoa- und Tonga-Inseln, Haille, 1867 .

18. Forbes, IV. A., A Synopsiz of the Meliphagine Genus Myzomela, with Descriptions of two new species, Proc. Zool. Soc. London, 1879, p. 256.

19. Gadow, H., Catalogue of the Birds in the British Museum, VIII, 1883, Cichlomorphae: Laniidae.

20. - Catalogue of the Birds in the Britssh Museum, IX, r884, Cinnyrimorphae: Nectariniidae and Meliphagidae.

21. Gould, J., On some Birds collected by Mr. J. Nac Gillivray, the Naturalist attached to H. M. ship Rattlesnake etc., Proc. Zool. Soc. London, 1856, p. I35.

22. Gray, G. R., List of New Caledonian Birds, Proc. Zool. Soc. London, 1859, p. 160.

23. - Catalogue of the Birds of the Tropical Islands of the Pacific Ocean in the Collection of the British Muscum, London, 1859. 
21. Gurney, J. H., On a new species of Harrier from New Caledonia, Proc. Zool. Soc. London, x865, p. 823 .

25. I tartert, E., Podargidae, Caprimulgidae, Macropteryoidae, Das Tierreich, Lieferung I, Aves, Berlin, 1897 .

25. Ingram Collingwood, On Tongue-marks in young Birds, The Ibis, (9). I, I907, p. 574.

$2 \bar{i}$ Jouan, H., Notes sur quelques animaux observés à la Nouvelle Calédonie pendant les années I86I et 1862, Mémoires de la Société Imp. des Sciences Naturelles de Cherbourg, 1863 186 f, p. 89

28. - Notes sur la Faune Ornithologique de la Nouvelle-Calédonie, observations faites en 1860, ibid., p. 197.

29) Knauer, F., Die Leuchtorgane der australischen Amandinen, Natur und Haus, 12, I903-Igof.

30. Layard, E. L., Descriptions of New Species of Birds from the Island of Lifu, New Caledonia, Ann. and Mag. Nat. Hist. (5), I, 1878, p. 374

31. - Notes on the Avifauna of New Caledonia and the Loyalty Islands, The Ibis, (4), 1880, p. 336.

22. - Short Notes from New Caledonia, ibid., (1), 4, I880, p. 38 r.

33. - Remarks on two Species of Halcyon, ibid.. (4), 4, 1880, p. 459.

3t. - and Layard, E. L. C., Notes on the Avifauna of New Caledonia, ibid., (4), I, I877, p. 35.5 .

3.5 - - Notes on the Avifauna of New Caledonia, with Renarks by the Rev. Canon Tristram, ibid., (4), $2,1878, \mathrm{p} 250$.

36. - - Letters to the Ibis, ibid., (4), 3, I879, p. Io7 and Iog.

37. - - Notes on the Avifauna of the Loyalty Islands, ibid., (4), 4, I880, p. 220.

38. - - Note on Dachycephala assimilis of J. Verreaux and O. Des Murs, ibid, (4), t, I88o, p. 760.

39. -- - Notes on the Avifauna of New Caledonia and the New Ilebrides, with Remarks by the Rev. Canon Tristram, ibid., (4). 5, 1881, p. I32.

to. - - Letter to the Ibis, ibid., (4). 5, I88r, p. 17r.

ir. - - Notes on the Avifauna of New Caledonia, a Catalogue of the Birds of the Island known to, with Remarks by the Rev. Canon Tristram, ibid., (4), 6. 1882, p. 493.

f:- - Description of a new species of Parrot of the Genus Nymphicus, Proc. Zool. Soc. London, I882, p. 408 .

43 Layard, E. L. C., Notes of a Collecting.trip in the New Hebrides, the Sulomon Islands etc., with Remarks by E. L. Layard, The Ibis, (4). 4, 1880, p. 290

14. Layard, E. L. and Tristram, H. B, On a new Thrush from the Loyalty Islands Group, The Ibis, (4), 3, 1879. p. 47 I.

15. Lemire, Ch., Voyage à Pied en Nouvelle-Calédonie, Paris, $188_{4}$

\$6 Lewek, Th., Über leuchtende Schnabel-Papillen bei Goulds-Amandinen, Die gefiederte WVelt, 30, $190 \mathrm{r}$.

47. Marie, E., Mélanges Ornithologiques sur la faune de la Nouvelle-Calédonie et Description d'une Espèce Nouvelle, 30 April 1870, Actes de la Société Linnéenne de Bordcaux, 27, 1869-70.

48. Meyer, A. B. and Wiglesworth, I.. W.. The Birds of Celebes and the Neighbouring Islands. 2 vol., Berlin, 1898.

19. Oberholser, H. C., A Monograph of the genus Collocalia, Proc. of the Acallemy of Natural Sciences of Philadelphia, vol. 58, Ig06, p. I77.

50. Ogilvie Grant, IV. R., On the Genus Turnix, The Ibis, (6), I, I889.

51. - Catalogue of the Birds in the British Museum, XXill, 1893, Game Birds.

52. - Catalogue of the Birds in the British Museum, XXVI, I898, Steganopodes, Pygopodes ete

5.3. Oustalet, E., Notes d'Ornithologie, Oiseaux de la Nouvelle Calédonie, des Nouvelles llébrides etc, Bull. de la Société Philomatique de Paris, (7), 3, 1878-1879, p. 217.

57. - Note sur le P'sitteuteles diadema, Bull. du Muséum d'Histoire Naturelle, Paris, 1, 1895. P. 10 .

5.5. Reichenow, A., Conspectus Psittacorum, Systematische Ubersicht aller bekannten I’apageiarten, Journal für Ornithologie, Jahrg. 29 (4. Folge, 9 Bd.), 188I.

5\%. Rey, E., Leuchtorgane am Rachenwinkel junger I'rachtinken, Referat v. Bütger, Der Zoologische Garten, 43, 1902, p. 35 . 
‥ Rothschild, W. u. Hartert, E., Notes on Papuan Birds, Novitates Zoolog, 8, 19or, p. 55

it Salvadori, T., Catalogue of the Birds in the British Museum, XX, I89r, Psittaci.

5.) - Catalogue of the Birds in the British Museum, XXI, 1893, Columbae.

10. - Catalogue of the Birds in the British Museum, XXVII, 1895, Chenomorphae etc.

(1. Salvin, Osbert, Catalogue of the Birds in the British Museum, XXV, I8g6, Tubinares.

u. Schalow, H., Notizen über einige nell-caledonische Vögel, Journal für Ornithologie, 35, (4. Folge, I5), $1887, \mathrm{P} .244$.

1.: Sclater, Ph. L., Characters of an undescribed species of Hawk from New Caledonia, The Ibis, I, 1859, p. 275 .

(1. - Eggs of the Pacific Porphyrio (P. vitiensis) from Mlaré, Proc. Zool. Soc. London, x886, p. 330.

45. Se ebohm, H., Catalogue of the Birds in the British Museum, V, I88r, Cichlomorphae: Turdidae.

(t). Sharpe, R. Bowdler, Catalogue of the Birds in the British Museum, I, 1874. Accipitres.

(1). - Catalogue of the Birds in the British Museum, III, 1877, Coliomorphae: Corvidae.

(3. - Catalogue of the Birds in the British Museum, IV, 1879, Cichlomorphae: Campophagidae and Muscicapidae.

(v). - Catalogue of the Birds in the British Museum, VII, 1883. Cichlomorphae: Timeliidae.

7). - Catalogue of the Birds in the British Museum, XIII, 189o, Sturniformes: Artamidae, Sturnidae, Ploceidae etc.

71. - Catalogue of the Birds in the British Museum, XVII, I892, Coraciae and Halcyones: Alcedinidae etc.

72. - Catalogue of the Birds in the British Museum, XXIII, I894, Fulicariae: Rallidae etc. and Alectorides: Rhinochetidae etc.

73. - Catalogue of the Birds in the British Museum, XXVI, 1898, Herodiones.

74. - On a Collection of Birds made by Captain A. M. Farkuhar in the New Hebrides, The Ibis, (7), 6, 1900, p. 337.

7). - A Hand-List of the Genera and Species of Birds, Vol. I-V, London, 1899-1909

7). Shelley, G. E., Catalogue of the Birds in the British Museum, XIX, I8gI, Scansores and Coccyges: Cuculidae.

7) Tristram, II. B., Notes on Collections of Birds sent from New Caledonia, from Lifu (one of the Loyalty Islands), and from the New Hebrides by E. L. Layard, The Ibis, (4), 3, 1879, p. 180.

73. - Catalogue of a Collection of Birds, Durliam, 1889

;). Verreaux, J. et O. Des Murs, Description d'Oiseaux Nouveaux de la Nouvelle Calédonie et Indication des Espéces déjà connues de ce pays, Revue et Magasin de Zoologie, (2), I2, I860, p. $3^{83}$ und 43 T.

8o Verreaux, J., Description de deux Oiseaux de la Collection zoologique du Muséun (Mlegalurulus Mariae J. Verr.), Nouv. Archives du Muséum d'Histoire Naturelle de Paris, 5, I869, Bulletin, p. I5.

8r. Wallace, A R., On the Identification of the Hirundo esculenta of Linmaeus, with a Synopsis of the Described Species of Collocalia, Proc. Zool. Soc. London, 1863, p. 382.

82. Wiglesworth, L. W., Aves Polynesiae, A Catalogue of the Birds of the Polynesian Subregion, Abhandlungen und Berichte des Kgl. Zoolog. u. Anthropol.Ethnogr. Museums zu Dresden 1890/9r, Berlin 1892.

83. - On Pachycephala chlorura and Eopsaltria cucullata, P. morariensis and E. caledonica, The Ibis, (7), 5. $1899, \mathrm{p} .4+3$.

\section{Nachtrag.}

8. Pouget le comte, Note sur le Kagou, Bull. Mensuel de la Société d'Acclimatation, Paris, (3), 2, 1875 , p. I62. 
Tafel I. 
Fig. I. Kopf von Zosterots latemlis grisonnte Gray; p. 33.

Fig. 2. Kopf von Zosterots lutemlis migrescins F. Sar., p. 34.

Fig. 3. Kopf von Znsterots luterulis melumops Gray, p. 35.

Diese drei Unterarten bilden eine Formenkette mit zunehmender Schwarzfärbung des Kopfes.

Fig. 4. Psideseryente romiri F. Sar, p. 22.

Fig. 5. Kopf von Liftomyan mbruma (Verreaux u. Des Murs), adult, p. 39.

Fig. 6. Kopf von Liftomya ambrym (Verreats u. Des Murs), Jugendkleid, p. 39.

Fig. 7 u. 8. Face- und Profilansicht des Kopfes eines Nestlings von Errthmm fsittucru (Gm.), p. 44, mit den Reflexionsperlen am Schnabelwinkel und den Zeichnungen im Schnabelinneren, dreimal vergrössert. 


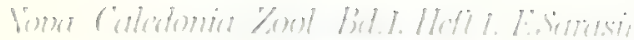
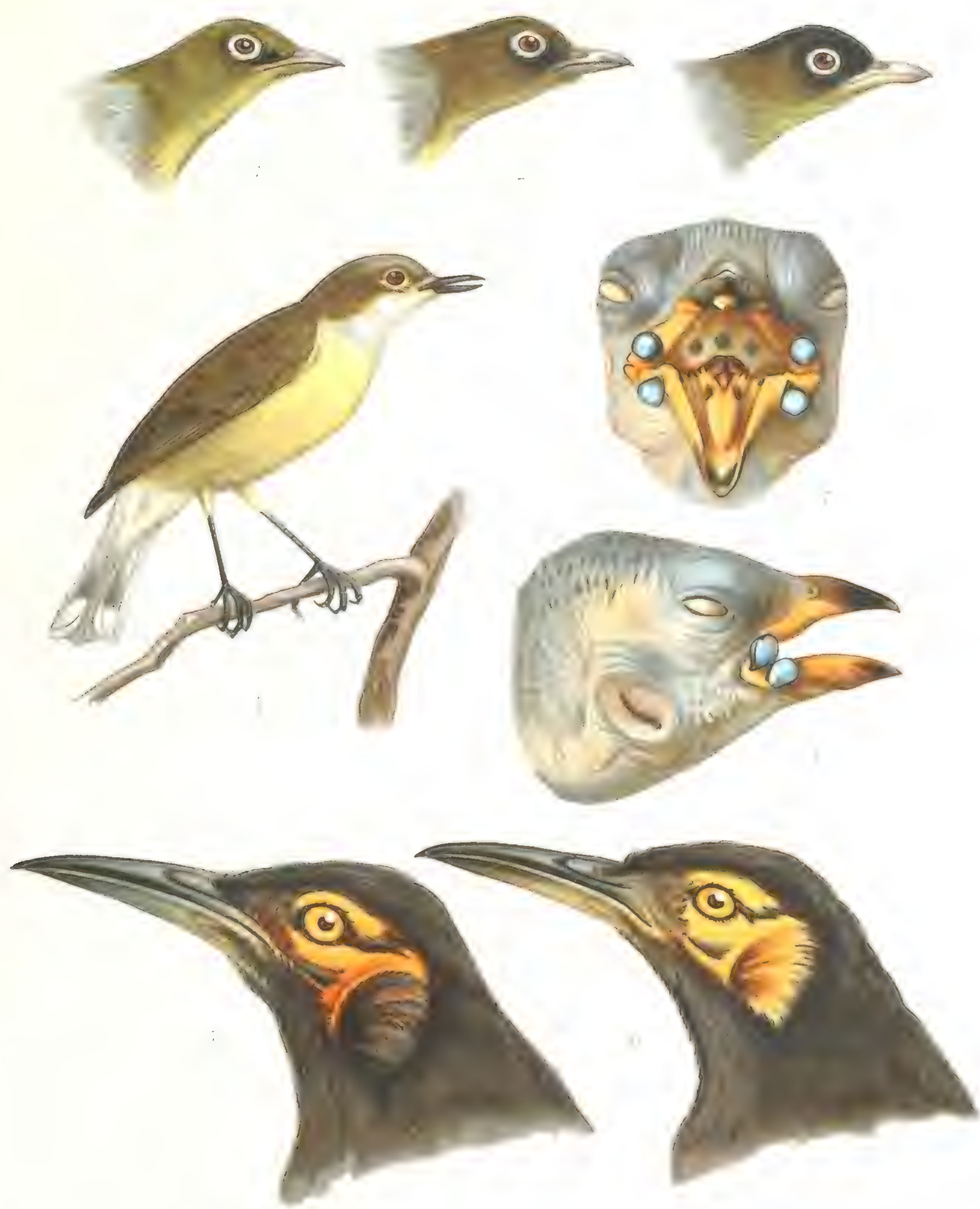

Tafel II. 
Fig. 9. Halbe Schwanzunterseite von I) Hifhorptems nutims typicus (Forst.), p. 28. Fig. Io. Halbe Schwanzunterseite von I hiphomptems nacints simillimus F. Sar., p. 28. Fig. II. Halbe Schwanzunterseite von IJyigm caledomian typica Bp., p. 23.

Fig. I2. Halbe Schwanzunterseite von Jlymgn caledonian mincnsis F. Sar., p. 25. Fig. I3. Halbe Schwanzunterseite von IIyugm aldonicu riminitons Gray, p. 24. Fig. I4. Halbe Schwanzunterseite von MJumg culdonian morensis F. Sar., p. 25. Diese vier. Hymbru-Unterarten bilden eine Formenkette mit sukzessiver Abnahme der Weissfärbung an den Schwanzfedern, p. 26.

Fig. I5. Halbe Schwanzunterseite von Psendogerygone Antilutemlis tyfica (Gray), 1). 20.

Fing. 16. Halbe Schwanzunterseite von L'sendogerysone Antilateralis lifuensis F. Sar. I. 2I. 

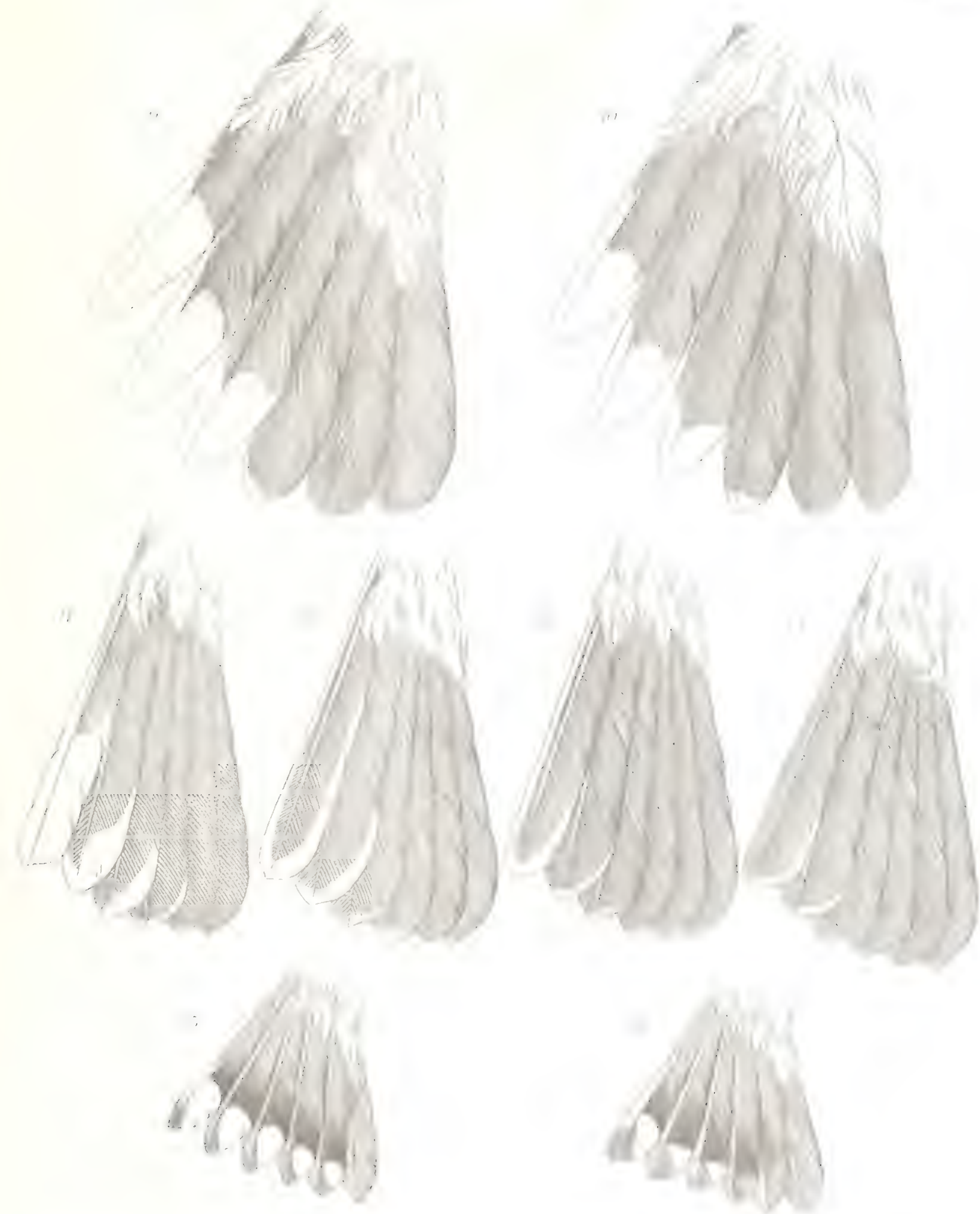

T a f e 1 III. 
Fig. I7. Nest des Kagu, Rhimochctus jubutus Verreaux u. Des Murs, halbe natürl. Grösse, p. $5^{8}$.

Fig. 18. Ei des Kagu, natürl. Grösse, p. $5^{8}$. 


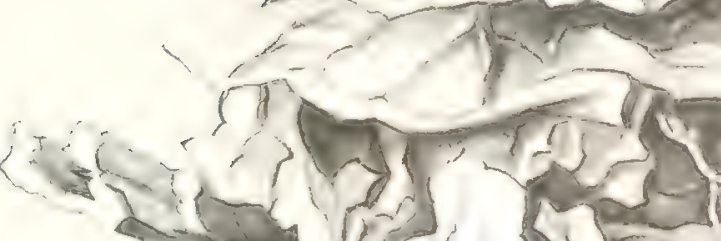
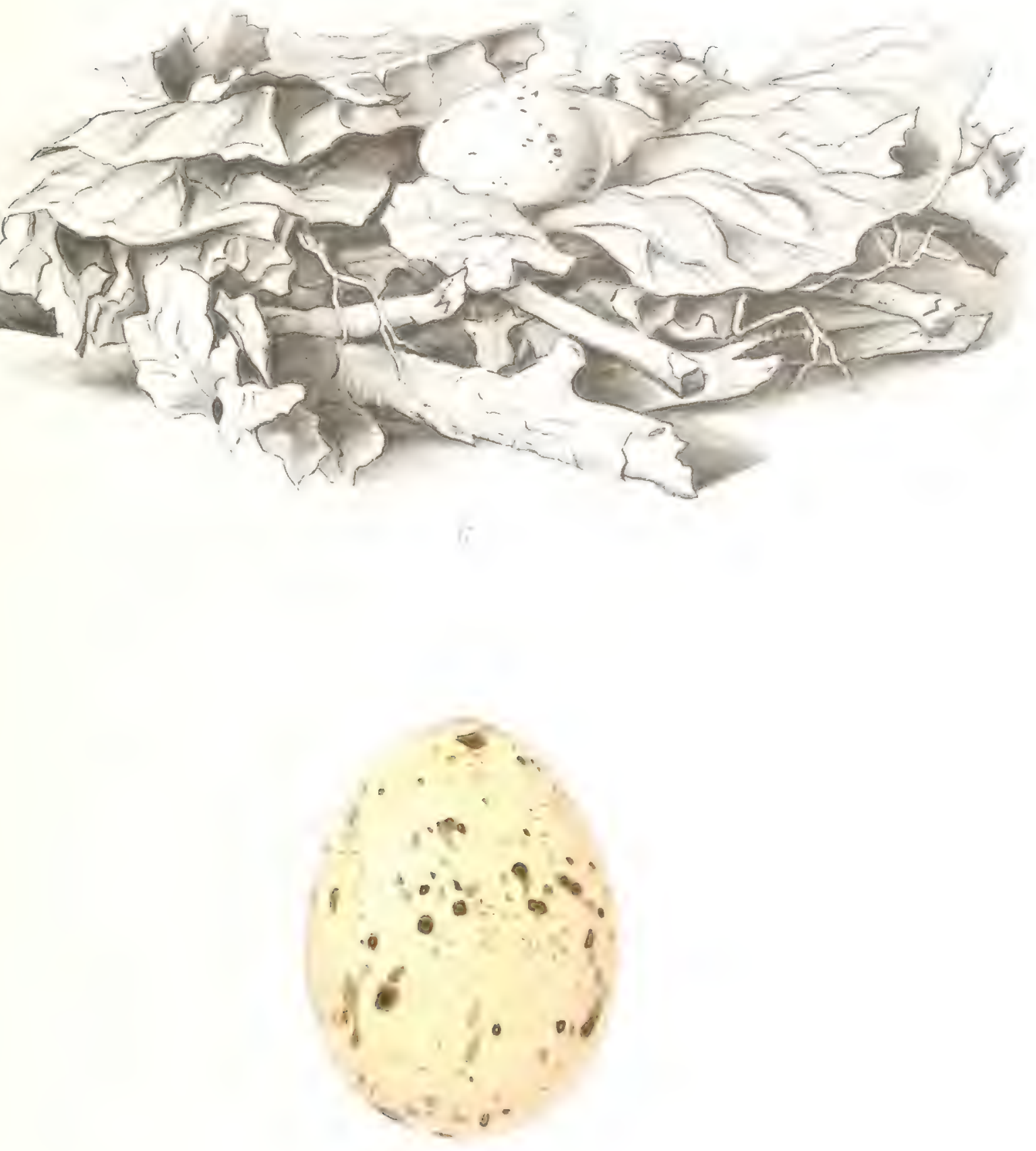




\title{
Ergebnisse naturwissenschaftlicher Forschun
} in den Jahren 1884 bis 1886

\author{
Dr. Paul Sarasin und Dr. Fritz Sarasin.
}

Die Augen und das Integument der Diad Über zwei parasitische Schnecken. Mit 5 Tafeln.

Aus der Entwickelungsgeschichte der Helix u

Knospenbildung bei Linckia multifora Lamarck. Mit 4 Tafeln.

\section{Über die Anatomie der Echinothuri} und die Phylogenie der Echinodermen.-- Mit 8 Tafeln.-- Preis Mk.

Entwickelungsgeschichte und Anatomie der ceylonischen Blindwühle. (Ichthyophis glutinosus.)

Die Weddas von Ceylon und die sie umgebenden Völkerschaften. Ein Folioband mit 600 Druckseiten mit in den Text gedruckten Heliogravüren, Holzschnitten, Tabellen und einem Atlas von 84 Tafeln in Heliogravüre und Lithographie. - Preis in Mappe Mk. 144.-

\section{Materialien zur Naturgeschichte der Insel Celebes.

$$
\text { Von }
$$

Dr. Paul Sarasin und Dr. Fritz Sarasin.

\author{
Die Süsswasser-Mollusken von Celebes. \\ Mit I3 Tafeln in Heliographüre und Lithographie. Preis Mk. 32.-. \\ Die Land-Mollusken von Celebes. \\ Mít $3^{I}$ Tafeln in Lithographie und Heliogravüre.
}

\section{Über die geologische Geschichte der Insel Celebes auf Grund der Tierverbreitung. \\ Mit 15 Tafeln in Lithographie - Preis Mk. 40.-.}

Entwurf einer geographisch-geologischen Beschreibung der Insel Celebes.

Mit Abbildungen und einer Lichtdrucktafel im Texte, to Tafeln in Heliogravüre und 3 Karten in Lithographie Preis Mk. 50.-

\section{Versuch einer Anthropologie der Insel Celebes.}

\section{Erster Teil:}

Die Toála-Höhlen von Lamontjong.

Mit 6 Tafeln in Lithographie und Lichtdruck.

Preis Mk. 18.-.

\section{Zweiter Teil:}

Die Varietäten des Menschen auf Celebes. Mit 22 Tafeln in Lithographie und Lichtdruck.

Preis Mk. 50.-.

\section{Reisen in Celebes.}

Ausgeführt in den Jahren I893-I896 und 1902-I903.

Von

Dr. Paul Sarasin und Dr. Fritz Sarasin.

Mit 240 Abbild. Im Texte, 12 Tafeln in Heliogravüre und Farbendruck, II Karten. - Zwei Bände geb. Mk. 24.- . 

